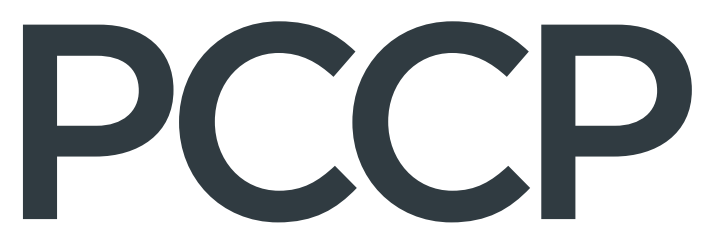

Volume 24

Number 13

7 April 2022

Pages 7553-8048

Physical Chemistry Chemical Physics rsc.li/pccp

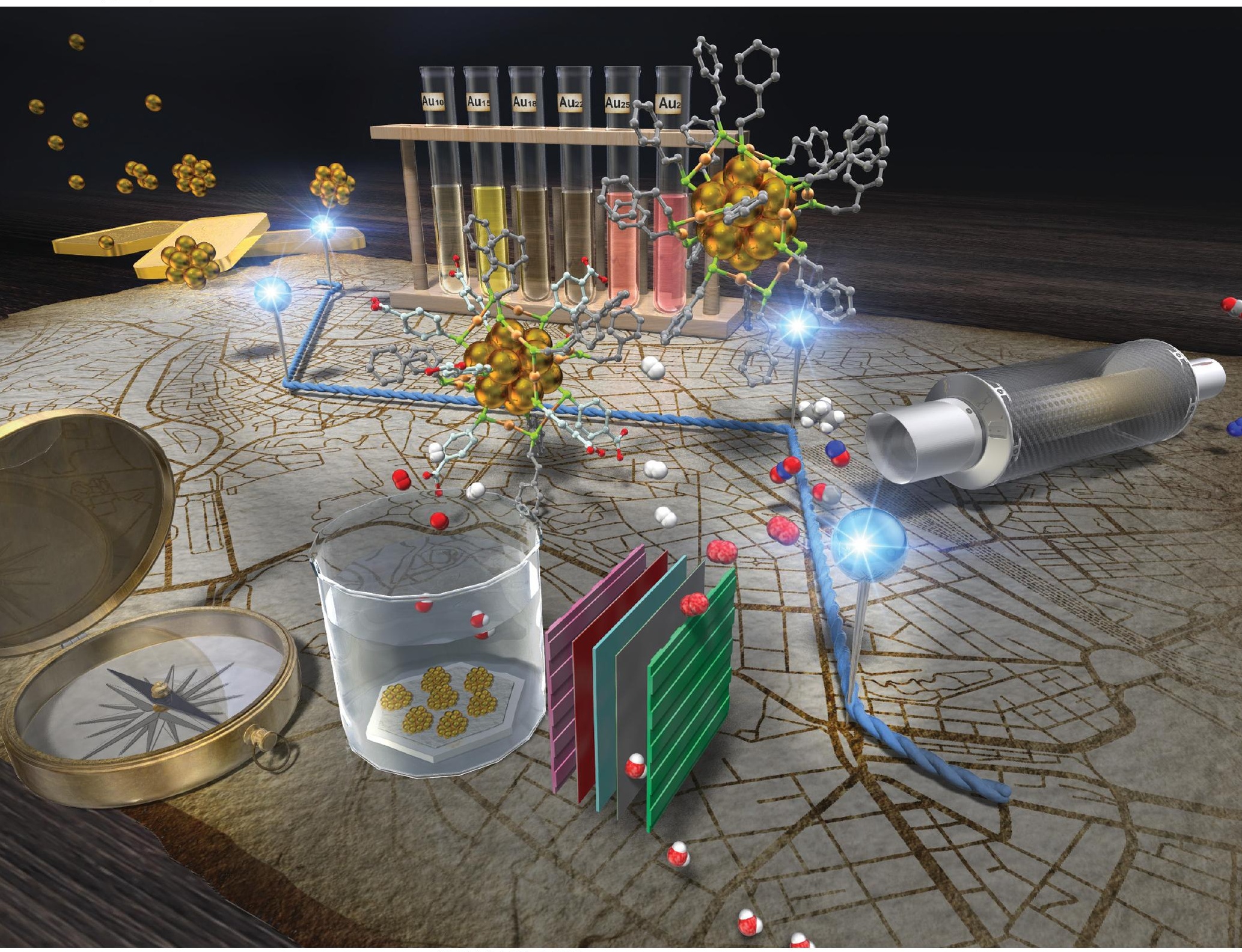

ISSN 1463-9076 
Check for updates

Cite this: Phys. Chem. Chem. Phys., 2022, 24, 7569

Received 13th December 2021, Accepted 27th January 2022

DOI: $10.1039 / d 1 c p 05689 a$

rsc.li/pccp

\title{
Metal-nanocluster science and technology: my personal history and outlook
}

\author{
Yuichi Negishi (D) ab
}

\begin{abstract}
Metal nanoclusters (NCs) are one of the leading targets in research of nanoscale materials, and elucidation of their properties (science) and development of control techniques (technology) have been continuously studied for the past 60 years or so. I have been continuously studying metal NCs since 1995 while changing my own interests, and thereby research topics, according to development of the field and the global situation. Specifically, I started my research on gas-phase metal NCs, and then investigated systematic isolation of glutathionate-protected gold NCs. Thereafter, I worked on development of flexible and precise techniques for controlling ligand-protected metal NCs and creation of highly functional energy and environmental catalysts using ligand-protected metal NCs. This personal account summarizes my previous studies on metal NCs. Through this personal history, I would like to describe my motivation for each previous subject, what type of research I want to perform for each subject in the future, and how I consider the outlook of the field.
\end{abstract}

\section{Introduction}

Research on nanoscale materials is generally believed to have begun with a talk by Feynman in 1959 entitled "There's Plenty of Room at the Bottom". . In this talk, he stated that in the nanoscale region of a few atoms, properties that are completely

\footnotetext{
${ }^{a}$ Department of Applied Chemistry, Faculty of Science, Tokyo University of Science, Kagurazaka, Shinjuku-ku, Tokyo 162-8601, Japan

${ }^{b}$ Research Institute for Science and Technology, Tokyo University of Science, Kagurazaka, Shinjuku-ku, Tokyo 162-8601, Japan.E-mail: negishi@rs.tus.ac.jp
}

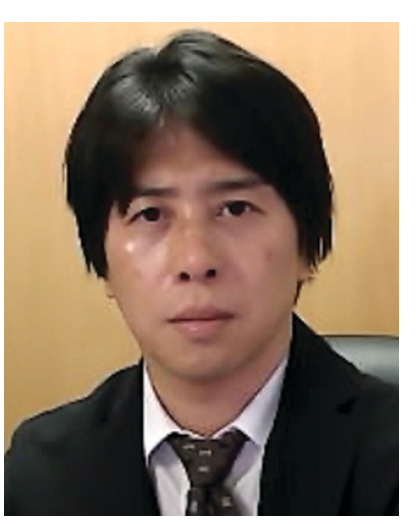

Yuichi Negishi
Yuichi Negishi is a Professor in the Department of Applied Chemistry at Tokyo University of Science. He received his $P h D$ degree in Chemistry in 2001 under the supervision of Prof. Atsushi Nakajima at Keio University. Before joining Tokyo University of Science in 2008, he was employed as an Assistant Professor at Keio University (with Associate Prof. Atsushi Nakajima) and at the Institute for Molecular Science (with Associate Prof. Tatsuya

Tsukuda). His current research interests include the precise synthesis of stable and functionalized metal nanoclusters and their applications in energy and environmental materials. different from the macroscopic world appear. He also claimed that it is very important for humanity to conduct research in this area, and he predicted that in the future we would be able to arrange atoms one by one as we wish to create desired materials. Later, high-resolution analysis devices, such as scanning tunneling microscopes ${ }^{2}$ and atomic force microscopes, ${ }^{3}$ were developed, which made it possible to directly observe atoms on a surface. In addition, instruments such as lasers and molecular beams ${ }^{4,5}$ have been successively developed, and much knowledge has been gained about the stability and electronic/geometric structure of aggregates consisting of metal atoms in a vacuum, namely, gas-phase metal nanoclusters (NCs). Since 2000, many countries have adopted nanotechnology as a national policy, ${ }^{6}$ which has led to dramatic advancement in the technology and knowledge related to these materials, as well as a dramatic increase in the number of researchers involved in research of nanoscale materials. Through this knowledge, it is now possible to synthesize metal NCs consisting of certain metal elements with atomic precision. ${ }^{7-27}$ In addition, through these studies, it has been experimentally demonstrated that in the nanoscale region, novel electronic/ geometric structures and physicochemical properties different from those of ordinary metals actually emerge. In recent years, a number of studies on creation of new materials that take advantage of the unique properties of such nanoscale materials have been reported. Thus, with regard to nanoscale materials, both elucidation of their properties (science) and development of control techniques (technology) have made great progress in the past 60 years or so. ${ }^{28-38}$

I have been continuously studying metal NCs since 1995 (Fig. 1). In this time, I have witnessed dramatic progress of the 


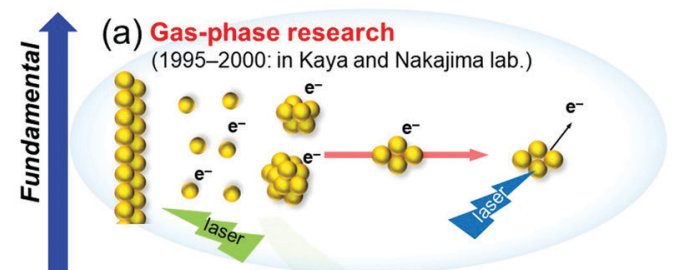

(b) Systematic isolation of $\mathrm{Au}_{n}(\mathrm{SG})_{m} \mathrm{NCs}$ (2000-2008: in Tsukuda lab.)

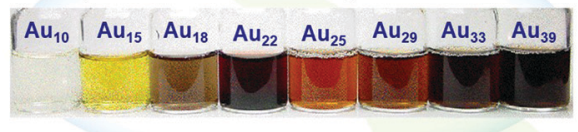

(c) Free control of ligand-protected metal NCs (2008-: in my own lab.) number of constituent atoms charge state ligand ligand
combination isomer geometric structure connection
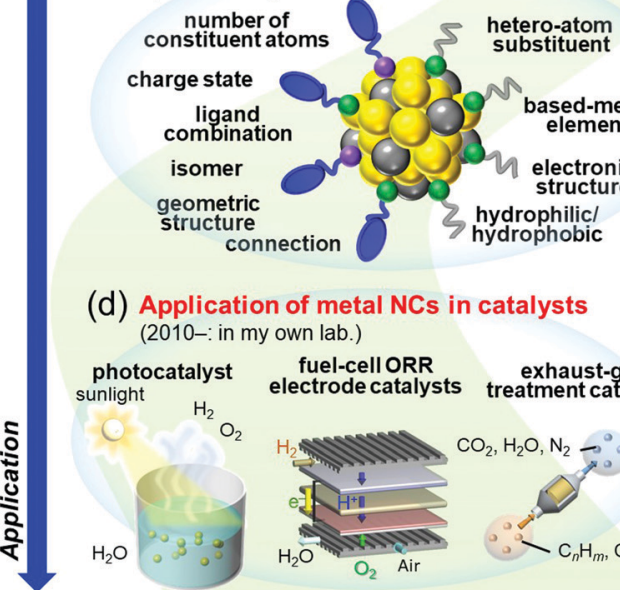

(d) Application of metal NCs in catalysts (2010-: in my own lab.)
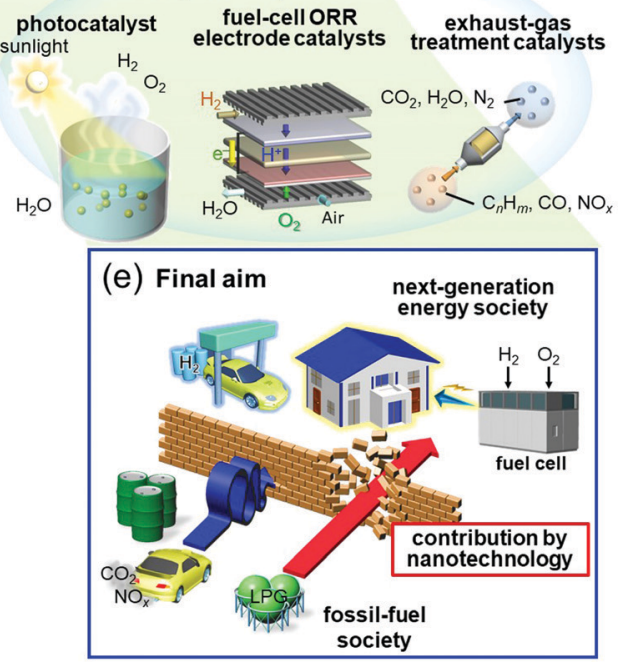

Fig. 1 (a-d) History of my research on NCs: (a) gas-phase research, (b) systematic isolation of glutathionate-protected Au NCs, (c) development of flexible and precise control techniques for ligand-protected metal NCs, and (d) application of metal NCs to energy and environmental catalysts. (e) Final aim of my research and what I would like to contribute through my studies. In this figure, LPG indicates the liquefied petroleum gas.

"science" and "technology" in related fields. In response to development of these fields and the state of the world, I have changed my own interests and research themes many times. Specifically, I started my research on gas-phase metal NCs (Fig. 1(a)), ${ }^{39-41}$ and then investigated systematic isolation of thiolate (SR)-protected gold ( $\mathrm{Au}) \mathrm{NCs}\left(\mathrm{Au}_{n}(\mathrm{SR})_{m}\right.$; Fig. 1(b)). ${ }^{42-47}$ Since 2008, I have been working on development of flexible and precise control techniques for ligand-protected metal NCs (Fig. 1(c)) and their use in creation of highly functional energy and environment catalysts (Fig. 1(d)). ${ }^{48}$ I have already written several accounts ${ }^{49-57}$ and reviews ${ }^{58-66}$ on each research topic. Therefore, in this personal account, I will describe my personal history in metal NCs. Through this personal history, I will explain what has led me to perform each type of research, what type of research I would like to perform in the future, and what I consider to be the future prospects in the field.

\section{Gas-phase research}

Isolation of metal NCs in a vacuum where there is no interaction with the outside world and investigation of their formation distribution, structure, and physical properties can provide an essential and fundamental understanding of the origin of the stability and mechanism of the size-specific structures and properties of metal NCs. Investigation of isolated metal NCs and supported metal NCs in the gas phase has a great advantage in this respect, and it has therefore been carried out for many years, with various improvements in the equipment. ${ }^{67-80}$

I conducted research on gas-phase NCs from 1995 to 2000 (Fig. 1(a)) under the guidance of Professor Kaya and Associate Professor Nakajima. In this research, NCs were produced by laser vaporization $^{4,5}$ and their electronic structures were investigated by negative-ion photoelectron spectroscopy (Fig. 2(a)). ${ }^{81}$ This research revealed that in the bulk, group 14 elements are classified as semiconductors for silicon ( $\mathrm{Si}$ ) and germanium (Ge), semi-metals for tin ( $\mathrm{Sn}$ ), and metals for lead ( $\mathrm{Pb}$ ), whereas in the fine size range all NCs have highest occupied molecular orbital (HOMO)-lowest unoccupied molecular orbital (LUMO) gaps and overall similar electronic structures (Fig. 2(b))..$^{40,82,83} \mathrm{In}$ a study of $\mathrm{Au}$-silver (Ag) alloy NCs, we experimentally demonstrated that not only controlling the number of constituent atoms, but also mixing the different elements is very effective for creating a new electronic structure (Fig. 2(c)). ${ }^{84}$ Through this research, I confirmed that new materials can be created by controlling the number of constituent atoms and chemical composition of NCs with atomic precision.

However, through this research, I also strongly felt that it is essential to develop a large-scale synthesis method for NCs to create new materials that take advantage of their size-specific properties while understanding their fundamental properties. In addition, at this time, I got the chance to deposit germanium oxide $\left(\mathrm{Ge}_{n} \mathrm{O}_{m}\right)$ NCs generated in a vacuum on a support and investigate their luminescence properties in air. ${ }^{85}$ Because the $\mathrm{Ge}_{n} \mathrm{O}_{m}$ NCs deposited at that time were originally oxides, their electronic structure did not significantly change even when exposed to air, and they exhibited blue luminescence in air. Through this experiment, I was impressed that it was essential to develop NCs that are stable in air to create NCs that can be used as materials.

\section{Isolation of glutathionate-protected Au NCs}

While my interest was shifting from gas-phase experiments to materials chemistry research, in 2000 , I got the chance to 
(a)

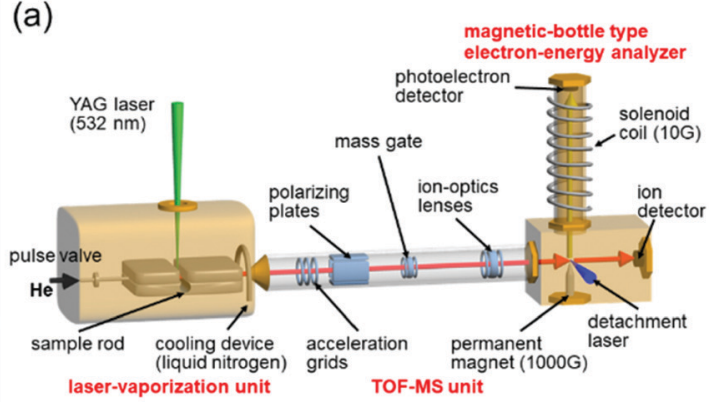

(b)

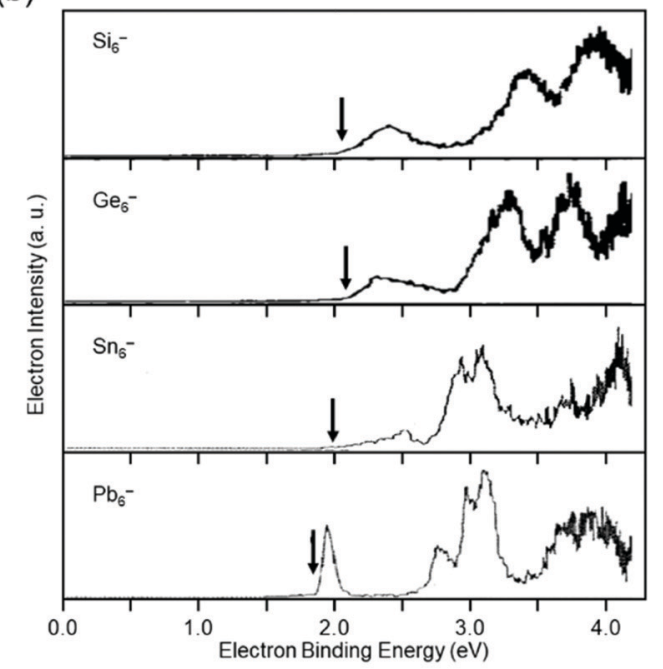

(c)

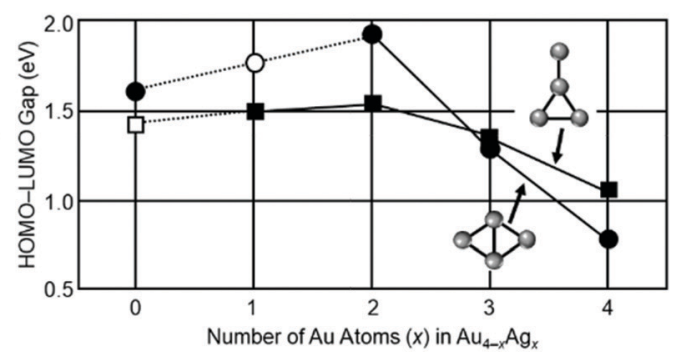

Fig. 2 (a) Schematic illustration of the apparatus used in my research on gas-phase NCs. (b) Photoelectron spectra of $\mathrm{Si}_{6}{ }^{-}, \mathrm{Ge}_{6}{ }^{-}, \mathrm{Sn}_{6}{ }^{-}$, and $\mathrm{Pb}_{6}{ }^{-}$ obtained by irradiating a $266 \mathrm{~nm}$ laser as a detachment laser. The vertical arrows indicate the thresholds energies. ${ }^{82,83}$ (c) Dependence of the HOMO-LUMO gaps of the rhombic and "T-form" isomers on the number of the $\mathrm{Ag}$ atoms $(x)$ for $\mathrm{Au}_{4-x} \mathrm{Ag}_{x}(x=0-4)$. The solid circles are the rhombic isomers and the solid squares are the T-form isomers. ${ }^{84}$ Reproduced with permission from ref. 82-84. Copyright 1997 Elsevier Science B.V., 2000 Elsevier Science B. V., and 2001 American Institute of Physics.

work as an Assistant Professor in the laboratory of Associate Professor Tsukuda, who had just established his own laboratory at the Institute for Molecular Science. Tsukuda also originally studied gas-phase NCs, but he started to work on liquid-phase synthesis of metal NCs at the end of his previous position. ${ }^{86}$ After joining his laboratory, we worked together to develop a precise synthesis method for metal NC in solution (Fig. 1(b)). These efforts were not immediately successful, and it took several years to achieve the first isolation. After a series of selections ${ }^{87}$ and abandonments of various material systems, we finally arrived at $\mathrm{Au}_{n}(\mathrm{SG})_{m} \mathrm{NCs}$ in $2003 .{ }^{42,88}$

$\mathrm{Au}$ and SR form strong bonds, and thereby SR forms selfassembled monolayers on Au surfaces. ${ }^{89-91}$ For these reasons, many technologies that take advantage of the combination of $\mathrm{Au}$ and SR have been developed in nanotechnology, such as dip-pen nanolithography ${ }^{92,93}$ and microcontact printing. ${ }^{94}$ In 1994, Brust et al..$^{95}$ reported that combination of $\mathrm{Au}$ and SR is also effective for formation of metal NCs. They found that $\mathrm{Au}_{n}(\mathrm{SC} 12)_{m}$ NCs (SC12 = dodecanethiolate) can be formed by reduction of Au salts with sodium borohydride in the presence of dodecanethiol in solution. The $\mathrm{Au}_{n}(\mathrm{SC} 12)_{m}$ NCs reported at this time had a particle-size distribution of 1-3 $\mathrm{nm}$. Regarding metal NCs, synthesis of metal NCs using phosphine $\left(\mathrm{PR}_{3}\right)$, carbon monoxide (CO), and halogens as ligands, such as $\mathrm{Au}_{n}\left(\mathrm{PR}_{3}\right)_{m}(\mathrm{Cl})_{l}, \mathrm{Pt}_{n}\left(\mathrm{PR}_{3}\right)_{m}(\mathrm{CO})_{l}(\mathrm{Pt}=$ platinum $)$ and $\mathrm{Pd}_{n}\left(\mathrm{PR}_{3}\right)_{m}(\mathrm{CO})_{l}(\mathrm{Pd}=$ palladium $)$, had been reported before the report of $\mathrm{Au}_{n}(\mathrm{SC} 12)_{m}$ NCs. Those had been isolated with atomic precision, and their geometric structures had been determined by single-crystal X-ray diffraction (SC-XRD). ${ }^{23,96}$ However, the number of constituent atoms of $\mathrm{Au}_{n}(\mathrm{SC} 12)_{m}$ NCs could not be controlled at atomic precision at this stage. Because $\mathrm{Au}_{n}(\mathrm{SC} 12)_{m}$ NCs are easier to synthesize and more stable in air than $\mathrm{Au}_{n}\left(\mathrm{PR}_{3}\right)_{m}(\mathrm{Cl})_{l}, \quad \mathrm{Pt}_{n}\left(\mathrm{PR}_{3}\right)_{m}(\mathrm{CO})_{l}$, and $\mathrm{Pd}_{n}\left(\mathrm{PR}_{3}\right)_{m}(\mathrm{CO})_{l} \mathrm{NCs}, \mathrm{Au}_{n}(\mathrm{SR})_{m}$ NCs were easy for researchers who had not previously worked with NCs to investigate. Although the number of researchers working on metal NCs dramatically increased after 2000 when many countries had adopted nanotechnology as a national policy, this was probably the reason why the number of researchers working on $\mathrm{Au}_{n}(\mathrm{SR})_{m}$ NCs particularly increased.

Whetten and co-workers ${ }^{97}$ and Murray and co-workers ${ }^{98}$ had worked on high-resolution separation of $\mathrm{Au}_{n}(\mathrm{SR})_{m}$ NCs since the 1990s. Among their studies, the work on $\mathrm{Au}_{n}(\mathrm{SG})_{m}$ NCs (SG = glutathionate) reported by Whetten and co-workers in $1998^{99}$ and $2000^{100}$ deserves special mention. They successfully separated a series of $\mathrm{Au}_{n}(\mathrm{SG})_{m}$ NCs at high resolution by polyacrylamide gel electrophoresis (PAGE, Fig. 3(a)) and reported that the chemical composition of the main product was $\mathrm{Au}_{28}(\mathrm{SG})_{16} \cdot{ }^{99}$

After these reports, Tsukuda and I started to work on $\mathrm{Au}_{n}(\mathrm{SG})_{m} \mathrm{NCs}$, where our first aim was to determine the chemical compositions of $\mathrm{Au}_{n}(\mathrm{SG})_{m}$ NCs other than the main product by mass spectrometry (MS). We had experienced development of the vacuum apparatus at our former poisitions. ${ }^{101}$ Therefore, we developed an electrospray ionization (ESI) unit that could deliver $\mathrm{Au}_{n}(\mathrm{SG})_{m}$ NCs synthesized in solution to a mass spectrometer without dissociation (Fig. $3(\mathrm{~b})) .{ }^{102}$ Using a mass spectrometer equipped with the original ESI unit, we succeeded in obtaining the ESI-MS spectra of all of the $\mathrm{Au}_{n}(\mathrm{SG})_{m}$ NCs separated by PAGE. In a paper published in 2004, we assigned the $\mathrm{Au}_{n}(\mathrm{SG})_{m} \mathrm{NCs}$ to $\mathrm{Au}_{18}(\mathrm{SG})_{11}, \mathrm{Au}_{21}(\mathrm{SG})_{12}$, $\mathrm{Au}_{25 \pm 1}(\mathrm{SG})_{14 \pm 1}, \mathrm{Au}_{28}(\mathrm{SG})_{16}, \mathrm{Au}_{32}(\mathrm{SG})_{18}$, and $\mathrm{Au}_{39}(\mathrm{SG})_{23} \cdot{ }^{103}$ However, further studies with modification of sample purification and the MS sections revealed that the chemical compositions 
(a)

(b)

(c)
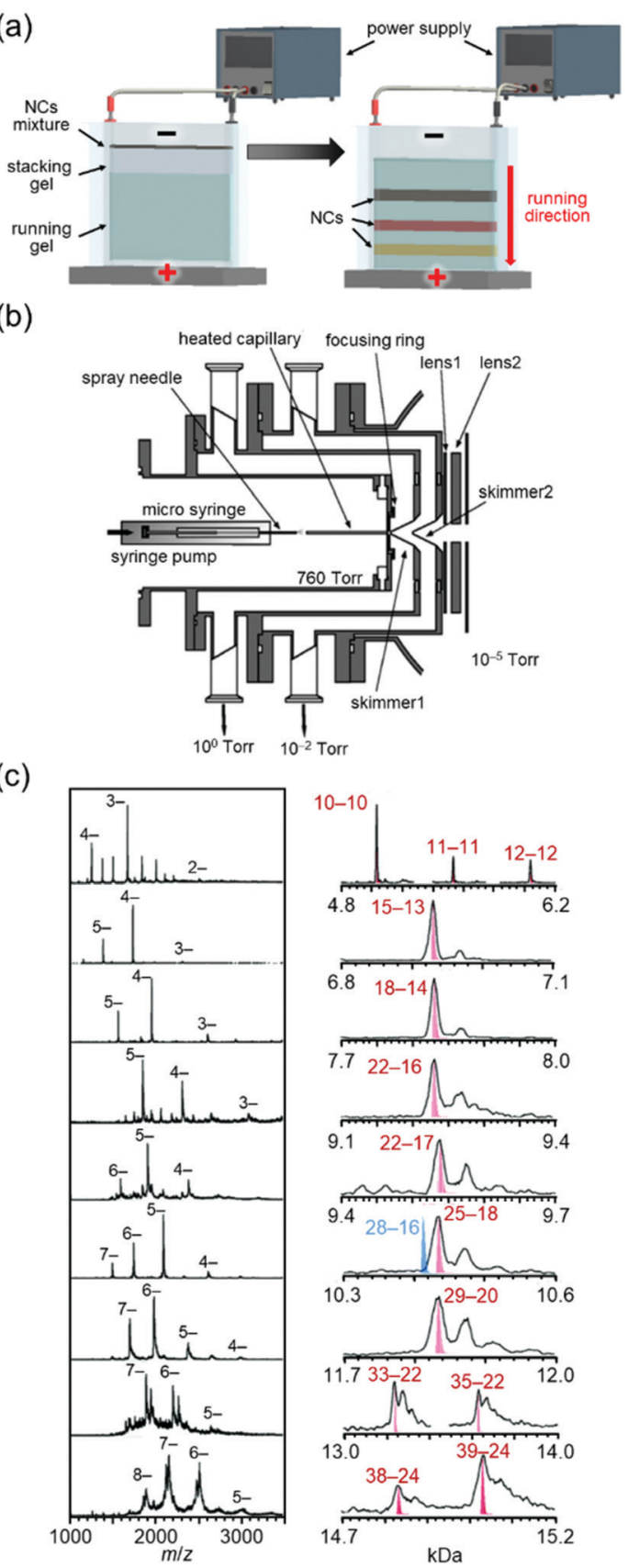

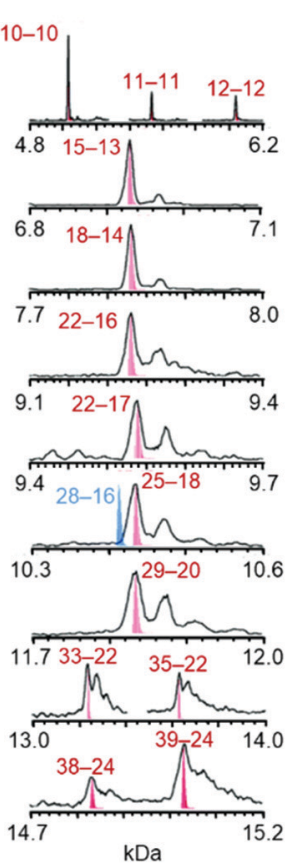

$\mathrm{kDa}$

(S(SG)). ${ }^{104}$ Through these studies, we succeeded in demonstrating that $\mathrm{Au}_{n}(\mathrm{SR})_{m}$ NCs can be treated as compounds with defined chemical compositions, similar to organic and complex compounds. Research of $\mathrm{Au}_{n}(\mathrm{SR})_{m}$ NCs has provided a deep understanding of the correlation between the chemical composition, stability, electronic structure, and luminescence properties of $\mathrm{Au}_{n}(\mathrm{SR})_{m} \mathrm{NCs}^{43,45,103-106}$

\section{Toward development of the ultimate nanotechnology and a deep understanding of ligand-protected metal NCs}

After reporting $\mathrm{Au}_{n}(\mathrm{SG})_{m} \mathrm{NCs}$, I got the opportunity to run my own laboratory at Tokyo University of Science in 2008. Therefore, after 2008, I began new projects. I had the feeling that atomic control of ligand-protected metal NCs would be the ultimate nanotechnology for metal-molecule complex systems. However, the NCs that we could control at my previous institute were limited to small $\mathrm{Au}_{n}(\mathrm{SR})_{m}$ NCs $(n=10-39)$ protected by certain SRs (SG, $\mathrm{S}(\mathrm{SA})$, and $\mathrm{S}(\mathrm{SG})$ ). To develop the ultimate nanotechnology for metal-molecule complex systems and thereby gain a better understanding of the correlation between the chemical composition, structure, and physical properties for ligand-protected metal NCs, it was necessary to develop new precise synthesis methods for (1) $\mathrm{Au}$ NCs with a large number of constituent atoms, (2) alloy NCs composed of several metal elements, (3) metal NCs composed of other elements, and (4) metal NCs protected by other ligands. According to the report by Teo et al. ${ }^{107}$ certain metal NCs could become the constituent units of "clusters of clusters". To create new materials using such connections in the future, it was necessary to also make further progress in (5) the connection techniques of ligand-protected metal NCs.

\subsection{Our strategy for flexible and precise control of ligand-protected metal NCs}

Since 2008, we have been working in parallel to develop the following six techniques: (1) isolation of Au NCs with a large number of constituent atoms ${ }^{108,109}$ (Section 4.2 and Fig. 4(a)), (2) isolation of alloy NCs ${ }^{110-117}$ (Section 4.3 and Fig. 4(b)), (3) isolation of metal NCs consisting of $\mathrm{Ag}$ or $\mathrm{Pt}^{118-121}$ (Section 4.4 and Fig. 4(c)), (4) isolation of metal NCs protected by other ligands ${ }^{122-128}$ (Section 4.5 and Fig. 4(d)), (5) connection of metal $\mathrm{NCs}^{129-131}$ (Section 4.6 and Fig. 4(e)), and (6) high-resolution separation of ligand-protected metal NCs by high-performance liquid chromatography (HPLC) $53,55,61,108-110,132-138$ (Section 4.6 and Fig. 4(f)). Through these six techniques, we have been attempting to develop flexible and precise control techniques for ligand-protected metal NCs, that is, the ultimate nanotechnology for metal-molecule complex systems (Fig. 4(g)), and thereby gaining a deeper understanding of the correlation between the chemical composition, structure, and physicochemical properties of ligand-protected metal NCs. 
(a) large Au NCs

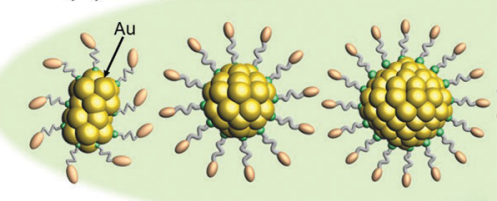

(b) alloy NCs

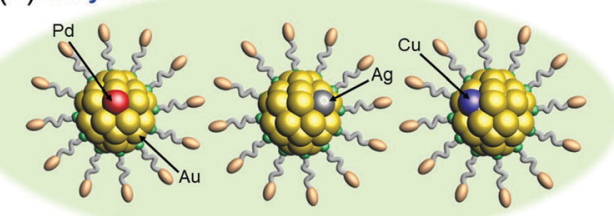

(c) other metal NCs

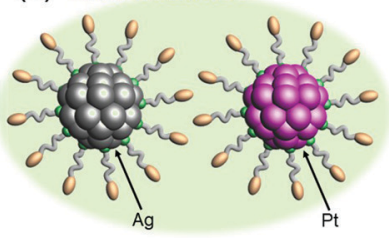

(f) high-resolution separation

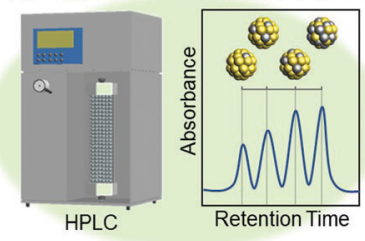

(e) connected structures

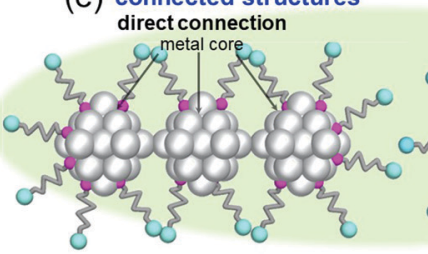

(g) free control techniques

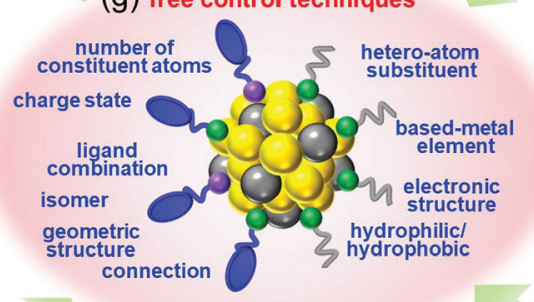

(d) metal NCs with the other ligand

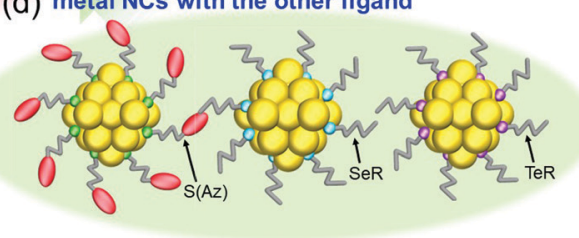

Fig. 4 Our strategy for developing ultimate control methods for ligand-protected metal NCs. Development of isolation methods for (a) large Au NCs, (b) Au-based alloy NCs, (c) Ag and Pt NCs, (d) metal NCs protected by S(Az), SeR, and TeR, (e) connected structures. (f) Development of high-resolution separation methods using HPLC. (g) Controllable parameters achieved by (a-f).

\subsection{Isolation of relatively large Au NCs}

In recent years, it has become possible to size-selectively synthesize relatively large $\mathrm{Au}_{n}(\mathrm{SR})_{m}$ NCs. ${ }^{139,140}$ However, as of 2008, the largest $\mathrm{Au}_{n}(\mathrm{SR})_{m}$ NCs that could be isolated with atomic precision were $\mathrm{Au}_{144} \mathrm{NCs},{ }^{47,141,142}$ for which I was also involved in determining the chemical composition. Therefore, since 2008 , we have been working on isolating $\mathrm{Au}_{n}(\mathrm{SR})_{m}$ NCs larger than $\mathrm{Au}_{144}$.

When the hydrophilic SRs (SG or S(SA)) described in Section 3 are used as ligands, relatively large $\mathrm{Au}_{n}(\mathrm{SR})_{m}$ NCs are difficult to synthesize. ${ }^{143}$ However, Whetten and co-workers ${ }^{97}$ and Wolfe and Murray ${ }^{144}$ reported that $\mathrm{Au}_{n}(\mathrm{SR})_{m}$ NCs larger than $\mathrm{Au}_{144}$ NCs can be synthesized when hydrophobic SRs, such as alkanethiolate and 2-phenylethanethiolate (PET), are used as ligands. Therefore, we attempted to separate each $\mathrm{Au}_{n}(\mathrm{SC12})_{m}$ NC from a mixture at high resolution by reversed-phase (RP) HPLC and then determine their chemical compositions by ESI-MS (Fig. 5(a)). ${ }^{108,109}$ Using these methods, we succeeded in systematically isolating $\mathrm{Au}_{n}(\mathrm{SC12})_{m}$ NCs up to $\mathrm{Au}_{\sim 520}(\mathrm{SC12})_{\sim 130}$ in 2014 (the paper was published in 2015). ${ }^{109}$

In parallel with us, Jin and co-workers and Dass and coworkers were also working on isolation of relatively large $\mathrm{Au}_{n}(\mathrm{SR})_{m} \mathrm{NCs}$, and as of 2014, they had reported isolation of $\mathrm{Au}_{329}(\mathrm{PET})_{84}\left(\right.$ or $\left.\mathrm{Au}_{333}(\mathrm{PET})_{79}\right), \mathrm{Au}_{\sim 500}(\mathrm{PET})_{\sim 120}$, and $\mathrm{Au}_{\sim 940}$ (PET) $\sim 160 \cdot{ }^{145-148}$ Through optical absorption spectroscopy of those NCs ${ }^{145-148}$ and density functional theory (DFT) calculations by Häkkinen and co-workers, ${ }^{149}$ it had been predicted that nonbulk to bulk transition occurs at around $\mathrm{Au}_{144}(\mathrm{SR})_{60}$ in the $\mathrm{Au}_{n}(\mathrm{SR})_{m}-\mathrm{NC}$ system. We worked with Tsukuda and Häkkinen to clarify the electronic/geometric structures of a series of isolated
$\mathrm{Au}_{n}(\mathrm{SC} 12)_{m}$ NCs $(n=38-\sim 520)$ to gain a better understanding of the details of the size at which non-bulk to bulk transition occurs. The results showed that non-bulk to bulk transition occurs between $\mathrm{Au}_{144}(\mathrm{SC12})_{60}$ and $\mathrm{Au}_{187}(\mathrm{SC12})_{68}$ in the $\mathrm{Au}_{n}(\mathrm{SC12})_{m}-\mathrm{NC}$ system (Fig. 5(b)). ${ }^{109}$ In subsequent papers by Jin and co-workers and Dass and co-workers, ${ }^{139,150-152}$ these electronic/geometric transitions were reported to occur in different size regions when the bulkier SR is used as the ligand.

\subsection{Isolation of Au-based alloy NCs}

Even if only one metal element is used as a constituent element, various electronic structures and physicochemical properties can be obtained by controlling the number of constituent atoms in the metal NCs. However, as mentioned in Section 2, if the size effect is combined with the synergy effect caused by mixing different elements, it is expected that a variety of different electronic structures and physicochemical properties can be increased. Therefore, since 2008, we have been working on isolation of alloy NCs and elucidation of their geometric/electronic structures and physicochemical properties. $^{110-117}$

When I started this research in 2008 , it was not easy to control the number of constituent atoms, even for metal NCs consisting of a single metal element. Furthermore, when I started my laboratory at Tokyo University of Science, I only had undergraduate students in my laboratory. Therefore, I thought that it was necessary to investigate metal-NC systems in which I had some experience to create new alloy NCs. Accordingly, $\mathrm{Au}_{n}(\mathrm{SR})_{m} \mathrm{NCs}$, which I had experience in handling, were selected as the base metal NCs for alloying. ${ }^{46,47}$ 


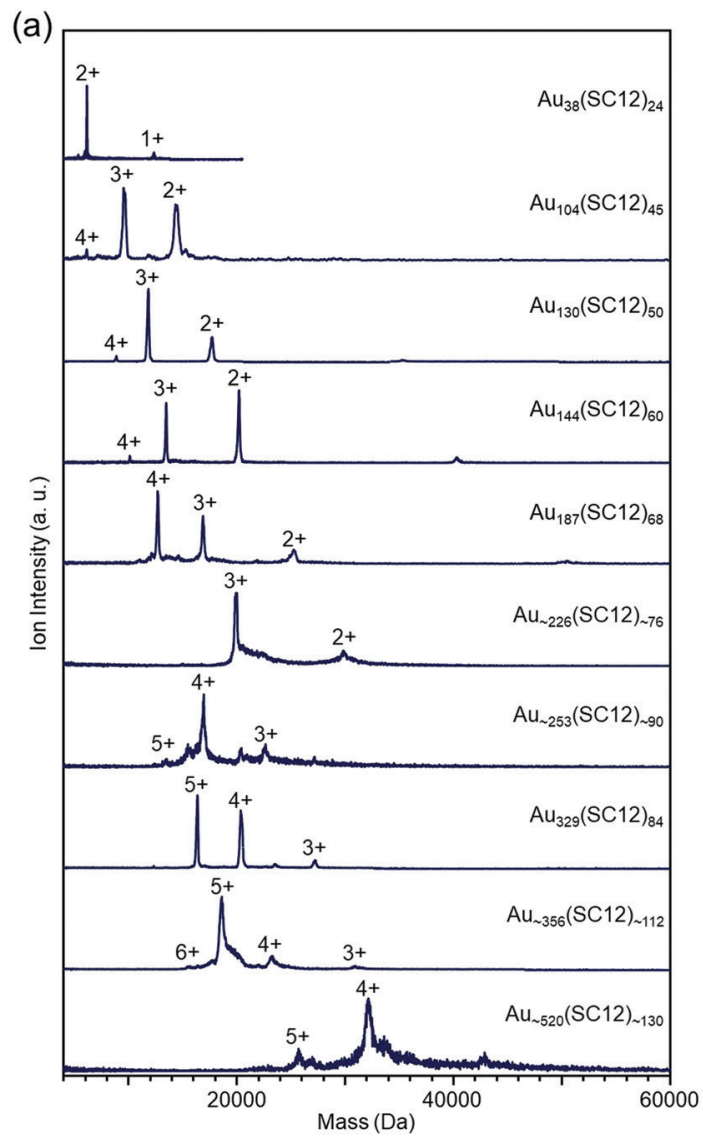

(b)

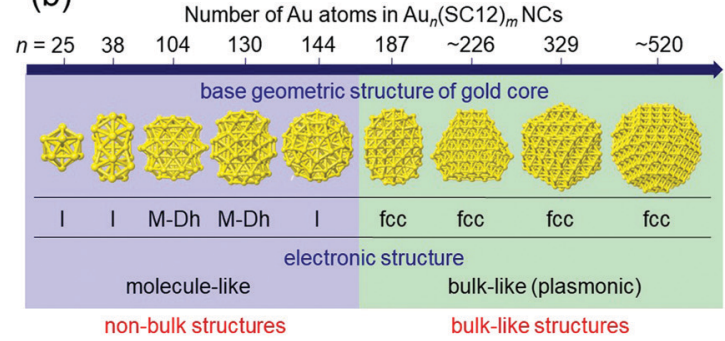

Fig. 5 (a) Positive-ion ESI mass spectra of $\mathrm{Au}_{n}(\mathrm{SC} 12)_{m}$ NCs. (b) Non-bulk to bulk transition between $\mathrm{Au}_{144}(\mathrm{SC} 12)_{60}$ and $\mathrm{Au}_{187}(\mathrm{SC} 12)_{68}$ in the $\mathrm{Au}_{n}(\mathrm{SC} 12)_{m}-\mathrm{NC}$ system. ${ }^{109}$ Reproduced with permission from ref. 109. Copyright 2015 American Chemical Society.

Specifically, we attempted to isolate alloy NCs in which some of the $\mathrm{Au}$ atoms in $\left[\mathrm{Au}_{25}(\mathrm{SR})_{18}\right]^{-}$and $\left[\mathrm{Au}_{38}(\mathrm{SR})_{24}\right]^{0}(\mathrm{SR}=\mathrm{SC} 12$ or PET $)^{153-157}$ were replaced by $\mathrm{Pd}, \mathrm{Ag}$, or $\mathrm{Cu}$ atoms.

Fortunately, we isolated $\left[\mathrm{Au}_{24} \operatorname{Pd}(\mathrm{SC} 12)_{18}\right]^{0}$ (Fig. 6(a)), ${ }^{110}$ $\left[\mathrm{Au}_{25-x} \mathrm{Ag}_{x}(\mathrm{SR})_{18}\right]^{-}(\mathrm{SR}=\mathrm{SC} 12$ or PET, $x=1-11$, Fig. $6(\mathrm{~b})),{ }^{111}$ $\left[\mathrm{Au}_{25-x} \mathrm{Cu}_{x}(\mathrm{PET})_{18}\right]^{-}(x=1-5$, Fig. $6(\mathrm{c})),{ }^{112}$ and $\left[\mathrm{Au}_{36} \mathrm{Pd}_{2}(\mathrm{PET})_{24}\right]^{0}$ (Fig. 6(d) $)^{114}$ at an early stage. Studies on the obtained alloy NCs showed that (1) these three different elements have different preferential substitution sites (Fig. 6(e)), ${ }^{110-112,114,158}$ (2) Pd substitution is effective for creating more stable metal NCs than $\mathrm{Au}_{n}(\mathrm{SR})_{m} \mathrm{NCs},{ }^{110,114}$ (3) $\mathrm{Ag}$ substitution is effective for creating metal NCs with larger HOMO-LUMO gaps than $\mathrm{Au}_{n}(\mathrm{SR})_{m}$ NCs (Fig. 6(f)), ${ }^{111}$ (4) Cu substitution is effective for creating metal NCs with smaller HOMO-LUMO gaps than $\mathrm{Au}_{n}(\mathrm{SR})_{m}$ NCs
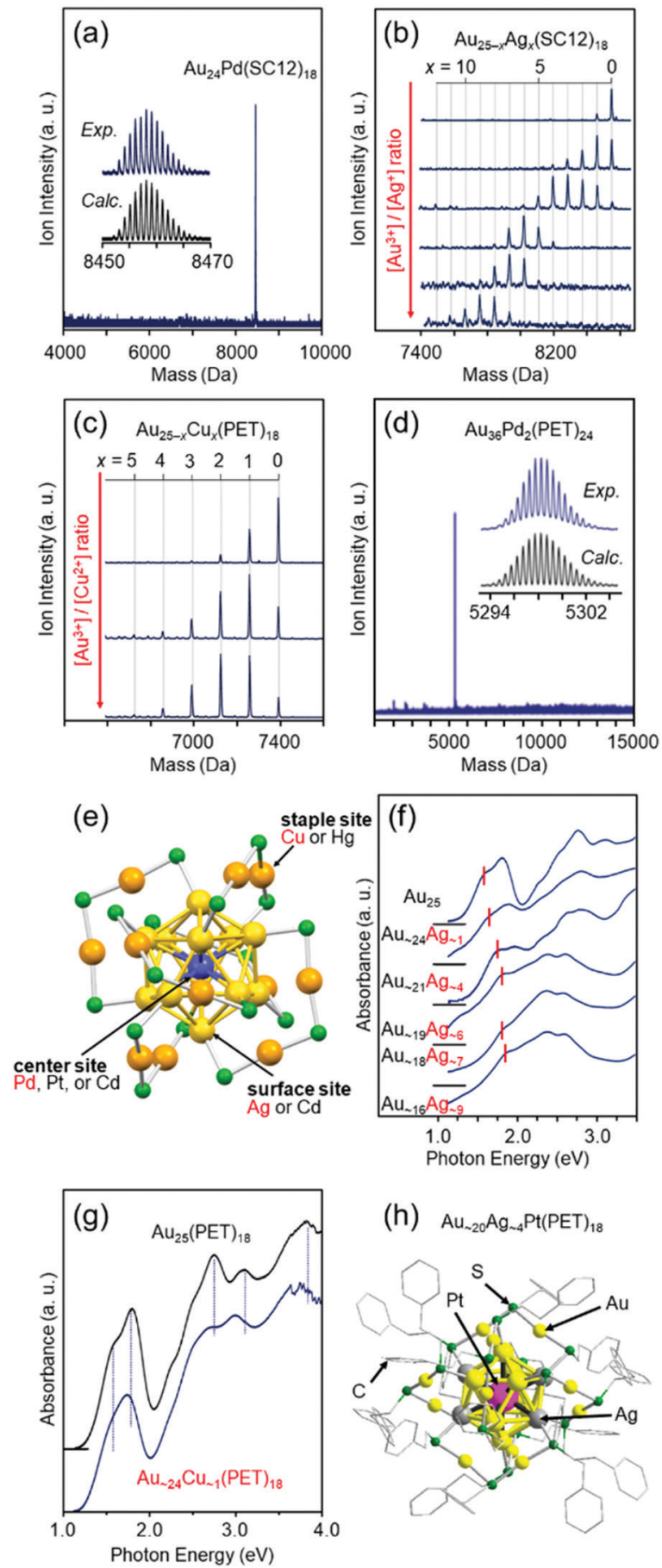

(h) $\mathrm{Au}_{\sim 20} \mathrm{Ag}_{\sim 4} \mathrm{Pt}(\mathrm{PET})_{18}$

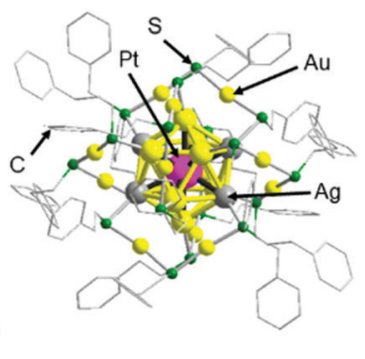

Fig. 6 Negative-ion MALDI mass spectra of (a) $\mathrm{Au}_{24} \mathrm{Pd}(\mathrm{SC} 12)_{18},{ }^{110}$ (b) $\mathrm{Au}_{25-x} \mathrm{Ag}_{x}(\mathrm{SC} 12)_{18},{ }^{111}$ and (c) $\mathrm{Au}_{25-x} \mathrm{Cu}_{x}(\mathrm{SC} 12)_{18 .}{ }^{112}$ (d) Negative-ion ESI mass spectrum of $\mathrm{Au}_{36} \mathrm{Pd}_{2}(\mathrm{PET})_{24}{ }^{114}$ (e) Preferential substitution site in $\mathrm{Au}_{25}(\mathrm{SR})_{18}$ for each element. ${ }^{116}$ Blue, yellow, and orange spheres represent $\mathrm{Au}$ atoms, and green spheres represent $\mathrm{S}$ atoms. The $\mathrm{R}$ groups are omitted for clarity. Optical absorption spectra of (f) $\left[\mathrm{Au}_{25-x} \mathrm{Ag}_{x}(\mathrm{SC} 12)_{18}\right]^{-}$and (g) $\left[\mathrm{Au} \sim 24 \mathrm{Cu}_{\sim 1}(\mathrm{PET})_{18}\right]^{-112,158}$ (h) Geometric structure of $\left[\mathrm{Au} \sim 20 \mathrm{Ag} \sim 4{ }_{4} \mathrm{Pt}(\mathrm{PET})_{18}\right]^{0}{ }^{0117}$ Reproduced with permission from ref. 110-112, 114, 116 and 117. Copyright 2010 The Royal Society of Chemistry, 2012 American Chemical Society, 2012 The Royal Society of Chemistry, 2016 The Royal Society of Chemistry, and 2018 American Chemical Society. 
(Fig. $6(\mathrm{~g})),{ }^{112,158}(5)$ heteroatom substitution with $\mathrm{Pd}, \mathrm{Ag}$, or $\mathrm{Cu}$ enhances the speed of ligand-exchange reaction of NCs, ${ }^{52,159,160}$ and (6) Pd substitution improves the hydrogen evolution reaction (HER), oxygen evolution reaction, and oxygen reduction reaction (ORR) activities of the NCs. ${ }^{48}$ In addition, studies on tri-metal $^{115}$ and tetra-metal ${ }^{116}$ alloy NCs have revealed that simultaneous substitution with different elements at different substitution sites causes superimposed addition of each substitution effect on the base metal NCs. ${ }^{116}$ In these early studies, the substitution sites were predicted based on DFT calculations by Nobusada and/or X-ray absorption fine structure (XAFS) analysis by Tsukuda and Yamazoe. However, since $2016,{ }^{128,161}$ we have also been able to determine the geometric structures of metal NCs by SC-XRD, and such studies have enabled us to (1) create $\left[\mathrm{Au}_{\sim 20} \mathrm{MAg}_{\sim 4}(\mathrm{PET})_{18}\right]^{-}(\mathrm{M}=\mathrm{Pd}$ or $\mathrm{Pt})$, where both the number and position of $\mathrm{Ag}$ substitution are controlled (Fig. 6(h)), ${ }^{117}$ and (2) change the Cu substitution site by combining $\mathrm{Cu}$ and $\mathrm{Pt}$ substitution. ${ }^{162}$

\subsection{Isolation of $\mathrm{Ag}$ and Pt NCs}

When I started my own laboratory, it was not easy to control the number of constituent atoms, even for $\mathrm{Au}_{n}(\mathrm{SR})_{m}$ NCs. Therefore, until 2010, the examples of isolated $\mathrm{Ag}_{n}(\mathrm{SR})_{m}$ NCs were limited to $\mathrm{Ag}_{7}(\mathrm{DMSA})_{4}$ (DMSA = meso-2,3-dimercaptosuccinic) reported by Jin and co-workers ${ }^{163}$ and $\mathrm{Ag}_{9}(\mathrm{~S}(\mathrm{SA}))_{8}$ reported by Pradeep and coworkers. ${ }^{164}$ Thus, we attempted to isolate larger $\mathrm{Ag}_{n}(\mathrm{SR})_{m}$ NCs.

Based on the report of Murray and co-workers, ${ }^{165}$ it was expected that using 4-(tert-butyl)benzylmercaptan (SBB) as a ligand would result in synthesis of stable $\mathrm{Ag}_{n}(\mathrm{SR})_{m}$ NCs. Therefore, we first synthesized a mixture of $\mathrm{Ag}_{n}(\mathrm{SR})_{m}$ NCs and then applied the reaction with thiols, which had been frequently used in isolation of $\mathrm{Au}_{n}(\mathrm{SR})_{m} \mathrm{NCs},{ }^{105,166}$ to the mixture to convert the unstable species to stable species. As a result, $\mathrm{Ag}_{n}(\mathrm{SBB})_{m} \mathrm{NCs}$ with an average particle size of $2.1 \mathrm{~nm}$ were successfully obtained in a size-selective manner. ${ }^{118}$ The obtained stable $\mathrm{Ag}_{n}(\mathrm{SBB})_{m}$ NCs were assigned to $\mathrm{Ag}_{\sim 280}(\mathrm{SBB})_{\sim 120}$ based on the results of ESI-MS. However, in this experiment, which was conducted in 2010 (the paper was published in 2011), the chemical composition was determined by a home-made MS apparatus without high resolution. In recent years, many ESI-MS apparatuses with high sensitivity and resolution have been developed. It is expected that the chemical composition of the stable $\mathrm{Ag}_{n}(\mathrm{SBB})_{m}$ NCs obtained in that study will be determined more accurately using such ESI mass spectrometers in the future.

$\mathrm{Ag}_{n}$ NCs are attractive because of their high quantum yield of luminescence $\mathrm{e}^{167}$ and high selectivity for carbon dioxide reduction. ${ }^{168}$ Since we have also been working on catalytic application of metal NCs, we have continued to work on development of isolation techniques for $\mathrm{Ag}_{n}$ NCs also after the report of $\mathrm{Ag}_{n}(\mathrm{SBB})_{m}$ NCs. As a result, for example, in 2013, we successfully isolated $\mathrm{Ag}_{44}(\mathrm{SePh})_{30}(\mathrm{SePh}=$ phenylselenolate $)$ in collaboration with Pradeep and co-workers (Fig. 7(a)). ${ }^{119}$ DFT calculations by Häkkinen and co-workers showed that $\mathrm{Ag}_{44}(\mathrm{SePh})_{30}$ has a geometric structure similar to that of $\left[\mathrm{Ag}_{44}(\mathrm{SR})_{30}\right]^{4-}\left(\mathrm{SR}=\mathrm{SPhF}_{2}\right.$ or 4 -mercaptobenzoic acid ( $p$-MBA $\left.)\right)$, whose geometric structure was determined just before our (a)

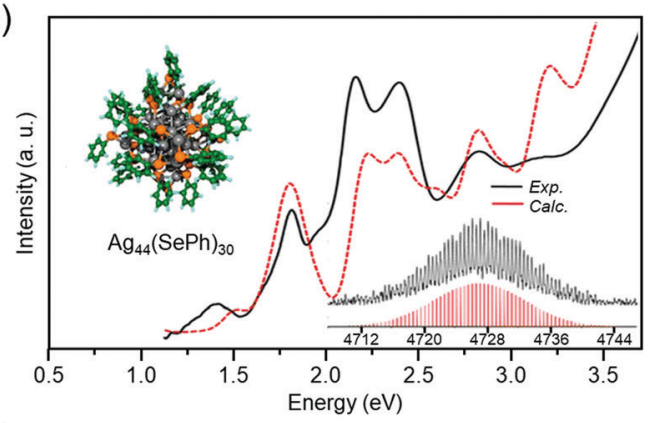

(b) $\left[\mathrm{Pt}_{17}\left(\mathrm{PPh}_{3}\right)_{8}(\mathrm{CO})_{12}\right]\left(\mathrm{SbF}_{6}\right)$

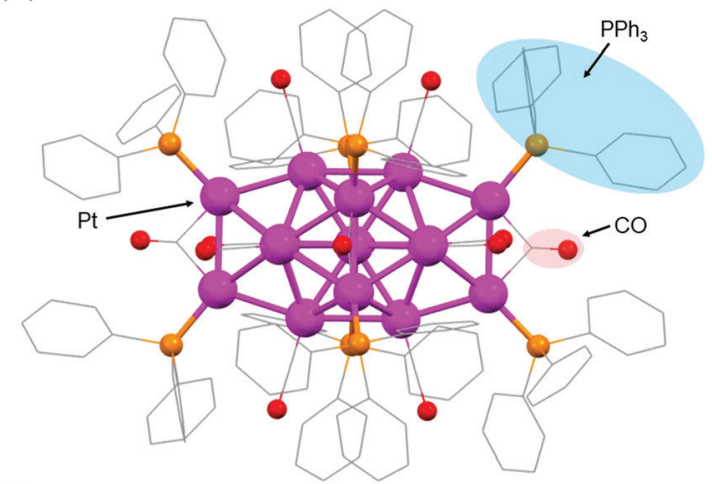

(c)

(d)
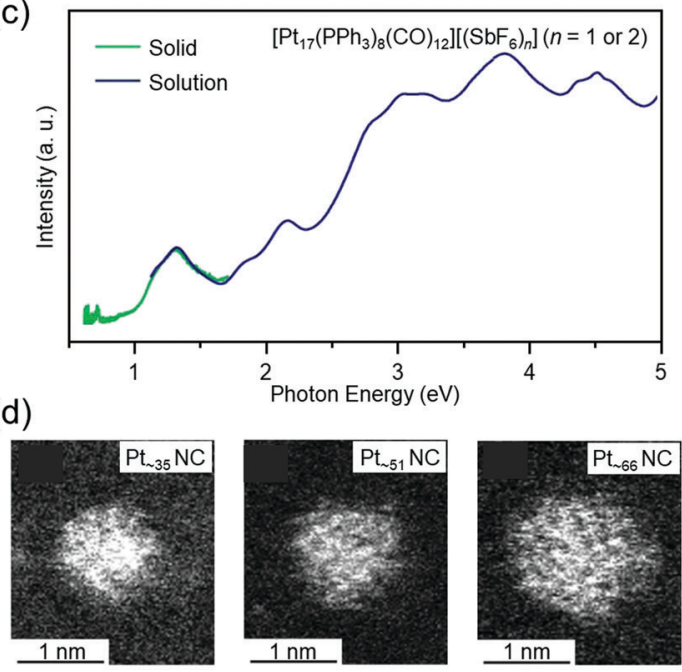

Fig. 7 (a) Optical absorption spectra, computationally relaxed structure, and expanded ESI mass spectrum of $\mathrm{Ag}_{44}(\mathrm{SePh})_{30}{ }^{119}$ (b) Geometric structure of $\left[\mathrm{Pt}_{17}\left(\mathrm{PPh}_{3}\right)_{8}(\mathrm{CO})_{12}\right]\left(\mathrm{SbF}_{6}\right)\left(\mathrm{SbF}_{6}{ }^{-}=\right.$hexafluoroantimonate) determined by SCXRD. ${ }^{120}$ (c) Optical absorption spectra of $\left[\mathrm{Pt}_{17}\left(\mathrm{PPh}_{3}\right)_{8}(\mathrm{CO})_{12}\right]\left[\left(\mathrm{SbF}_{6}\right)_{n}\right](n=1$ or 2$)$ in dichloromethane solution (blue) and the solid state $\left[\mathrm{Pt}_{17}\left(\mathrm{PPh}_{3}\right)_{8}(\mathrm{CO})_{12}\right]\left[\left(\mathrm{SbF}_{6}\right)_{n}\right]$ ( $n=1$ or 2) (green). ${ }^{120}$ (d) High-angle scattering dark-field scanning transmission electron microscopy (HAADF-STEM) images of $\mathrm{Pt}_{n}(\mathrm{PET})_{m}(\mathrm{CO})$, NCs with $n=$ $\sim 35$ (left), $\sim 51$ (center), and $\sim 66$ (right). ${ }^{121}$ Reproduced with permission from ref. 119-121. Copyright 2013 American Chemical Society, 2017 American Chemical Society, and 2021 The Royal Society of Chemistry.

reports by Zheng and co-workers ${ }^{169}$ and Bigioni and coworkers. ${ }^{170}$ In addition to this NC, we recently succeeded in isolating several new $\mathrm{Ag} \mathrm{NCs}^{171}$ using anions as templates (the paper is being prepared for submission).

Isolation of $\mathrm{Pt}_{n}$ NCs has been reported by Chini and co-workers and Longoni and co-workers. ${ }^{22,27}$ In their studies, 
CO was used as the main ligand, but in later studies on $\mathrm{Pt}_{n}$ and its alloy NCs by Dahl, Slovokhotov, Zacchini, etc., $\mathrm{PR}_{3}$ was also used as a ligand. ${ }^{23,172,173}$ In these studies, the geometric structures of the metal NCs were determined by SC-XRD. For $\mathrm{Au}_{n}(\mathrm{SR})_{m} \mathrm{NCs}$, in 2007, Kornberg, Ackerson and co-workers reported the geometric structure of $\left[\mathrm{Au}_{102}(p \text {-MBA })_{44}\right]^{0}$, which was the first report of the geometric structure of $\mathrm{Au}_{n}(\mathrm{SR})_{m}$ NCs determined by SC-XRD. ${ }^{174}$ The advancement of research of $\mathrm{Pt}_{n}$ and its alloy NCs at that time was astonishing. However, synthesis and the subsequent handling of the reported $\mathrm{Pt}_{n}$ NCs had to be carried out under CO or an inert-gas atmosphere, ${ }^{23,172,173}$ which was not easy for those who were not used to using CO gas or Schlenk techniques. Therefore, we searched for $\mathrm{Pt}_{n}$ NCs that could be synthesized by mixing reagents in air, similar to $\mathrm{Au}_{n}(\mathrm{SR})_{m}$ NCs.

When a Pt salt is dissolved in polyol and the resulting solution is heated, the Pt salt is reduced to generate Pt atoms (polyol reduction). ${ }^{175-179}$ The polyol generates CO, and the generated $\mathrm{CO}$ coordinates to the $\mathrm{Pt}$ surface. Addition of $\mathrm{PR}_{3}$ to the solution of the resulting product is expected to give $\mathrm{Pt}_{n}\left(\mathrm{PR}_{3}\right)_{m}(\mathrm{CO})_{l}$ NCs without the need for a $\mathrm{CO}$ atmosphere. Indeed, we successfully isolated $\left[\mathrm{Pt}_{17}\left(\mathrm{PPh}_{3}\right)_{8}(\mathrm{CO})_{12}\right]^{z+}\left(\mathrm{PPh}_{3}=\right.$ triphenylphosphine, $z=1$ or 2) with atomic precision by this method (Fig. 7(b)). ${ }^{120}$ The obtained NC had a geometric structure similar to previously reported $\left[\mathrm{Pt}_{17}\left(\mathrm{PEt}_{3}\right)_{8}(\mathrm{CO})_{12}\right]^{0}\left(\mathrm{PEt}_{3}=\right.$ triethylphosphine $)^{23}$ and $\left[\mathrm{Pt}_{13} \mathrm{Au}_{4}\left(\mathrm{PPh}_{3}\right)_{8}(\mathrm{CO})_{12}\right]^{0.172}$ Optical absorption spectroscopy revealed that $\left[\mathrm{Pt}_{17}\left(\mathrm{PPh}_{3}\right)_{8}(\mathrm{CO})_{12}\right]^{z+}(z=1$ or 2$)$ has a discrete electronic structure similar to a small $\mathrm{Au}_{n}(\mathrm{SR})_{m} \mathrm{NC}$ (Fig. 7(c)). ${ }^{102}$

For $\mathrm{Pt}_{n}$ NCs, we have also succeeded in obtaining a series of $\mathrm{Pt}_{n}(\mathrm{PET})_{m}(\mathrm{CO})_{l}$ NCs $(n=\sim 35, \sim 51$, and $\sim 66)$ in high yields $(\sim 80 \%$ yield for $\mathrm{Pt} \sim 66)$ by changing the ligand from $\mathrm{PPh}_{3}$ to PET (Fig. 7(d)). ${ }^{121}$ Unfortunately, the chemical compositions of these $\mathrm{Pt}_{n}(\mathrm{PET})_{m}(\mathrm{CO})_{l}$ NCs cannot be controlled with atomic precision at present. Therefore, the chemical compositions and geometric structures of these NCs have not been accurately determined. Thus, we are now attempting to apply various size-focusing methods ${ }^{166,180}$ to $\mathrm{Pt}_{n}(\mathrm{PET})_{m}(\mathrm{CO})_{l}$ NCs to isolate the $\mathrm{Pt}_{n}(\mathrm{PET})_{m}(\mathrm{CO})_{l}$ NCs with a single chemical composition. If these efforts are successful and the chemical compositions and geometric structures of the isolated $\mathrm{Pt}_{n}(\mathrm{PET})_{m}(\mathrm{CO})_{l}$ NCs are accurately determined, it is expected that a deeper understanding of the chemical compositions and geometric structures of the $\mathrm{Pt}_{n}(\mathrm{PET})_{m}(\mathrm{CO})_{l}$ NCs that can be isolated will be obtained.

\subsection{Isolation of metal NCs protected by functional ligands}

For ligand-protected metal NCs, it is possible to impart new functions by controlling not only the metal core, but also the functional groups of the ligands. The solvent solubility, redox potential, ${ }^{181-184}$ luminescence properties, ${ }^{185}$ optical activity, ${ }^{186}$ and catalytic activity of $\mathrm{Au}_{n}(\mathrm{SR})_{m}$ NCs are remarkably dependent on the functional group structure of SR. If $\mathrm{Au}_{n}(\mathrm{SR})_{m}$ NCs with these characteristics are protected by $\mathrm{SR}$, which changes its molecular structure in response to light irradiation, it is expected that the physicochemical properties of $\mathrm{Au}_{n}(\mathrm{SR})_{m}$ NCs can be reversibly changed by light irradiation. (a)
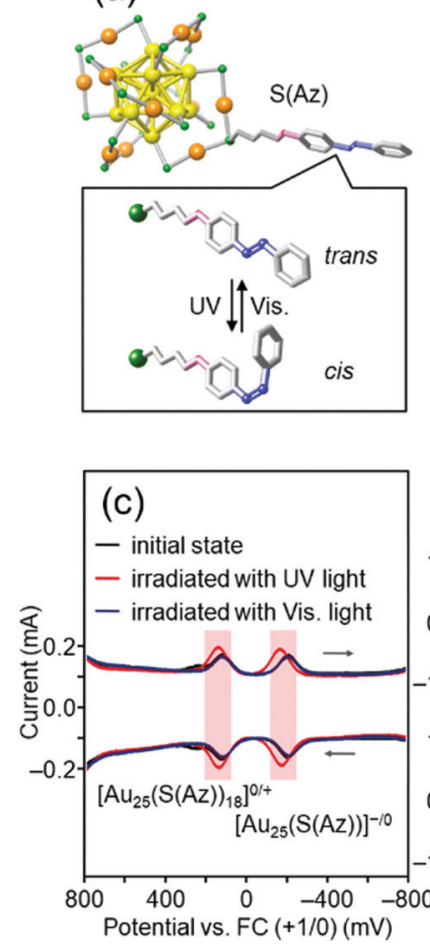

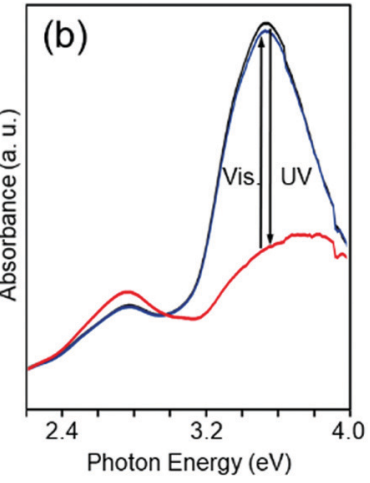

(d)

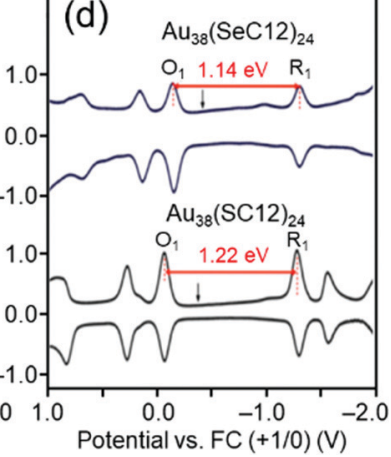

Fig. 8 (a) Proposed geometric structure of $\left[\mathrm{Au}_{25}(\mathrm{~S}(\mathrm{Az}))_{18}\right]^{-}$and (b) the photoresponsive behavior in the optical absorption spectra of $\left[\mathrm{Au}_{25}(\mathrm{~S}(\mathrm{Az}))_{18}\right]^{-}$in toluene solution in the energy range $2.2-4.0 \mathrm{eV} .^{122}$ The visible photostationary state (blue line) overlaps with the initial state (black line). (c) Photoresponse of the differential pulse voltammetry (DPV) curve of $\left[\mathrm{Au}_{25}(\mathrm{~S}(\mathrm{Az}))_{18}\right]^{-122}$ (d) DPV curves of $\left[\mathrm{Au}_{38}(\mathrm{SeC} 12)_{24}\right]^{\mathrm{O}}$ and $\left[\mathrm{Au}_{38}(\mathrm{SC} 12)_{24}\right]^{\mathrm{O}}$ in $\mathrm{CH}_{2} \mathrm{Cl}_{2}$ containing $0.1 \mathrm{M}\left(\mathrm{C}_{4} \mathrm{H}_{9}\right)_{4} \mathrm{NClO}_{4}{ }^{126} \mathrm{O}_{1}$ and $\mathrm{R}_{1}$ indicate the first oxidation and reduction peaks of the NCs, respectively. The black arrows indicate the solution open-circuit potentials. The red arrows indicate the electrochemical HOMO-LUMO gaps of $\left[\mathrm{Au}_{38}(\mathrm{SeC} 12)_{24}\right]^{0}$ and $\left[\mathrm{Au}_{38}(\mathrm{SC} 12)_{24}\right]^{0}$. Reproduced with permission from ref. 122 and 126. Copyright 2012 The Royal Society of Chemistry and 2013 American Chemical Society.

Azobenzene is a typical photoresponsive molecule. ${ }^{187,188}$ It changes from trans to cis by ultraviolet (UV)-light irradiation and from cis to trans by visible-light irradiation. When SR containing azobenzene is used as a protective ligand, $\mathrm{Au}_{n}(\mathrm{SR})_{m}$ NCs, whose physicochemical properties repeatedly change by light irradiation, could be created. Accordingly, we have synthesized $\mathrm{Au}_{25}(\mathrm{~S}(\mathrm{Az}))_{18}$ protected by an azobenzene derivative thiolate (S(Az)) (Fig. 8(a)) to create such photoresponsive $\mathrm{Au}_{n}(\mathrm{SR})_{m}$ NCs. $^{122}$ When the obtained $\mathrm{Au}_{25}(\mathrm{~S}(\mathrm{Az}))_{18}$ was irradiated with light, $\mathrm{S}(\mathrm{Az})$ repeatedly underwent photoisomerization (Fig. 8(b)). In addition, the redox potential of $\mathrm{Au}_{25}(\mathrm{~S}(\mathrm{Az}))_{18}$ reversibly changed with such structural changes (Fig. 8(c)). These results demonstrated that the combination of azobenzene and $\mathrm{Au}_{25}$ NCs can be used to create $\mathrm{Au}_{n}(\mathrm{SR})_{m}$ NCs with photoresponsive redox potentials.

$\mathrm{Au}_{25}(\mathrm{SR})_{18}$ has a compact and symmetric metal core (Fig. 8(a)). ${ }^{153,154}$ Therefore, the metal-core structure of $\mathrm{Au}_{25}(\mathrm{~S}(\mathrm{Az}))_{18}$ remains almost unchanged even after isomerization of the ligand by photoirradiation. The change in the redox potential is considered to be because of the change in the dipole moment of the S(Az) 
molecule caused by isomerization of azobenzene, which in turn changes the orbital energy of $\mathrm{Au}_{25}(\mathrm{~S}(\mathrm{Az}))_{18 \cdot}{ }^{189,190}$ In 2016, Jin and co-workers reported that $\left[\mathrm{Au}_{28}(\mathrm{SR})_{20}\right]^{0}$ can change the metal-core structure depending on the functional group structure of the ligand. ${ }^{191}$ Therefore, in the future, we will combine $\mathrm{S}(\mathrm{Az})$ with a $\mathrm{Au}_{n}(\mathrm{SR})_{m}$ NC whose metal core was easily deformable, ${ }^{192}$ and thereby create "intelligent" $\mathrm{Au}_{n}(\mathrm{SR})_{m}$ NCs in which the metal-core structure changes by light irradiation, leading to significant changes in the redox potential, luminescence properties, optical activity, and catalytic activity.

In the above study of $\mathrm{Au}_{25}(\mathrm{~S}(\mathrm{Az}))_{18}$, a new function was provided to the $\mathrm{Au}_{n}$ NCs by including a function in a functional group that was not directly bound to Au. However, changing the functional group directly bound to $\mathrm{Au}($ i.e., $\mathrm{S}$ ) to Se is expected to change the binding mode between $\mathrm{Au}$ and the ligand, ${ }^{193}$ thereby providing $\mathrm{Au}_{n}$ NCs with new physical and chemical properties. With this expectation, we precisely synthesized $\left[\mathrm{Au}_{25}(\mathrm{SeR})_{18}\right]^{-}$ (SeR $=$ octaneselenolate $(\mathrm{SeC} 8)$ or dodecaneselenolate $(\mathrm{SeC} 12)),{ }^{123,124}\left[\mathrm{Au}_{25}(\mathrm{PET})_{18-y}(\mathrm{SePh})_{y}\right]^{-} \quad(y=1-18),{ }^{128}$ $\left[\mathrm{Au}_{25-x} \mathrm{Cu}_{x}(\mathrm{SeC} 8)_{18}\right]^{-}(x=1-9){ }^{125}$ and $\left[\mathrm{Au}_{38}(\mathrm{SeC} 12)_{24}\right]^{-126}$ with selenolate (SeR) ligands. Studies on the obtained $\mathrm{Au}$ NCs revealed that changing the ligand from SR to SeR (1) changes the binding mode between $\mathrm{Au}$ and the ligand, thereby making the Au NCs more stable, ${ }^{124}$ and (2) has the effect of narrowing the HOMO-LUMO gap of the $\mathrm{Au}$ NCs (Fig. 8(d)). ${ }^{124,126,128}$ We have also systematically synthesized $\left[\mathrm{Au}_{25}(\mathrm{SC} 8)_{18-y}(\mathrm{TePh})_{y}\right]^{-}(\mathrm{TePh}=$ phenyltellurolate, $y=$ 1-18) containing a tellurolate (TeR) in the ligand layer. ${ }^{127,128} \mathrm{We}$ found that changing the ligand from SR to TeR further narrows the HOMO-LUMO gap of the Au NCs. ${ }^{127,128}$

Based on a study of two-dimensional self-assembled monolayers, ${ }^{194}$ changing the ligand from SR to SeR or TeR is expected to induce an increase in the conductivity between the $\mathrm{Au}$ core and the ligand. High conductivity is a desired feature in creation of single-molecule devices based on Au NCs, ${ }^{195}$ and we hope to clarify this point in future studies by comparing the conductivities of $\mathrm{Au}_{n}(\mathrm{SR})_{m}, \mathrm{Au}_{n}(\mathrm{SeR})_{m}$, and $\mathrm{Au}_{n}(\mathrm{TeR})_{m}$ NCs.

\subsection{Connection of ligand-protected metal NCs}

Among ligand-protected metal NCs, icosahedral NCs have been reported to become constituent units of "clusters of clusters". 196 For example, in the 1990s, Teo and co-workers reported synthesis of $\left[\left(p-\operatorname{tol}_{3} \mathrm{P}\right)_{10} \mathrm{Au}_{13} \mathrm{Ag}_{12} \mathrm{Cl}_{7}\right]^{2+}$ (p-tol ${ }_{3} \mathrm{P}=$ tris(4-methylphenyl)phosphine) consisting of two $\mathrm{Au}_{13-x} \mathrm{Ag}_{x}{ }^{197}$ and $\left[\left(p \text {-tol }{ }_{3} \mathrm{P}\right){ }_{12} \mathrm{Au}_{18} \mathrm{Ag}_{20} \mathrm{Cl}_{14}\right]^{0}$ consisting of three $\mathrm{Au}_{13-x} \mathrm{Ag}_{x}{ }^{198}$ In 2007, I was also involved in isolation of $\left[\mathrm{Au}_{25}\left(\mathrm{PPh}_{3}\right)_{10}(\mathrm{SCn})_{5} \mathrm{Cl}_{2}\right]^{2+}(\mathrm{SCn}=$ alkanethiolate, $n=$ 2-18), which consists of two $\mathrm{Au}_{13}$ NCs. ${ }^{199}$ Further development of techniques for connecting metal NCs could lead to fabrication of ultra-thin metal nanowires. Therefore, we have also been working on development of techniques to connect metal NCs.

The first connected structure that was successfully isolated was $\left[\mathrm{Au}_{24} \mathrm{Pd}\left(\mathrm{PPh}_{3}\right)_{10}(\mathrm{PET})_{5} \mathrm{Cl}_{2}\right]^{+}$(Fig. 9(a)). ${ }^{129}$ This connected structure was size-selectively synthesized under appropriate conditions. In this connected structure, only one central Au atom is substituted by a different atom, unlike most of the connected structures reported in previous papers. ${ }^{200-203}$ DFT calculations by Jiang and co-workers showed that $\left[\mathrm{Au}_{24} \mathrm{Pd}\left(\mathrm{PPh}_{3}\right)_{10}(\mathrm{PET})_{5} \mathrm{Cl}_{2}\right]^{+} \mathrm{NCs}$ (a) $\left[\mathrm{Au}_{24} \mathrm{Pd}\left(\mathrm{PPh}_{3}\right)_{10}(\mathrm{PET})_{5} \mathrm{Cl}_{2}\right] \mathrm{Cl}$

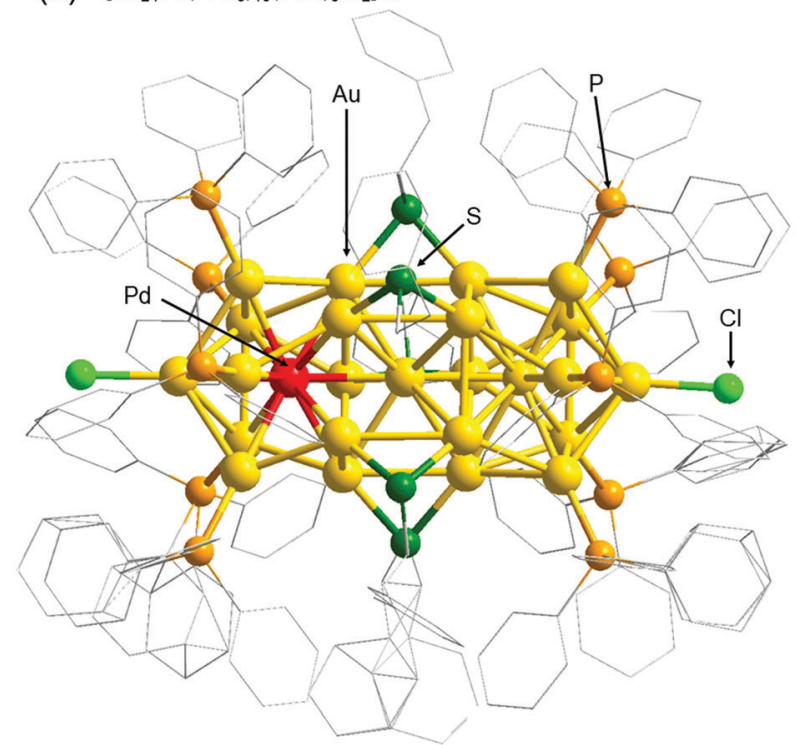

(b) $\left[\mathrm{Ag}_{23} \mathrm{Pd}_{2}\left(\mathrm{PPh}_{3}\right)_{10} \mathrm{Cl}_{7}\right]^{0}$

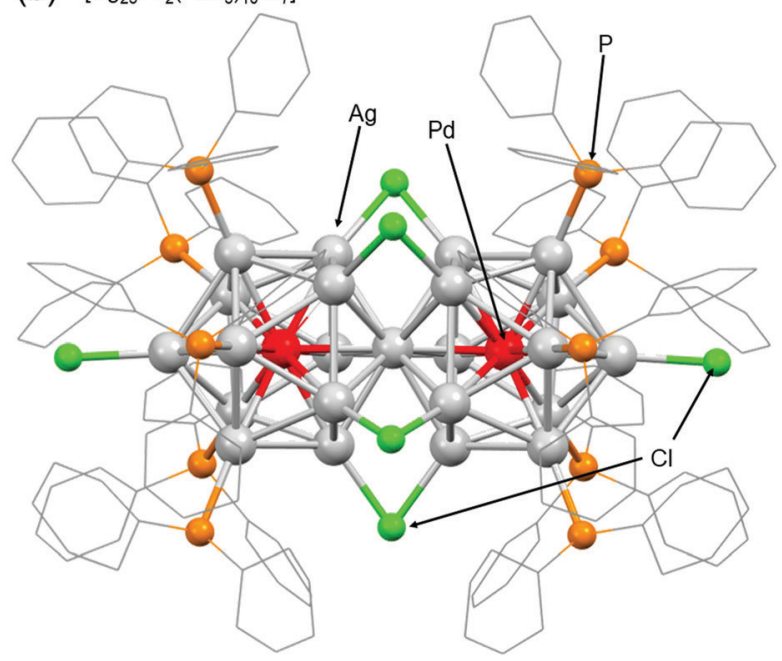

Fig. 9 Geometric structures of (a) $\left[\mathrm{Au}_{24} \mathrm{Pd}\left(\mathrm{PPh}_{3}\right)_{10}(\mathrm{PET})_{5} \mathrm{Cl}_{2}\right] \mathrm{Cl}$ and (b) $\left[\mathrm{Ag}_{23} \mathrm{Pd}_{2}\left(\mathrm{PPh}_{3}\right)_{10} \mathrm{Cl}_{7}\right]^{0}{ }^{0}{ }^{129,131}$ Reproduced with permission from ref. 129 and 131. Copyright 2018 The Royal Society of Chemistry and 2021 American Institute of Physics.

with these hetero bi-icosahedral cores have dipole moments in the $\mathrm{NC}^{129}$ Very recently, we also succeeded in synthesizing $\left[\mathrm{Ag}_{23} \mathrm{Pd}_{2}\left(\mathrm{PPh}_{3}\right)_{10} \mathrm{Cl}_{7}\right]^{0}$ consisting of two $\mathrm{Ag}_{12} \mathrm{Pd}$ cores (Fig. 9(b)). ${ }^{131}$ Stability experiments and DFT calculations by Iwasa and co-workers indicated that it is very important to strengthen the framework of individual icosahedral cores and increase their stability to form the connected structures described by the chemical formula $\left[\mathrm{Ag}_{23} \mathrm{M}_{2}\left(\mathrm{PPh}_{3}\right)_{10} \mathrm{Cl}_{7}\right]^{z}(\mathrm{M}=\mathrm{Ag}, \mathrm{Pd}$, or Pt, $z=2+$ or 0$){ }^{131}$

In the above study, two metal NCs were connected. On the other hand, in the study on $\left[\mathrm{Au}_{4} \mathrm{Pt}_{2}(\mathrm{SR})_{8}\right]^{0}$ (SR = PET (Fig. 10(a)) or 2-chlorobenzylmercaptane $\left.\left(\mathrm{SCH}_{2} \mathrm{PhCl}\right)\right)$, we successfully connected them continuously in one dimension. ${ }^{130}$ This was the second report of formation of a one-dimensional connected structure, following that reported by Maran and co-workers for $\left[\mathrm{Au}_{24} \mathrm{M}(\mathrm{SR})_{18}\right]^{0}(\mathrm{M}=\mathrm{Au}, \mathrm{Hg}$, or $\mathrm{Cd}, \mathrm{SR}=$ butanethiolate or 
(a) $\left[\mathrm{Au}_{4} \mathrm{Pt}_{2}(\mathrm{PET})_{8}\right]_{n}$

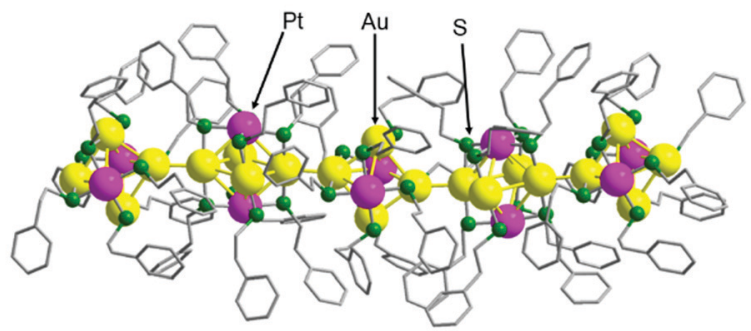

(b)

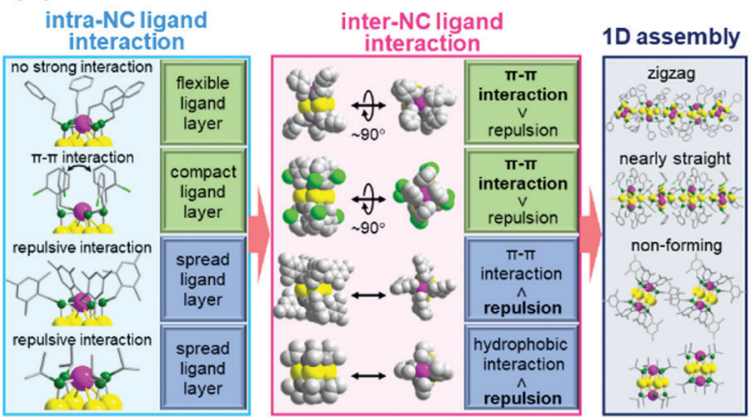

Fig. 10 (a) Crystal structure of $\left[\mathrm{Au}_{4} \mathrm{Pt}_{2}(\mathrm{PET})_{8}\right]_{n}$. (b) Relationships between intra-NC ligand interactions, which are related to the distribution of the ligands within each NC, inter-NC ligand interactions, and one-dimensional assembly. Reproduced with permission from ref. 130. Copyright 2020 The Royal Society of Chemistry.

pentanethiolate) ${ }^{204-206}$ (note that although it was not mentioned in the paper, ${ }^{207}\left[\mathrm{Au}_{4} \mathrm{Pd}_{2}(\mathrm{PET})_{8}\right]^{0}$ reported by Wu and co-workers also seemed to form a similar connected structure). A series of studies with SR ligands revealed that it is important to design the ligand interaction within $\left[\mathrm{Au}_{4} \mathrm{Pt}_{2}(\mathrm{SR})_{8}\right]^{0}$ to form one-dimensional connected structures and control their geometry (Fig. 10(b)). ${ }^{130}$ The obtained one-dimensional connected structures have a semiconductor band gap, and the band gap size can be modulated by the ligand structure. These findings are expected to provide clear design guidelines for creation of metal-NC connected structures with desired geometric structures and physicochemical properties. We are now also working on connection of these metal NCs via linker molecules. ${ }^{62,208-213}$

\subsection{Development of high-resolution separation methods}

Most of the ligand-protected metal NCs and their connected structures discussed in Sections 4.2-4.6 can be isolated by only mixing the reagents and washing the by-products in the ambient atmosphere. However, all NCs cannot be necessary isolated by such a simple process in the case of $\mathrm{Au}_{n}(\mathrm{SC} 12)_{m} \mathrm{NCs}^{109}$ described in Section 4.2. Therefore, it was necessary to develop new high-resolution separation techniques for ligand-protected metal NCs to isolate the metal NCs precisely and systematically, and thereby to understand the correlation between the chemical composition and the structure/properties.

PAGE (Fig. 3(a)), which is described in Section 3, is suitable for high-resolution separation of hydrophilic compounds, but it is not so suitable for high-resolution separation of hydrophobic compounds. On the other hand, HPLC (Fig. 11(a)) is suitable for
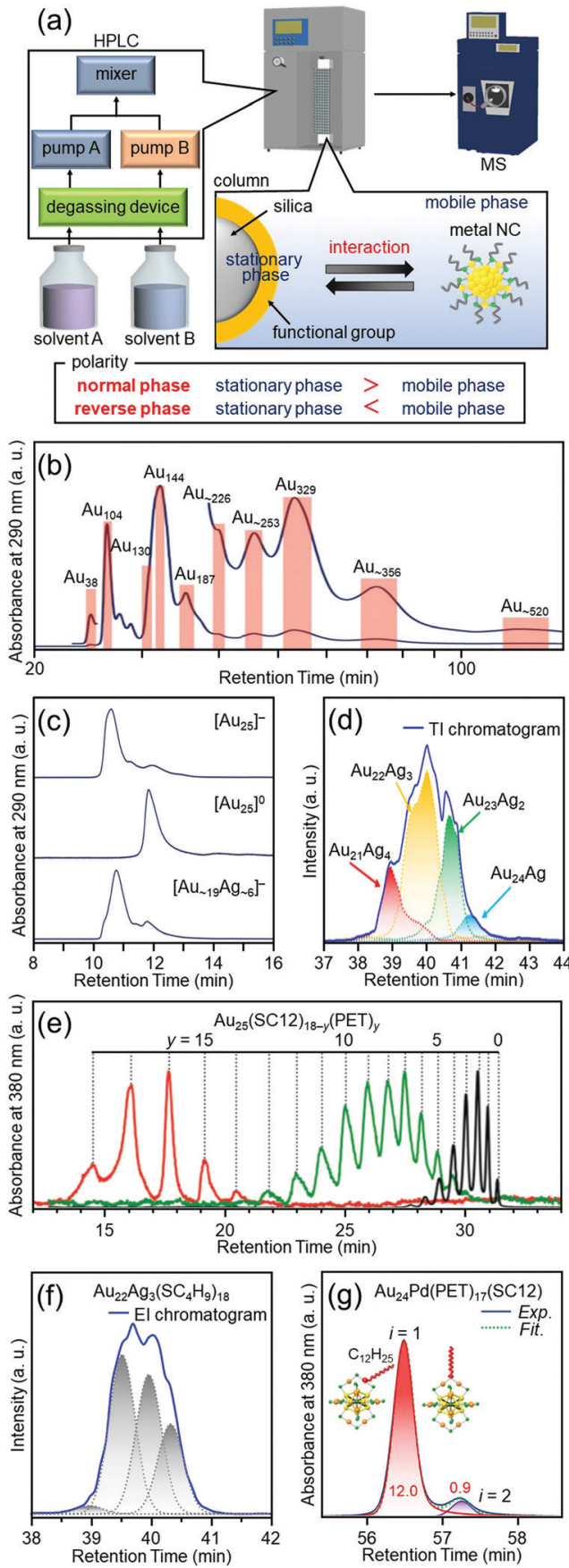

Fig. 11 (a) Schematic illustration of HPLC separation techniques. ${ }^{61}$ Chromatograms of (b) the crude sample of $\mathrm{Au}_{n}(\mathrm{SC} 12)_{m} \mathrm{NCs}^{109}$ and (c) $\left[\mathrm{Au}_{25}(\mathrm{SC} 12)_{18}\right]^{-}$, $\left[\mathrm{Au}_{25}(\mathrm{SC} 12)_{18}\right]^{0}$, and $\left[\mathrm{Au} \sim 19 \mathrm{Ag}_{\sim 6}(\mathrm{SC} 12)_{18}\right]^{-111}$ (d) Extracted ion (EI) chromatogram of $\left[\mathrm{Au}_{25-x} \mathrm{Ag}_{x}\left(\mathrm{SC}_{4} \mathrm{H}_{9}\right)_{18}\right]^{0.132} \mathrm{TI}$ means total ion. (e) Chromatogram of $\mathrm{Au}_{25}(\mathrm{SC} 12)_{18-y}(\mathrm{PET})_{y}{ }^{134}$ (f) El chromatogram of $\mathrm{Au}_{22} \mathrm{Ag}_{3}$, which represents separation of several types of isomers. ${ }^{132}$ (g) Chromatogram of $\mathrm{Au}_{24} \mathrm{Pd}(\mathrm{PET})_{17}(\mathrm{SC} 12)$, which represents separation of coordination isomers. ${ }^{137}$ Reproduced with permission form ref. 61,109 , 111, 132, 134 and 137. Copyright 2020 The Royal Society of Chemistry, 2015 American Chemical Society, 2010 The Royal Society of Chemistry, 2018 American Chemical Society, and 2013 American Chemical Society.

separation of both hydrophilic and hydrophobic compounds. Indeed, in 2003, Murray and co-workers succeeded in isolating 
$\mathrm{Au}$ NCs, such as $\mathrm{Au}_{38}, \mathrm{Au}_{140}$, and $\mathrm{Au}_{225}$ (the chemical composition is reported one in the papers), from a mixture of $\mathrm{Au}_{n}(\mathrm{SC6})_{m}$ NCs (SC6 = hexanethiolate) by RP-HPLC. ${ }^{144,214,215}$

Inspired by the work of Murray and co-workers, we attempted to separate metal NCs, which were difficult to isolate by only washing the by-products, at the atomic and molecular levels by advanced use of RP-HPLC. ${ }^{53}$ As a result, in addition to separation depending on the number of constituent atoms (Fig. 11(b)), ${ }^{108,109}$ ligand-protected metal NCs were also successfully separated depending on the charge state (Fig. 11(c)), ${ }^{110}$ alloy composition (Fig. 11(d)), ${ }^{132,138}$ ligand combination (Fig. 11(e)), ${ }^{133,134}$ and structural isomer (Fig. 11(f and g)). ${ }^{132,137}$ The separation techniques described in Fig. 11(f and $\mathrm{g}$ ) led to not only control of the structural isomers, but also elucidation of the reaction mechanisms of the metal-exchange ${ }^{138}$ and ligand-exchange ${ }^{137}$ reactions. Although these high-resolution separations were achieved for hydrophobic metal NCs, in later studies, we also succeeded in separating hydrophilic metal NCs depending on their constituent atoms with high resolution by ion-pair chromatography ${ }^{135}$ or hydrophilic-interaction chromatography. ${ }^{136}$

In the future, we would like to use two-dimensional HPLC ${ }^{216}$ for such high-resolution separations. It allows the use of two different separation modes. We expect that this will make it possible, for example, to first separate the products generated by ligand exchange depending on the number of exchanged ligands, ${ }^{134}$ and then to separate the products of the same chemical composition depending on the optical isomers ${ }^{217}$ generated by the position of the exchanged ligands.

\subsection{Summary of control of ligand-protected metal NCs}

We have succeeded in developing several new techniques for (1) isolation of large Au NCs, (2) isolation of alloy NCs, (3) isolation of metal NCs consisting of Ag or Pt, (4) isolation of metal NCs protected by functional ligands, (5) connection of metal NCs, and (6) high-resolution separation of metal NCs. Other groups have also been simultaneously working in these areas, and they have developed several other isolation methods. ${ }^{7,218}$ Through these studies, the control techniques for ligandprotected metal NCs, that is, "bottom-up nanotechnology for complexes composed of metals and molecules", has been dramatically enhanced in recent years. In the future, it is expected that the "science of ligand-protected metal NCs" will be further deepened by further development of these control techniques.

\section{Toward creation of high-performance energy and environmental catalysts}

When I started investigating gas-phase NCs in 1995, I was not concerned about the applications of metal NCs as materials. However, after I had deposited $\mathrm{Ge}_{n} \mathrm{O}_{m}$ NCs on a support and observed their luminescence in air with my own eyes, I thought to contribute to society by applying metal NCs as materials in future studies. Because energy and environmental issues have become major global challenges, I decided to contribute to the field of energy and environmental materials.

\subsection{Social problems to be solved by chemistry}

In the 21st century, there are serious issues regarding energy and the environment, such as depletion of fossil fuels and destruction of the environment on a global scale. Therefore, chemistry in the 21st century is expected to address these issues, and thereby build a clean and sustainable society. The energy conversion system shown in Fig. 12 is one of the systems

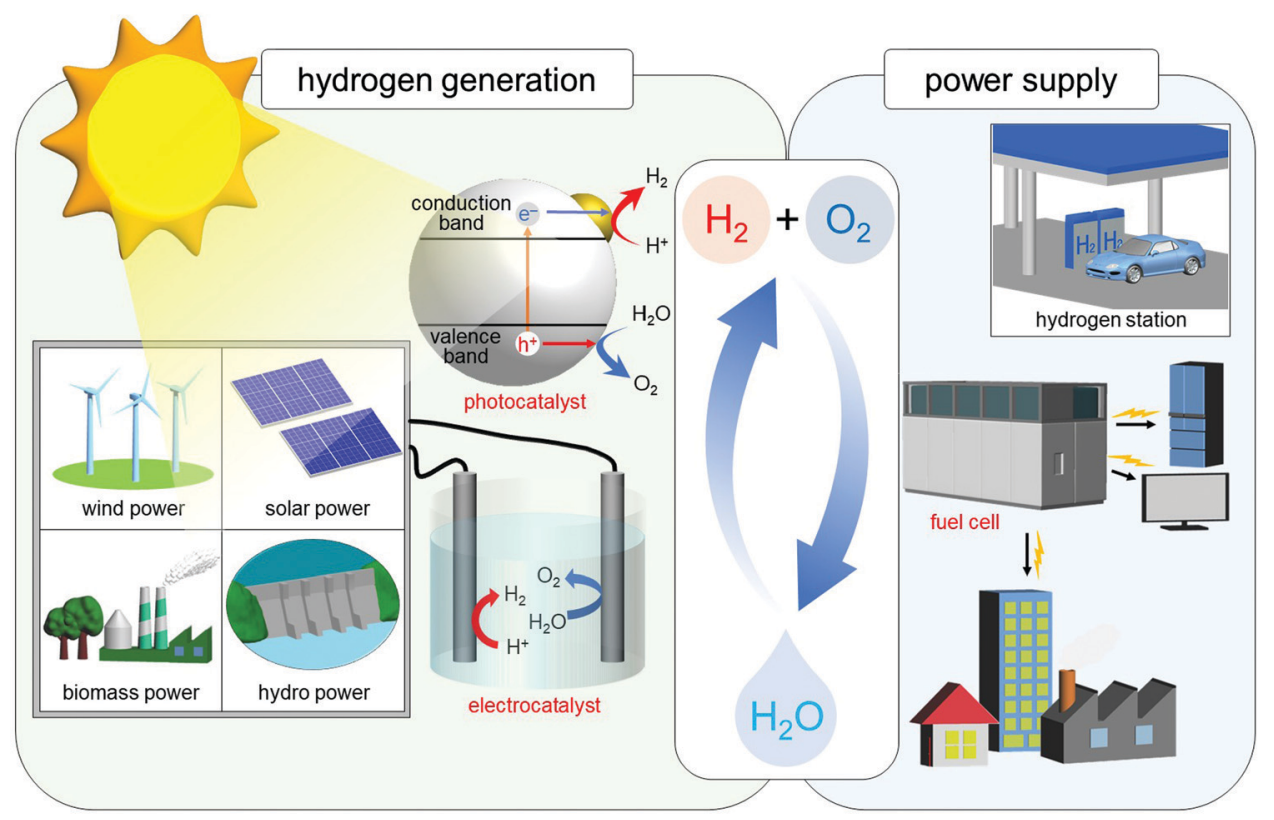

Fig. 12 Schematic of the energy-conversion system for constructing a sustainable society. Note that in addition to solar power, sunlight also produces wind, biomass, and hydro power. Reproduced with permission from ref. 56. Copyright 2021 The Royal Society of Chemistry. 
necessary to build such a society. In this system, hydrogen $\left(\mathrm{H}_{2}\right)$ is produced by photocatalysts or electrocatalysts, and the obtained $\mathrm{H}_{2}$ is converted to electricity by fuel cells. Using such a system, it is possible to obtain energy from only water and sunlight, which are almost unlimited on earth. In addition, this system allows the energy medium $\left(\mathrm{H}_{2}\right)$ to be circulated, thus preventing the issues of energy depletion. Furthermore, this system does not generate carbon dioxide, which leads to global warming. In this system, the properties of the photocatalyst, ${ }^{219}$ electrocatalyst, ${ }^{63,220-232}$ and fuel cell ${ }^{60,224,233-238}$ are highly dependent on the chemistry. Therefore, modern chemistry is expected to improve the functions of these components. Considering the fact that the shift to $\mathrm{H}_{2}$ society cannot be realized immediately, it is necessary to improve the current system at the same time. In other words, automotive exhaust-gas purification catalysts, ${ }^{239}$ which inhibit emission of harmful gases, need to be further improved. Therefore, we have been working on development of highly functionalized water-splitting photocatalysts, fuel-cell electrocatalysts, and automotive exhaust-gas purification catalysts (Fig. 1(d and e)) using precise metal NCs, in addition to developing flexible and precise control techniques for metal NCs.

\subsection{Our strategy for activation of energy and environmental catalysts}

For preparation of water-splitting photocatalysts, fuel-cell electrocatalysts, and automotive exhaust-gas purification catalysts, metal nanoparticles (NPs) are generally loaded on the support by impregnation (Fig. 13(a) $)^{240}$ or photodeposition method (Fig. 13(b)). ${ }^{241}$ In the impregnation method, metal NPs are immobilized on the support by stirring the support and metal salt in solution followed by calcination (Fig. 13(a)). In the photodeposition method, the support is dispersed in a solution containing the precursor metal salts of the metal NPs, which is then irradiated with light. The electrons and holes generated by photoexcitation are used to reduce or oxidize the precursor metal salts of the metal NPs, thereby immobilizing the metal NPs on

(a) impregnation

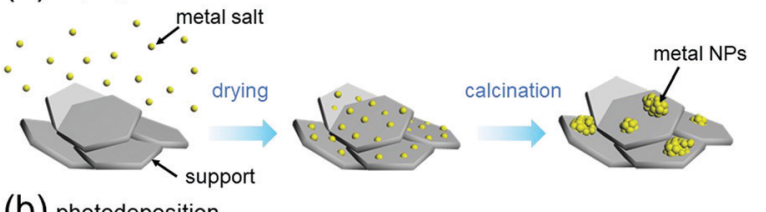

(b) photodeposition

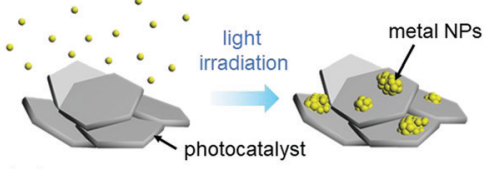

(c) metal-NC adsorption-calcination

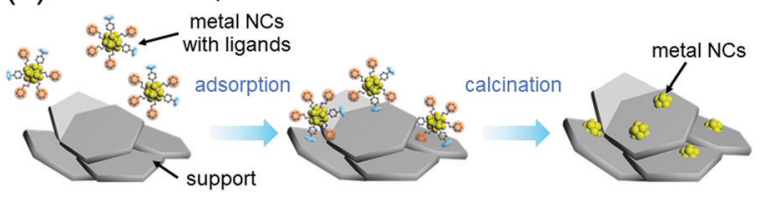

Fig. 13 Comparison of (a) impregnation, (b) photodeposition, and (c) metal-NC adsorption-calcination methods. the surface of the support (Fig. 13(b)). These loading methods are widely used because of their simplicity. However, the size distributions of the metal NPs obtained by these methods are wide because the metal atoms are aggregated on the support. Therefore, it is extremely difficult to load precisely controlled metal NPs on the support by these methods.

On the other hand it is possible to load metal NCs with a controlled particle size on the support by adsorbing ligandprotected metal NCs synthesized in the liquid phase onto the support and then removing the ligand by calcination (Fig. 13(c)). ${ }^{242-244}$ If the chemical composition of the loaded metal NCs can be controlled with atomic precision, it could be possible to create high-performance heterogeneous catalysts based on selective loading of highly active metal NCs. ${ }^{66}$ For atomically controlled loaded metal NCs, a deep understanding of the electronic/geometric structure of the loaded metal NCs and the electronic/geometric interaction between the loaded-metal NCs and the catalyst surface can be obtained by various high-resolution analyses and theoretical calculations (Fig. 14(a)). ${ }^{11,245-255}$ It is expected that this will provide a deep understanding of the important factors for high activation and clear design guidelines for further activation (Fig. 14(b)). Design and creation of appropriate metal NCs based on the obtained information are expected to lead to further functionalization of water-splitting photocatalysts, fuel-cell electrocatalysts, and automotive exhaust-gas purifying catalysts (Fig. 14). However, when we started this work, there were no examples of atomically precise control of loaded metal NCs on these catalysts using ligand-protected metal NCs as precursors.

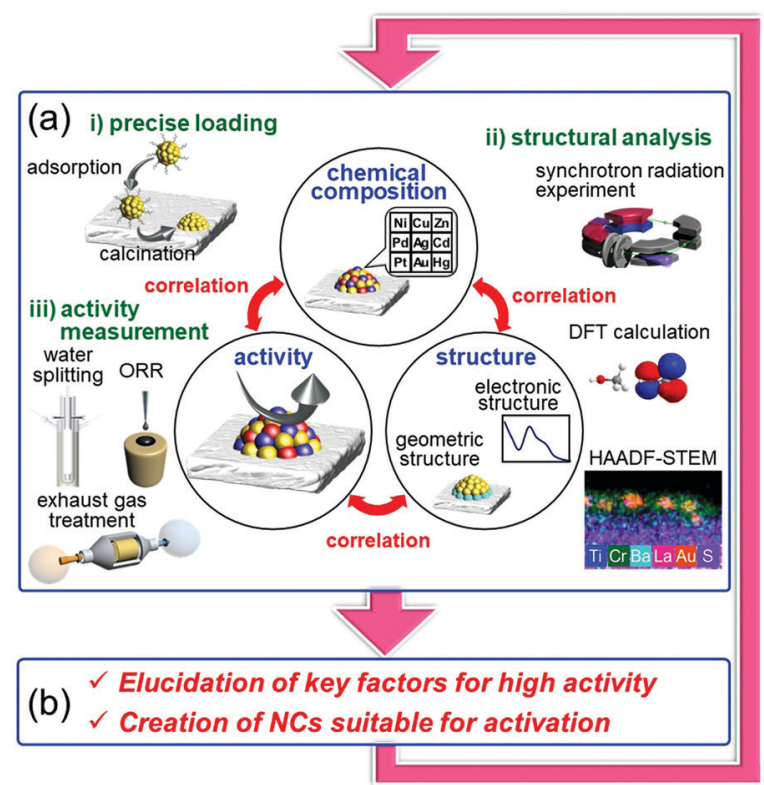

Fig. 14 Our strategy for activation of energy and environmental catalysts: elucidation of (a) the correlation between the chemical composition, structure, and activity and (b) the key factors for the activity and therefore for creation of NCs suitable for activation. This cycle is repeated to create high-performance energy and environmental catalysts. 


\subsection{Activation of water-splitting photocatalysts}

Using photocatalytic reactions (Fig. 12), ${ }^{256-267}$ it is possible to produce $\mathrm{H}_{2}$ directly from water and sunlight. Therefore, watersplitting photocatalysis is considered to be one of the cleanest energy production reactions. However, at present, the energy conversion efficiency from sunlight to $\mathrm{H}_{2}$ (STH) is only about $1.1 \%{ }^{268}$ To realize practical use of water-splitting photocatalysts, it is essential to improve the STH to about 5-10\% in the future. ${ }^{264}$

In many cases, metal/metal-oxide NPs/NCs (cocatalysts) should be loaded on water-splitting photocatalysts as the active sites (Fig. 12). Controlling their particle sizes is very effective for improving the water-splitting activity. ${ }^{64,258,269}$ Therefore, we have focused on (1) precisely controlling the loaded metal NCs on the photocatalyst using precise ligand-protected metal NCs as precursors, (2) elucidating the details of how control of the cocatalyst affects the water-splitting activity, and (3) actually improving the functionality of the water-splitting photocatalyst.

The first step was to precisely load $\mathrm{Au}_{n}$ NCs onto $\mathrm{BaLa}_{4-}$ $\mathrm{Ti}_{4} \mathrm{O}_{15}$ (an UV-light-driven water-splitting photocatalyst), ${ }^{270}$ which is one of the most advanced photocatalysts developed by our collaborator, Kudo and co-workers. ${ }^{256}$ We successfully determined the appropriate precursor NCs for precise loading (Fig. 15(a)), the appropriate adsorption conditions, and the appropriate calcination conditions. ${ }^{271,272}$ Activity measurement (Fig. 15(b)) of the obtained $\mathrm{Au}_{25}$ NC-loaded $\mathrm{BaLa}_{4} \mathrm{Ti}_{4} \mathrm{O}_{15}\left(\mathrm{Au}_{25} /\right.$ $\mathrm{BaLa}_{4} \mathrm{Ti}_{4} \mathrm{O}_{15}$ ) revealed that the small $\mathrm{Au}$ cocatalyst accelerates not only the HER, but also the oxygen $\left(\mathrm{O}_{2}\right)$-photoreduction reaction, which is one of the reverse reactions. ${ }^{273}$ Therefore, we next attempted to form a layer to prevent the reverse reaction on the $\mathrm{Au}_{25}$ cocatalyst. Maeda, Domen and co-workers reported that formation of a chromium oxide $\left(\mathrm{Cr}_{2} \mathrm{O}_{3}\right)$ layer is extremely effective for preventing the reverse reaction. ${ }^{244,274-283}$ However, using their formation method, it was difficult to form the $\mathrm{Cr}_{2} \mathrm{O}_{3}$ layer on the $\mathrm{Au}_{25}$ cocatalyst while maintaining the number of constituent atoms of the cocatalyst. Therefore, we developed a new method for formation of the $\mathrm{Cr}_{2} \mathrm{O}_{3}$ layer. ${ }^{273}$ Specifically, the $\mathrm{Cr}_{2} \mathrm{O}_{3}$ layer was first loaded on $\mathrm{BaLa}_{4} \mathrm{Ti}_{4} \mathrm{O}_{15}\left(\mathrm{Cr}_{2} \mathrm{O}_{3} / \mathrm{BaLa}_{4} \mathrm{Ti}_{4} \mathrm{O}_{15}\right)$, and then $\mathrm{Au}_{25}(\mathrm{SG})_{18}$ was adsorbed on $\mathrm{Cr}_{2} \mathrm{O}_{3} / \mathrm{BaLa}_{4} \mathrm{Ti}_{4} \mathrm{O}_{15}$. The obtained catalyst $\left(\mathrm{Au}_{25}(\mathrm{SG})_{18} / \mathrm{Cr}_{2} \mathrm{O}_{3} / \mathrm{BaLa}_{4} \mathrm{Ti}_{4} \mathrm{O}_{15}\right)$ was calcined in an electric furnace under low vacuum to remove the ligands of $\mathrm{Au}_{25}(\mathrm{SG})_{18}$ and embed $\mathrm{Au}_{25}$ into the $\mathrm{Cr}_{2} \mathrm{O}_{3}$ layer (Fig. 15(c)). The obtained $\mathrm{Cr}_{2} \mathrm{O}_{3} /$ $\mathrm{Au}_{25} / \mathrm{BaLa}_{4} \mathrm{Ti}_{4} \mathrm{O}_{15}$ photocatalyst showed high water-splitting activity. Thus, we succeeded in creating a highly active watersplitting photocatalyst with the advantage of high HER activity of fine Au NCs by combining miniaturization of the Au cocatalyst with formation of the reverse-reaction prevention layer (Fig. 15(c)). In a later study using $\mathrm{Au}_{25}$ as the cocatalyst, it was found that even higher activity can be obtained by substituting one $\mathrm{Pt}$ atom for one $\mathrm{Au}$ atom in the $\mathrm{Au}_{25}$ cocatalyst. ${ }^{284}$ On the basis of the various experimental results, we concluded that $\mathrm{Au}_{24} \mathrm{Pt}$ / $\mathrm{BaLa}_{4} \mathrm{Ti}_{4} \mathrm{O}_{15}$ showed higher water-splitting activity than $\mathrm{Au}_{25} /$ $\mathrm{BaLa}_{4} \mathrm{Ti}_{4} \mathrm{O}_{15}$, mainly because (1) photoexcited electrons can more easily transfer from $\mathrm{BaLa}_{4} \mathrm{Ti}_{4} \mathrm{O}_{15}$ to the metal NCs in $\mathrm{Au}_{24} \mathrm{Pt} / \mathrm{BaLa}_{4} \mathrm{Ti}_{4} \mathrm{O}_{15}$ than in $\mathrm{Au}_{25} / \mathrm{BaLa}_{4} \mathrm{Ti}_{4} \mathrm{O}_{15}$ and (2) $\mathrm{Au}$ in $\mathrm{Au}_{24} \mathrm{Pt}$ is more negatively charged than $\mathrm{Au}$ in $\mathrm{Au}_{25}$ (Fig. 15(d)).

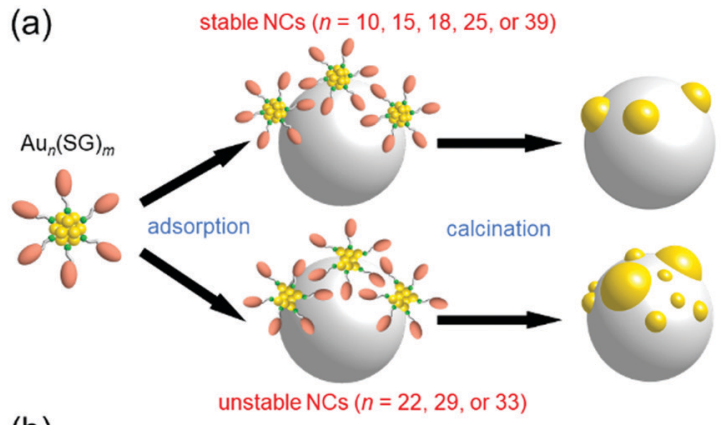

(b)
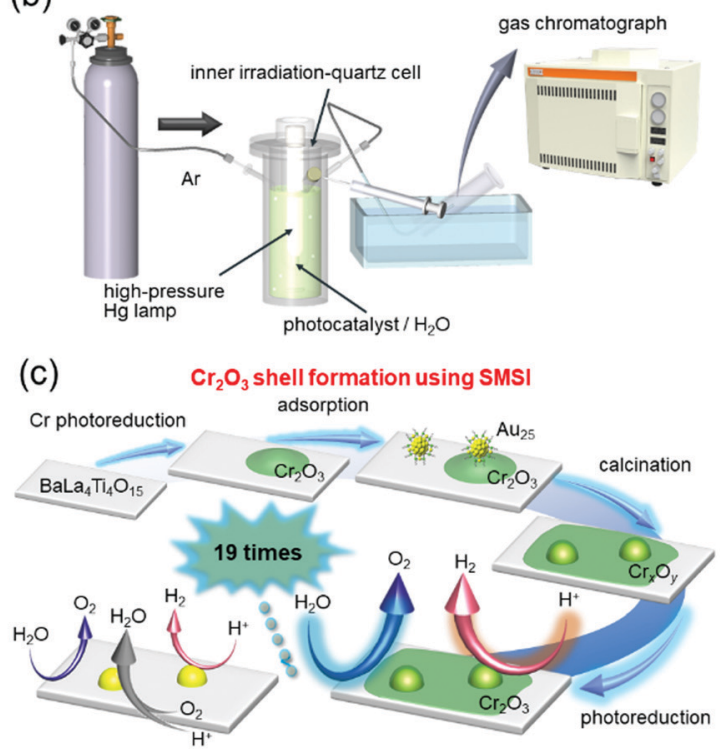

(d)

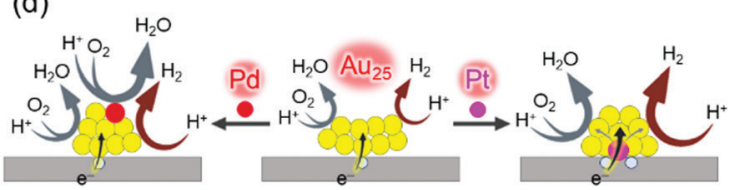

Fig. 15 (a) $\mathrm{Au}_{n}(\mathrm{SG})_{m}$ suitable for loading $\mathrm{Au}_{n} \mathrm{NCs}$ on the photocatalyst while retaining the number of constituent atoms. ${ }^{272}$ (b) Schematic of the system used to estimate the photocatalytic activity. ${ }^{273}$ (c) Schematic of preparation of $\mathrm{Cr}_{2} \mathrm{O}_{3} / \mathrm{Au}_{25} / \mathrm{BaLa}_{4} \mathrm{Ti}_{4} \mathrm{O}_{15}$ and its water-splitting activity. ${ }^{273}$ (d) Proposed structures of $\mathrm{Au}_{24} \mathrm{M} / \mathrm{BaLa}_{4} \mathrm{Ti}_{4} \mathrm{O}_{15}$ for $\mathrm{M}=\mathrm{Au}$, Pd, and Pt and the effect of the geometric/electronic structure on each reaction over metal-NC cocatalysts. ${ }^{284}$ Reproduced with permission from ref. 272, 273 and 284. Copyright 2015 American Chemical Society, 2018 American Chemical Society, and 2019 American Chemical Society.

In the above study, Au was used as the metal element for the cocatalyst. However, based on the volcano plot ${ }^{285}$ for $\mathrm{H}_{2}$ adsorption and desorption, rhodium $(\mathrm{Rh})$ is predicted to have higher catalytic activity than Au for the HER. Therefore, it is expected that highly active water-splitting photocatalysts can be created by loading a fine cocatalyst consisting of rhodium and chromium oxides $\left(\mathrm{Rh}_{2-x} \mathrm{Cr}_{x} \mathrm{O}_{3}\right)^{286-289}$ on the photocatalysts. Therefore, we also attempted to load fine $\mathrm{Rh}_{2-x} \mathrm{Cr}_{x} \mathrm{O}_{3}$ NCs on $\mathrm{BaLa}_{4} \mathrm{Ti}_{4} \mathrm{O}_{15}$. Unfortunately, there have been no reports of precise synthesis of $\mathrm{Rh}_{2-x} \mathrm{Cr}_{x} \mathrm{O}_{3}$ NCs. Therefore, in this experiment, we used $\mathrm{Rh}_{2}(\mathrm{SG})_{2}$ complexes ( $\left.\mathrm{Rh}-\mathrm{SG}\right)$ as precursors, which were aggregated on $\mathrm{BaLa}_{4} \mathrm{Ti}_{4} \mathrm{O}_{15}$ and then calcined. As a result, we succeeded in loading monodispersed $\mathrm{Rh}_{2-x} \mathrm{Cr}_{x} \mathrm{O}_{3} \mathrm{NCs}$ 
(a)
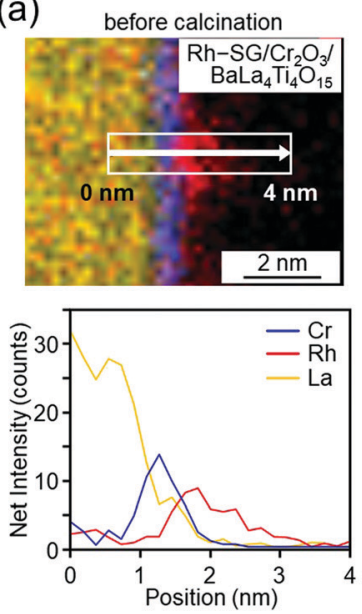

(b)

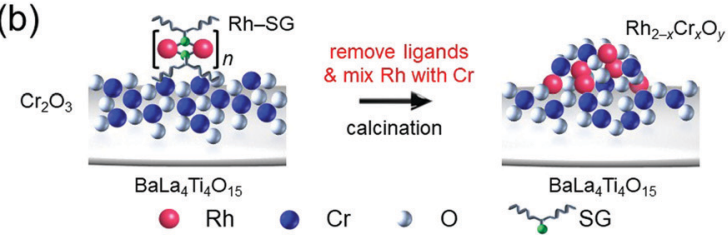

(c)

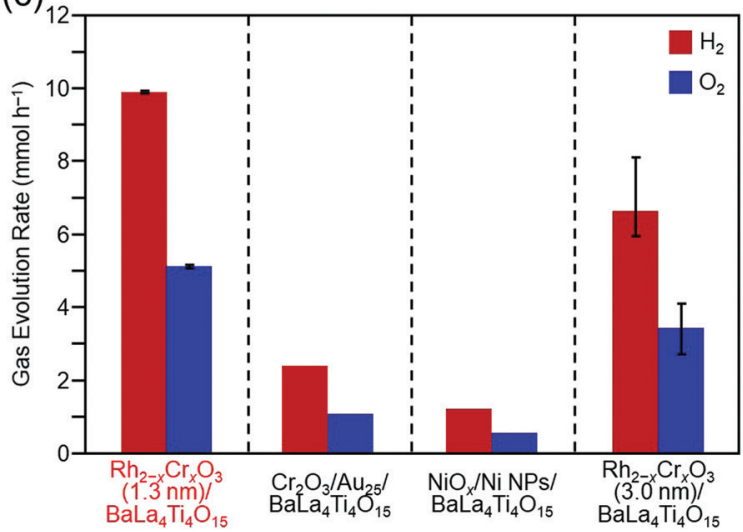

Fig. 16 HAADF-STEM images of Rh-SG complexes adsorbed on the $\mathrm{Cr}_{2} \mathrm{O}_{3} / \mathrm{BaLa}_{4} \mathrm{Ti}_{4} \mathrm{O}_{15}$ photocatalyst before and after calcination (Rh-SG/ $\mathrm{Cr}_{2} \mathrm{O}_{3} / \mathrm{BaLa}_{4} \mathrm{Ti}_{4} \mathrm{O}_{15}$ and $\mathrm{Rh}_{2-x} \mathrm{Cr}_{x} \mathrm{O}_{y} / \mathrm{BaLa}_{4} \mathrm{Ti}_{4} \mathrm{O}_{15}$, respectively). (a) Line analysis of elemental mapping of $\mathrm{Rh}-\mathrm{SG} / \mathrm{Cr}_{2} \mathrm{O}_{3} / \mathrm{BaLa}_{4} \mathrm{Ti}_{4} \mathrm{O}_{15}$ (left) and $\mathrm{Rh}_{2-x} \mathrm{Cr}_{x} \mathrm{O}_{y} / \mathrm{BaLa}_{4} \mathrm{Ti}_{4} \mathrm{O}_{15}$ (right). (b) Schematic of the phenomenon that occurred during the calcination process. (c) Comparison of the gasevolution rates over different photocatalysts: $\mathrm{Rh}_{2-} \mathrm{Cr}_{x} \mathrm{O}_{3}(1.3 \mathrm{~nm}) / \mathrm{BaLa}_{4} \mathrm{Ti}_{4} \mathrm{O}_{15}$ (0.09 wt\% Rh and 0.10 wt\% $\mathrm{Cr}$ ), $\mathrm{Cr}_{2} \mathrm{O}_{3} / \mathrm{Au}_{25} / \mathrm{BaLa}_{4} \mathrm{Ti}_{4} \mathrm{O}_{15}$ (0.10 wt\% Au and 0.50 $w t \% \mathrm{Cr}$ ), Ni NiO$/ \mathrm{NPs} / \mathrm{BaLa}_{4} \mathrm{Ti}_{4} \mathrm{O}_{15}(0.50 \mathrm{wt} \% \mathrm{Ni})$, and $\mathrm{Rh}_{2-x} \mathrm{Cr}_{x} \mathrm{O}_{3}(3.0 \mathrm{~nm}) /$ $\mathrm{BaLa}_{4} \mathrm{Ti}_{4} \mathrm{O}_{15}(0.10 \mathrm{wt} \% \mathrm{Rh}$ and $0.15 \mathrm{wt} \% \mathrm{Cr}$ ). Reproduced with permission from ref. 290. Copyright 2020 Willey-VCH.

with particle sizes of $1.3 \pm 0.3 \mathrm{~nm}$ on $\mathrm{BaLa}_{4} \mathrm{Ti}_{4} \mathrm{O}_{15}$ (Fig. 16(a and b)). ${ }^{290}$ The obtained photocatalyst showed the highest apparent quantum yield of $16 \%$ for $\mathrm{BaLa}_{4} \mathrm{Ti}_{4} \mathrm{O}_{15}$ (excitation wavelength $=270 \mathrm{~nm}$, Fig. 16(c)). The loading method of $\mathrm{Rh}_{2-x} \mathrm{Cr}_{x} \mathrm{O}_{3}$ NCs developed in this study can in principle be applied to other photocatalysts. In addition, $\mathrm{Rh}_{2-x} \mathrm{Cr}_{x} \mathrm{O}_{3}$ NCs are useful cocatalysts for many water-splitting photocatalysts. ${ }^{286-289,291,292}$ In the future, it is expected that high quantum yields will be obtained for many other water-splitting photocatalysts using this technique.
For practical use of a water-splitting photocatalyst, it is essential that the photocatalyst causes water splitting by visible light (visible-light-driven water-splitting photocatalyst), which accounts for about $40 \%$ of solar energy. Currently, there are only a few semiconductor photocatalysts that enable complete water splitting in one step using visible light. ${ }^{264}$ However, overall water splitting by visible light can also be achieved by photocatalytic systems using a two-step reaction called the Z-scheme, which mimics plant photosynthesis. ${ }^{257,260}$ We are currently working on improving the functionality of both of these visible-light-driven water-splitting photocatalysts based on the knowledge obtained in research of $\mathrm{BaLa}_{4} \mathrm{Ti}_{4} \mathrm{O}_{15}$.

\subsection{Activation of ORR electrode catalysts}

The polymer electrolyte fuel cell (PEFC, Fig. 12) is already in practical use. However, a significant amount of Pt is used in current PEFCs, which makes the current PEFCs extremely expensive. This has impeded widespread use of PEFCs, and thereby transition to a society using $\mathrm{H}_{2}$ as an energy source (Fig. 12) has stagnated. Even if the cost of PEFCs can be lowered by improving the parts other than the Pt catalyst, we will inevitably encounter a shortage of Pt if the current Pt catalyst is used. Therefore, it is essential to reduce the amount of Pt used in PEFC electrocatalysts to build a clean and sustainable society.

In PEFCs, the ORR at the cathode is the rate-limiting reaction. Pt NPs with particle sizes of $2-3 \mathrm{~nm}$ loaded on carbon black (CB) (Pt NPs/CB) are widely used ORR cathodes. Recently, the following facts were reported by Yamamoto and coworkers, ${ }^{293,294}$ Nakajima and co-workers, ${ }^{295}$ and Fischer and co-workers ${ }^{296}$ for smaller $\sim 1 \mathrm{~nm}$ particle size $\mathrm{Pt}_{n}$ NCs: (1) the $\mathrm{Pt}_{n}$ NCs have higher mass activity than the currently used Pt NPs and (2) the mass activity of the $\mathrm{Pt}_{n} \mathrm{NCs}_{\text {dramatically varies }}$ depending on the number of constituent atoms. Therefore, it is expected that if highly active $\sim 1 \mathrm{~nm} \mathrm{Pt}_{n} \mathrm{NCs}$ can be sizeselectively synthesized and then loaded on $\mathrm{CB}$, highly active ORR catalysts can be created, which will lead to cost reduction of PEFCs.

As described in Section 4.4, we have already developed a method to isolate $\left[\mathrm{Pt}_{17}\left(\mathrm{PPh}_{3}\right)_{8}(\mathrm{CO})_{12}\right]^{z+}(z=1$ or 2$)$ with atomic precision by simple manipulation in air. ${ }^{120}$ In addition, by further modification of this method, we successfully synthesized a series of $\mathrm{Pt}_{n}(\mathrm{PET})_{m}(\mathrm{CO})_{l} \mathrm{NCs}(n=\sim 35, \sim 51$, and $\sim 66)$ in a size-selective manner with a narrow particle-size distribution. ${ }^{121}$ $\mathrm{Pt}_{n} / \mathrm{CB}$ catalysts were then prepared by adsorbing these $\mathrm{Pt}_{n}$ NCs on $\mathrm{CB}$ and partially removing the ligands at appropriate temperatures (Fig. 17(a and b)). We found that the mass activities of $\mathrm{Pt}_{n} / \mathrm{CB}(n=\sim 35, \sim 51$, and $\sim 66)$ were higher than that of commercial Pt NPs/CB (Fig. 17(c)). ${ }^{121}$ Among the $\mathrm{Pt}_{n} / \mathrm{CB}$ catalysts, $\mathrm{Pt}_{\sim 51} / \mathrm{CB}$ showed 2.1 times higher mass activity than the commercial Pt NPs/CB catalyst. On the basis of estimation of the electrochemical activity area and specific activity, we concluded that $\mathrm{Pt}_{n} / \mathrm{CB}$ shows higher ORR mass activity than commercial Pt NPs/CB because both the percentage of surface $\mathrm{Pt}$ atoms and specific activity of each surface Pt atom are higher for $\mathrm{Pt}_{n} / \mathrm{CB}$ than for commercial Pt NPs/CB. 


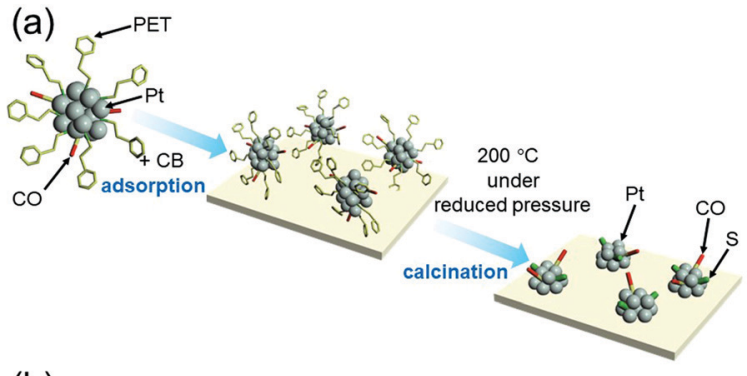

(b)
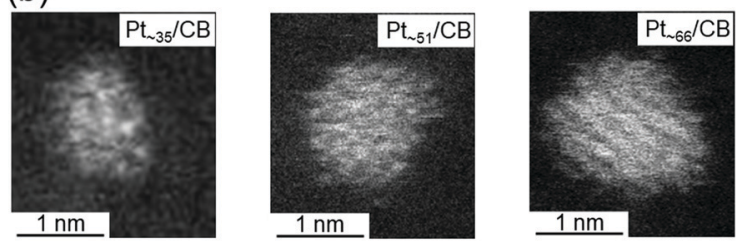

(c)

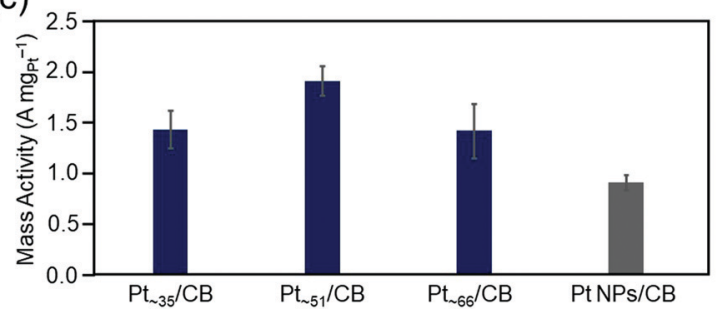

Fig. 17 (a) Schematic illustration of controlled loading of $\sim 1 \mathrm{~nm}$ Pt NCs on CB. (b) HAADF-STEM images of $\mathrm{Pt}_{n} / \mathrm{CB}$ with $n=\sim 35$ (left), $\sim 51$ (center), and $\sim 66$ (right). (c) ORR mass activity at $0.6 \mathrm{~V} v$ s. the reversible hydrogen electrode for $\mathrm{Pt}_{\sim 35} / \mathrm{CB}, \mathrm{Pt} \sim 51 / \mathrm{CB}, \mathrm{Pt} \sim 66 / \mathrm{CB}$, and commercial $\mathrm{Pt} N \mathrm{NP} / \mathrm{CB}$. In this figure, the average values obtained by performing the experiments three times are reported. Reproduced from ref. 121 Copyright 2021 The Royal Society of Chemistry.

Regarding the ORR activity of Pt NCs, it has been reported that the presence of $\mathrm{Pt}$ atoms in the generalized coordination number (GCN) region of 7.7-8.3 on the surface of the Pt NCs induces high activity. ${ }^{297,298}$ The GCN is a coordination number that takes into account the second nearest neighbor atoms in addition to the nearest neighbor atoms. When surface atoms are removed and concave cavities are created on the Pt-NC surface, Pt atoms with such GCNs are generated on the surface of the Pt NC. Unfortunately, in our previous studies, we did not obtain detailed information about the geometric structures of $\mathrm{Pt}_{n} / \mathrm{CB}(n=\sim 35, \sim 51$, and $\sim 66)$. Therefore, we are currently working on elucidating the details of their geometric structures by obtaining high-resolution high-angle scattering dark-field scanning transmission electron microscopy (HAADF-STEM) images and analyzing the GCNs in the obtained geometric structures by DFT calculations. This is expected to provide a deep understanding of the factors that lead to high activity and clear design guidelines for further enhancement of the activity.

\subsection{Activation of automobile exhaust-gas purification catalysts}

It is expected that electric vehicles and fuel-cell vehicles will be widely used in the future. However, conventional vehicles (gasoline and diesel vehicles) are also estimated to account for $30-50 \%$ of the total market until 2030 . Pt is widely used as an exhaust-gas purification catalyst, along with Pd and Rh, because of its catalytic activity to purify the harmful substances contained in exhaust gases. ${ }^{239}$ However, reduction of Pt use is a critical issue at present because $\mathrm{Pt}$ is a rare and expensive precious metal. In addition, with the widespread use of automobiles, such as hybrid vehicles, where the engine is repeatedly stopped and restarted, high activation at low temperatures is also an issue that needs to be overcome. ${ }^{239}$

Studies on Pt-free catalysts are now being performed to overcome the above issues. However, the activity and durability of Pt are overwhelmingly superior to those of non-metallic materials. Reducing the particle size of the Pt catalyst is an extremely effective way to both reduce the amount of Pt used and improve the functionality of the Pt catalyst. Indeed, Anderson and co-workers demonstrated that $\mathrm{Pt}_{n}$ NCs $(n=14-18)$ loaded on alumina $\left(\mathrm{Pt}_{n} / \mathrm{Al}_{2} \mathrm{O}_{3}\right)$ have high catalytic activity for $\mathrm{CO}$ oxidation, one of the automotive exhaust-gas purification reactions, using a vacuum apparatus. $^{70}$

We have prepared $\mathrm{Pt}_{17} / \gamma-\mathrm{Al}_{2} \mathrm{O}_{3}$ catalysts by adsorbing $\left[\mathrm{Pt}_{17}\left(\mathrm{PPh}_{3}\right)_{8}(\mathrm{CO})_{12}\right]^{z+}(z=1 \text { or } 2)^{120}$ on $\gamma-\mathrm{Al}_{2} \mathrm{O}_{3}$ and then partially removing the ligands at appropriate temperatures. ${ }^{299}$ HAADFSTEM images and XAFS measurements showed that Pt does not become oxidized ${ }^{300}$ in $\mathrm{Pt}_{17} / \gamma-\mathrm{Al}_{2} \mathrm{O}_{3}$, and it maintains the skeletal structure of $\mathrm{Pt}_{17} \mathrm{NC}$ (Fig. 18(a-c)). To evaluate the catalytic performance of the obtained catalysts under conditions as close as possible to those of actual vehicles, $\mathrm{Pt}_{17} / \gamma-\mathrm{Al}_{2} \mathrm{O}_{3}$ was coated on a honeycomb substrate and the catalytic performance for $\mathrm{CO}$ or propylene $\left(\mathrm{C}_{3} \mathrm{H}_{6}\right)$ oxidation was evaluated under these conditions (Fig. 18(d)). The measurements of the HAADF-STEM images and catalytic activity were performed in collaboration with Nagaoka of Johnson Matthey Japan. ${ }^{299}$ We found that $\mathrm{Pt}_{17} /$ $\gamma-\mathrm{Al}_{2} \mathrm{O}_{3}$ has higher $\mathrm{CO}$ oxidation activity at each temperature than Pt NPs $/ \gamma-\mathrm{Al}_{2} \mathrm{O}_{3}$ loaded with Pt NPs with average particle size of $3.1 \pm 3.1 \mathrm{~nm}$ by the impregnation method, and, therefore, it is capable of purifying $\mathrm{CO}$ at lower temperature than Pt NPs/ $\gamma-\mathrm{Al}_{2} \mathrm{O}_{3}$ (Fig. 18(e)). Previous studies have suggested that in oxidation of $\mathrm{CO}, \mathrm{CO}$ and $\mathrm{O}_{2}$ are activated at $\mathrm{Pt}$ on the terrace and Pt in the step, respectively. ${ }^{72,301,302}$ In the structures shown in Fig. 18(b and c), most of the terrace Pt atoms are located near the Pt step. This seems to be one of the factors that leads to effective reaction of $\mathrm{CO}$ and $\mathrm{O}_{2}$, that is, oxidation of $\mathrm{CO}$, over $\mathrm{Pt}_{17} / \gamma-\mathrm{Al}_{2} \mathrm{O}_{3}$. High oxidation capacity of $\mathrm{Pt}_{17} / \gamma-\mathrm{Al}_{2} \mathrm{O}_{3}$ at low temperatures was also observed for oxidation of $\mathrm{C}_{3} \mathrm{H}_{6}$. These results indicate that $\mathrm{Pt}_{17} / \gamma-\mathrm{Al}_{2} \mathrm{O}_{3}$ is a promising catalyst for reducing the amount of $\mathrm{Pt}$ used and improving the catalytic performance at low temperatures.

To use $\mathrm{Pt}_{17} / \gamma-\mathrm{Al}_{2} \mathrm{O}_{3}$ as a practical catalyst, it is necessary to investigate the catalytic activity and durability of the catalyst with the loading amount in the actual vehicle and at the exhaust-gas mixture ratio ${ }^{302-305}$ during actual operation. We are currently performing measurements under such conditions in collaboration with industry.

\subsection{Elucidation of the ligand-removal mechanism}

In our catalyst preparation process (Fig. 13(c)), (1) metal NCs are precisely synthesized using ligands and then (2) the 
(a)

(b)
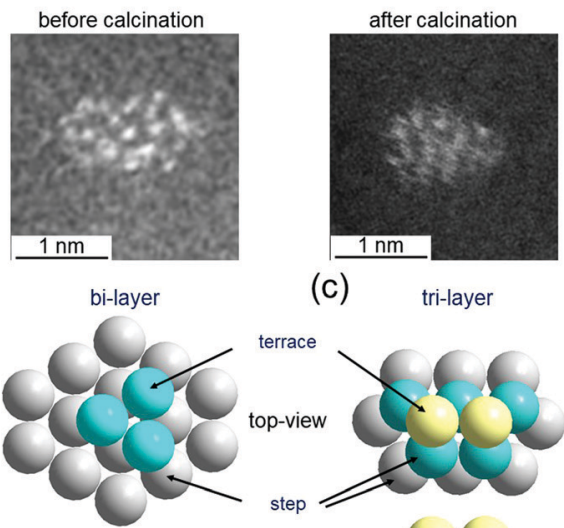

(d)
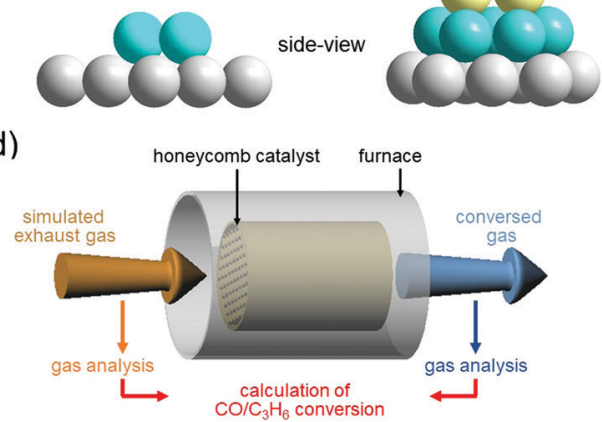

(e)

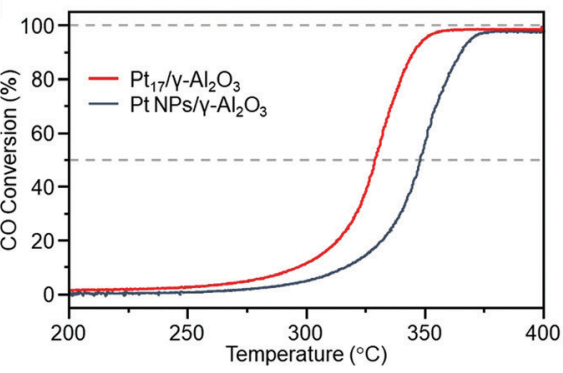

Fig. 18 (a) HAADF-STEM images of $\mathrm{Pt}_{17}\left(\mathrm{PPh}_{3}\right)_{8}(\mathrm{CO})_{12} / \gamma-\mathrm{Al}_{2} \mathrm{O}_{3}$ (left) and $\mathrm{Pt}_{17} / \gamma-\mathrm{Al}_{2} \mathrm{O}_{3}$ (right). Two proposed structures for $\mathrm{Pt}_{17}$ on $\gamma-\mathrm{Al}_{2} \mathrm{O}_{3}$ based on the HAADF-STEM images of $\mathrm{Pt}_{17} / \gamma-\mathrm{Al}_{2} \mathrm{O}_{3}$ : (b) bi-layer and (c) tri-layer. In (b) and (c), both top and side views are shown. (d) Schematic illustration of estimation of $\mathrm{CO}$ and $\mathrm{C}_{3} \mathrm{H}_{6}$ conversion over $\mathrm{Pt}_{17} / \gamma-\mathrm{Al}_{2} \mathrm{O}_{3}$ or Pt NPS/ $\gamma-\mathrm{Al}_{2} \mathrm{O}_{3}$ coated on a cordierite honeycomb substrate. (e) $\mathrm{CO}$ conversion over $\mathrm{Pt}_{17} / \gamma-\mathrm{Al}_{2} \mathrm{O}_{3}$ (red curve) and $\mathrm{Pt} \mathrm{NPs} / \gamma-\mathrm{Al}_{2} \mathrm{O}_{3}$ (gray curve). Reproduced from ref. 299. Copyright 2020 The Royal Society of Chemistry.

resulting NCs are adsorbed on a support. The presence of the ligand on the surface of the metal NCs generally leads to a decrease in the activity ${ }^{306,307}$ because it prevents the approach of the reactants to the metal-NC surface and induces modulation of the electronic structure of the metal NCs. Therefore, (3) some or all of the ligands are removed by calcination to produce high-activity metal NCs. However, removal of the ligands simultaneously induces aggregation of the metal NCs and a resulting decrease in the catalytic activity. Thus, in calcination, it is extremely important to remove only the ligands while maintaining the number of constituent atoms of the metal NCs (Fig. 19(a)).

Regarding removal of the ligands, in the studies reported in Section 5.3-5.5, the calcination conditions were determined by confirming the presence or absence of ligands in the catalysts

(a)
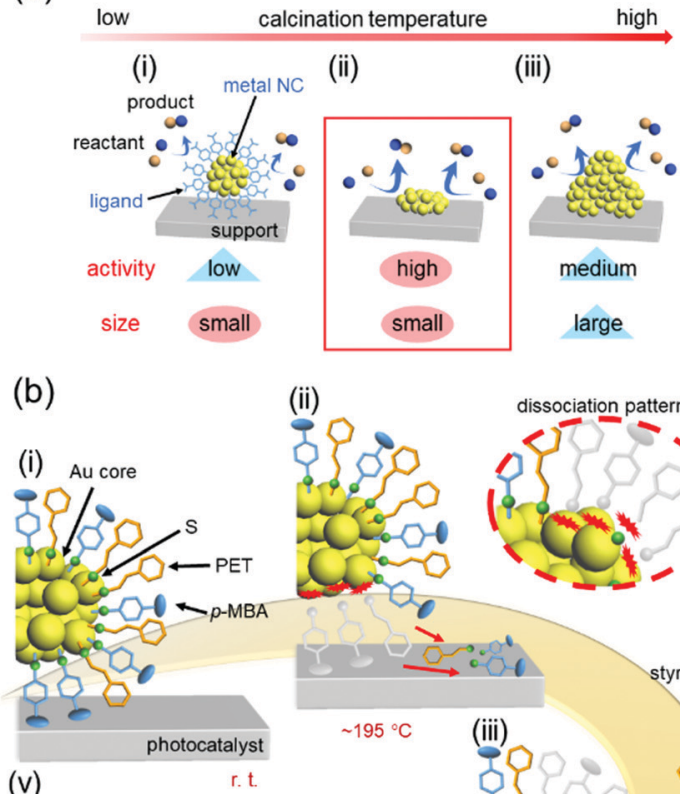

(v)
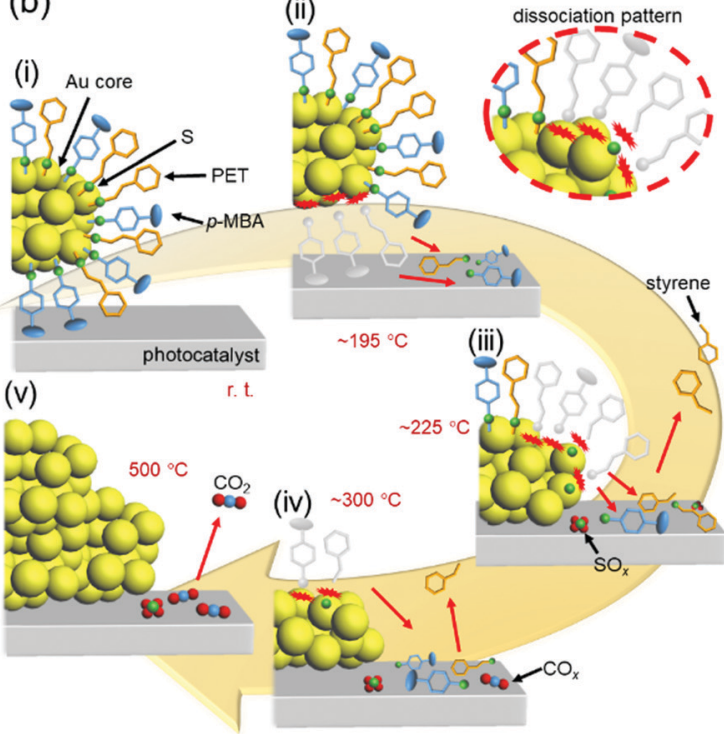

(iv) $\sim 300^{\circ} \mathrm{C}$

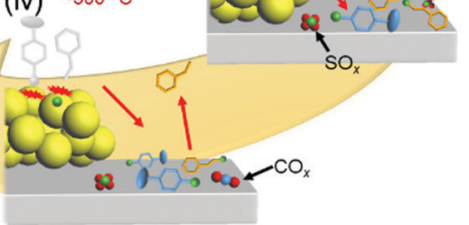

Fig. 19 (a) Schematic illustrations of the typical phenomena caused by increasing the calcination temperature in metal-oxide-supported ligand-protected metal NCs: (i) a small size is maintained but the activity is low, (ii) high activity is achieved while maintaining a small size, and (iii) the activity decreases owing to aggregation. (b) Proposed phenomenon occurring at each temperature during calcination of $\mathrm{Au}_{25}(\mathrm{PET}) \sim 9$ $(p-M B A)_{\sim 9} / \mathrm{BaLa}_{4} \mathrm{Ti}_{4} \mathrm{O}_{15}$ at (i) room temperature, (ii) ca. $195{ }^{\circ} \mathrm{C}$, (iii) $\mathrm{ca}$. $225{ }^{\circ} \mathrm{C}$, (iv) ca. $300{ }^{\circ} \mathrm{C}$, and (v) $500{ }^{\circ} \mathrm{C}$. Reproduced from ref. 308. Copyright 2021 Willey-VCH.

after calcination by X-ray photoelectron spectroscopy (XPS) and XAFS. However, through these studies, we felt that it was essential to understand the reaction mechanisms occurring during calcination to perform calcination under appropriate conditions and thereby create high-performance heterogeneous catalysts. Therefore, we recently worked on elucidation of the reaction mechanism during ligand calcination. ${ }^{308}$ Specifically, the ligand desorption process in $\mathrm{Au}_{25}(\mathrm{PET})_{\sim 9}(p \text {-MBA })_{\sim 9} / \mathrm{BaLa}_{4} \mathrm{Ti}_{4} \mathrm{O}_{15}$ during calcination was followed by five techniques: direct insertion probe-mass spectrometry, XAFS, Fourier-transform infrared spectroscopy, XPS, and TEM observation. As a result, we succeeded in elucidating that the ligand desorption process consists of dissociation of the ligand on the metal-NC surface, adsorption of the generated compound on the support, and desorption of the compound from the support, and at what temperatures these processes occur (Fig. 19(b)). Based on the obtained knowledge, we also succeeded in developing a method to form the $\mathrm{Cr}_{2} \mathrm{O}_{3}$ shell on the surface of Au NCs while preventing 
their aggregation, and thereby obtained a highly active and stable water-splitting photocatalyst. ${ }^{308}$

The desorption temperature of SR from the Au-NC surface is strongly related to the interactions between the ligands on the $\mathrm{Au}-\mathrm{NC}$ surface, as well as the strengths of the Au-S and S-C bonds. ${ }^{308}$ In addition, the temperature for desorption from the support is related to the strength of the compound-support interaction. $^{309}$ Furthermore, the easiness of dissociation/ desorption of the ligands and the resulting aggregation of the $\mathrm{Au}$ NCs slightly varies depending on the calcination atmosphere. ${ }^{309,310}$ However, previous calcinations with different SR functional groups, supports, and atmospheres have often suggested occurrence of the phenomena in Fig. 19(b). ${ }^{243,271,309,311-314}$ Therefore, it is assumed that a phenomenon similar to Fig. 19(b) also occurs in calcination of the other $\mathrm{Au}_{n}(\mathrm{SR})_{m} \mathrm{NCs} /$ metal oxides, although the temperature at which it occurs is different. There had not been a unified view on the behavior in $\mathrm{Au}_{n}(\mathrm{SR})_{m}$ NCs/ metal oxides during calcination before this study. ${ }^{312,315}$ We succeeded in elucidating the details of the phenomena occurring during calcination of $\mathrm{Au}_{25}(\mathrm{PET})_{\sim 9}(p-\mathrm{MBA})_{\sim 9} /$ metal-oxide catalysts by combining five measurements. The knowledge gained in this study is expected to provide clear design guidelines for creation of high-performance heterogeneous catalysts.

\subsection{Summary of activation of energy and environmental catalysts using controlled metal NCs}

We succeeded in precisely controlling the metal NCs on the support with atomic precision using precise ligand-protected metal NCs as precursors. Studies of the obtained energy and environmental catalysts revealed the correlation between the number of constituent atoms/chemical composition of the loaded metal NCs and the material function of each catalyst. Through these studies, each catalyst has been successfully highly functionalized. Specifically, we have achieved producing the highest water-splitting activity for $\mathrm{BaLa}_{4} \mathrm{Ti}_{4} \mathrm{O}_{15},{ }^{290}$ one of the most advanced water-splitting photocatalyst, creating electrode catalysts with higher ORR activity than the Pt catalysts currently used in fuel cells ${ }^{121}$ and improving the functionality of automotive exhaust-gas purification catalysts. ${ }^{299}$ These results strongly suggest that the bottom-up nanotechnology established in the metal-NC field can contribute to construction of a clean and sustainable society, that is, provide solutions for the issues faced by modern society.

For these catalytic applications, in the future, we will work on alloying ${ }^{316}$ with various metal elements for the metal NC contained in each catalyst. In addition, the geometric and electronic structures of the loaded metal NCs during the reaction $^{317}$ will be revealed to gain a better understanding of the structure-property relationship of the loaded metal NCs and provide design guidelines for further enhancement of their activity. We believe that these catalysts could be further enhanced by repeating the cycle shown in Fig. 14 while incorporating the obtained knowledge. Regarding these applied studies, we would also like to continue our study while deepening both the science and technology of metal NCs.

\section{Conclusions}

Nanoscale materials have the following interesting and important features: (1) they possess great potential and value that cannot be found in bulk materials and (2) the nanoscale is the level of emergence of material functions, and thus if materials can be controlled at the nanoscale, we can control the properties of the larger materials. In this paper, I have described the contents of and motivation for my own studies in this field. The knowledge and skills required to study metal NCs are likely to change in the future, depending on the stage of the study and the situation in the world. However, the importance of understanding and controlling metal NCs will not change because they are deeply related to understanding and controlling various materials in the fields of energy, environment, and materials. I hope that the science and technology in the metal-NC field will be further advanced in the future through collaboration among researchers in many fields across physics, chemistry, and biology.

\section{Outlook}

The studies that we will perform in the future or are currently being performed have already been described at the end of each section. Therefore, in this section, I will describe the studies to be performed in the future for further development of the field of metal NCs (Fig. 20).

\subsection{Elucidation of the synthesis mechanism}

Recent work by Xie and co-workers has revealed the details of the reaction mechanism for synthesis of hydrophilic SR-protected metal NCs. ${ }^{318,319}$ In addition, recent studies by Pradeep and co-workers, ${ }^{320-322}$ Bürgi and co-workers, ${ }^{323}$ and Pei and co-workers $^{324}$ have advanced our understanding of the reaction mechanism for synthesis of ligand-protected alloy NCs through metal exchange. However, the mechanism for synthesis of hydrophobic ligand-protected metal NCs in a two-phase system, which was first reported by Brust and co-workers, ${ }^{95}$ has yet to be elucidated at the atomic and molecular levels. Similarly, ligandexchange-induced structure transformation ${ }^{325}$ is not yet understood at the atomic or molecular level with respect to the chemical composition that induces the structural transformation. In the future, it is expected that high-resolution separation, mass spectrometry, ion-mobility experiments, and theoretical calculations will be used to clarify the details of reactions whose mechanisms are currently unknown (Fig. 20(a)), which will make it possible to further control synthesis of metal NCs.

\subsection{Preparation of a textbook for students}

For ligand-protected metal NCs, there was not a good textbook until 2014. ${ }^{10}$ However, taking into account the number of syntheses, reactions, and applications reported so far, it seems that metal-NC chemistry has reached a stage where many textbooks for undergraduate and graduate students should be published, like for organic chemistry ${ }^{326}$ and coordination chemistry. ${ }^{327}$ Publication of such a textbook would dramatically 

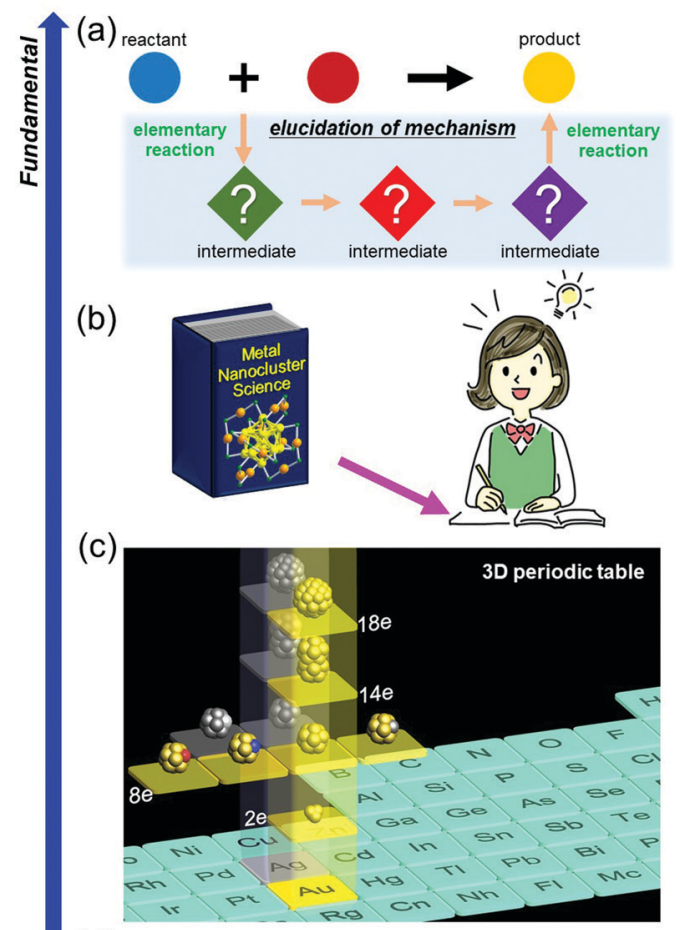

(d)

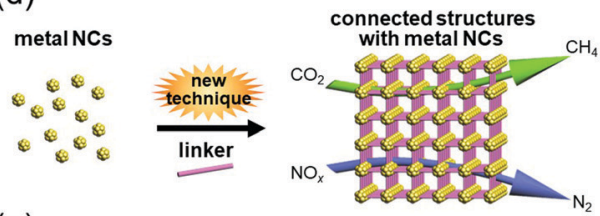

(e)

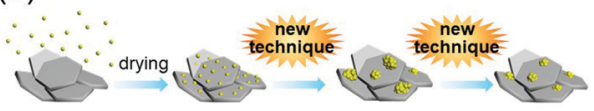

(f)

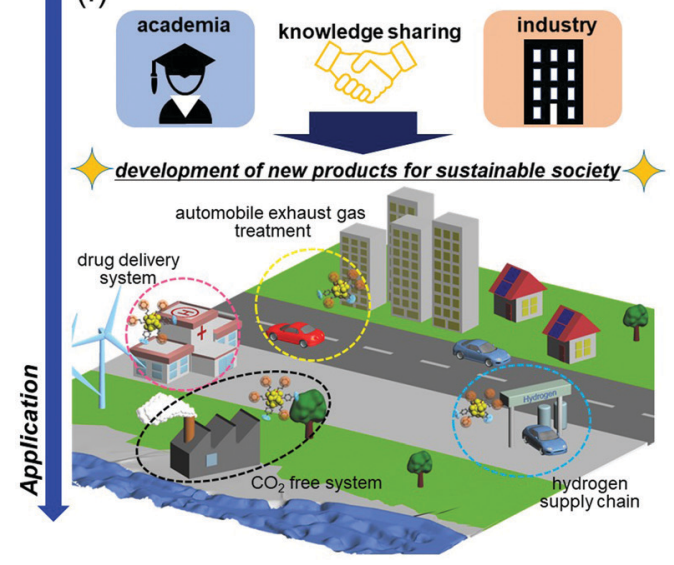

Fig. 20 Outlook in the metal-NC field. (a) Elucidation of the synthesis mechanism. (b) Preparation of a textbook for students. (c) Development of super-atomic chemistry. This figure was reproduced with permission from ref. 330. (d) Control of the connected structures. (e) Control of the supported metal NCs without calcination at high temperature. (f) Industry-academia collaboration to realize industrial development and a more comfortable society. Copyright 2021 Willey-VCH.

increase the number of students and researchers working on metal-NC research, thereby further deepening and expanding the field of metal NCs. Publication of a textbook that includes the latest information on metal NCs is an urgent issue for creation of new materials with size-specific properties and thereby solving many issues in the world (Fig. 20(b)).

\subsection{Development of super-atomic chemistry}

Metal NCs, which consist of metal atoms such as Au and Ag, become stable when the total number of valence electrons fills a closed-shell electronic structure. Because this phenomenon is similar to that for atoms, metal NCs can be considered to be super-atoms. ${ }^{328}$ Super-atoms are expected to be the constituent units of a variety of functional materials, like conventional atoms. The use of super-atoms as constituent units is expected to lead to creation of materials that are difficult to create with conventional atoms. Several researchers have been actively working on super-atomic metal NCs, in the fields of both gasphase metal $\mathrm{NCs}^{67,329}$ and ligand-protected metal NCs. ${ }^{330,331}$ However, more researchers need to be involved in this field to enrich the library of super-atomic metal NCs, just like not all conventional atoms were discovered by only a few researchers. It is expected that the number of researchers working on superatomic metal NCs will increase in the future, which will lead to completion of a three-dimensional periodic table (Fig. 20(c)). ${ }^{330}$

\subsection{Control of connected structures}

Although studies of applications of ligand-protected metals NCs have been performed, at present, their main applications are limited to catalysts and chemical sensors in the dispersed state. If ligand-protected metal NCs could be connected in a regular pattern, they could be applied to designable electronic and luminescent devices and reaction-selective highly active catalysts. Connection techniques of ligand-protected metal NCs would also be indispensable for creation of materials with super-atomic metal NCs (Section 7.3) as a constituent unit. However, at present, there are few examples of direct connection of ligand-protected metal NCs through metal-metal bonds. Since 2017, connection of metal NCs through linker molecules has also been vigorously studied by several groups, including Zang and co-workers. ${ }^{208}$ However, there have been few reports on connected structures, except for Ag NCs. In the future, it is expected that techniques to connect various ligand-protected metal NCs (synthesis of connected structures) will be developed, which will lead to creation of more diverse functions and expansion of the application fields (Fig. 20(d)).

\subsection{Control of supported metal NCs without calcination at high temperature}

As described in Section 5, it has recently become possible to control the number of constituent atoms and chemical composition of the loaded metal NCs on the support using ligand-protected metal NCs as a precursor. ${ }^{332}$ However, the method involves removal of the ligands by calcination at high temperature, which wastes energy. This waste of energy might become a hindrance to industrial application of metal NCs. Therefore, it is expected that a new method to control the number of constituent atoms and chemical composition of the loaded metal NCs on the support will be 
developed in the future (Fig. 20(e)). I expect that such control can be realized if a size-convergence method can be found for loaded metal NCs, similar to the case of ligand-protected metal NCs dispersed in solution. In other words, it is expected that the number of constituent atoms and chemical composition of the loaded metal NCs can be controlled by combining the conventional loading method and size-convergence method. If such a method can be developed, it might also be possible to control the geometric structure of the loaded metal NCs. Although control of ligandprotected metal NCs dispersed in solution was once thought to be extremely difficult to achieve with atomic precision, many control methods have been developed. ${ }^{7}$ I hope that control of the number of constituent atoms and chemical composition of the loaded metal NCs on the support by an easier method will also be achieved through the enthusiasm of the readers of this paper.

\subsection{Collaboration between academia and industry}

The researchers in the field of metal NCs have discovered potential applications of metal NCs in various fields, as well as new facts hidden in nanoscale materials. For example, the applications described in Section 5 are such examples. Collaboration between industry and academia seems to be essential for successfully connecting the scientific discoveries found in these academic fields to development of industry. It is not necessary for all researchers in the academic field to collaborate with industry because the challenges that need to be overcome in the academic field and in industry are probably different. Thus, I would like to encourage young researchers to continue to make great effort to explore the new science hidden in the metal-NC field. However, the field of metal NCs is important in terms of both science and technology, and the techniques established in the field of metal NCs also have the potential to contribute to construction of the next-generation society (Section 5). For this reason, I urge researchers who already have the seeds of technology to also engage in industryuniversity collaborations so that the knowledge and techniques discovered in the field of metal NCs can be successfully linked to development of industry and society (Fig. 20(f)).

\section{Conflicts of interest}

There are no conflicts to declare.

\section{Acknowledgements}

I thank the collaborators of the work summarized in this review, especially Prof. Koji Kaya, Prof. Atsushi Nakajima (Keio University), and Prof. Tatsuya Tsukuda (The University of Tokyo), for their guidance in the early stage of my career. I also thank Mr Masanobu Kawachi, Mr Shun Kato, and Mr Yusuke Horita for their assistance with making the figures. This work was supported by the Japan Society for the Promotion of Science (JSPS) KAKENHI (grant numbers 20H02698 and 20H02552), Scientific Research on Innovative Areas "Coordination Asymmetry" (grant numbers 17H05385 and 19H04595), Scientific
Research on Innovative Areas "Innovations for Light-Energy Conversion" (grant numbers 18H05178 and 20H05115), and the JST Adaptable and Seamless Technology transfer Program through Target-driven R\&D (A-STEP, grant number JPMJTM20MS). Funding from Nissanken, the Yashima Environment Technology Foundation, and the Yazaki Memorial Foundation for Science and Technology is gratefully acknowledged.

\section{References}

1 R. P. Feynman, There's Plenty of Room at the Bottom An Invitation to Enter a New Field of Physics, 1960.

2 G. Binnig, H. Rohrer, C. Gerber and E. Weibel, Phys. Rev. Lett., 1982, 49, 57-61.

3 G. Binnig, C. F. Quate and C. Gerber, Phys. Rev. Lett., 1986, 56, 930-933.

4 V. E. Bondybey and J. H. English, J. Chem. Phys., 1982, 76, 2165-2170.

5 R. E. Smalley, Laser Chem., 1983, 2, 167-184.

6 N. Lane, National Nanotechnology Initiative: The Initiative and Its Implementation Plan, Washington, D. C., 2000.

7 R. Jin, C. Zeng, M. Zhou and Y. Chen, Chem. Rev., 2016, 116, 10346-10413.

8 I. Chakraborty and T. Pradeep, Chem. Rev., 2017, 117, 8208-8271.

9 X. Kang, Y. Li, M. Zhu and R. Jin, Chem. Soc. Rev., 2020, 49, 6443-6514.

10 T. Tsukuda and H. Häkkinen, Protected Metal Clusters: From Fundamentals to Applications, Elsevier, Amsterdam, 2015.

11 Y. Du, H. Sheng, D. Astruc and M. Zhu, Chem. Rev., 2020, 120, 526-622.

12 H. Hirai, S. Takano, T. Nakamura and T. Tsukuda, Inorg. Chem., 2020, 59, 17889-17895.

13 K. Konishi, M. Iwasaki and Y. Shichibu, Acc. Chem. Res., 2018, 51, 3125-3133.

14 C. E. Briant, B. R. C. Theobald, J. W. White, L. K. Bell, D. M. P. Mingos and A. J. Welch, J. Chem. Soc., Chem. Commun., 1981, 201-202.

15 M. McPartlin, R. Mason and L. Malatesta, J. Chem. Soc. D, $1969,334$.

16 E. G. Mednikov and L. F. Dahl, Philos. Trans. R. Soc., A, 2010, 368, 1301-1332.

17 G. Schmid, Chem. Rev., 1992, 92, 1709-1727.

18 M. Schulz-Dobrick and M. Jansen, Z. Anorg. Allg. Chem., 2007, 633, 2326-2331.

19 B. K. Teo, X. Shi and H. Zhang, J. Am. Chem. Soc., 1992, 114, 2743-2745.

20 J. D. Roth, G. J. Lewis, L. K. Safford, X. Jiang, L. F. Dahl and M. J. Weaver, J. Am. Chem. Soc., 1992, 114, 6159-6169.

21 A. Ceriotti, N. Masciocchi, P. Macchi and G. Longoni, Angew. Chem., Int. Ed., 1999, 38, 3724-3727.

22 I. Ciabatti, C. Femoni, M. C. Iapalucci, G. Longoni and S. Zacchini, J. Cluster Sci., 2014, 25, 115-146.

23 S. S. Kurasov, N. K. Eremenko, Y. L. Slovokhotov and Y. T. Struchkov, J. Organomet. Chem., 1989, 361, 405-408. 
24 L. Hao, G. J. Spivak, J. Xiao, J. J. Vittal and R. J. Puddephatt, J. Am. Chem. Soc., 1995, 117, 7011-7012.

25 V. G. Albano, P. L. Bellon, M. Manassero and M. Sansoni, J. Chem. Soc. D, 1970, 1210-1211.

26 P. Chini, J. Organomet. Chem., 1980, 200, 37-61.

27 M. Paolieri, I. Ciabatti and M. Fontani, J. Cluster Sci., 2019, 30, 1623-1631.

28 H. Yu, B. Rao, W. Jiang, S. Yang and M. Zhu, Coord. Chem. Rev., 2019, 378, 595-617.

29 M. Agrachev, M. Ruzzi, A. Venzo and F. Maran, Acc. Chem. Res., 2019, 52, 44-52.

30 K. Kwak and D. Lee, Acc. Chem. Res., 2019, 52, 12-22.

31 B. Nieto-Ortega and T. Bürgi, Acc. Chem. Res., 2018, 51, 2811-2819.

32 N. A. Sakthivel and A. Dass, Acc. Chem. Res., 2018, 51, 1774-1783.

33 R. L. Whetten, H.-C. Weissker, J. J. Pelayo, S. M. Mullins, X. López-Lozano and I. L. Garzón, Acc. Chem. Res., 2019, 52, 34-43.

34 B. Bhattarai, Y. Zaker, A. Atnagulov, B. Yoon, U. Landman and T. P. Bigioni, Acc. Chem. Res., 2018, 51, 3104-3113.

35 Z. Gan, N. Xia and Z. Wu, Acc. Chem. Res., 2018, 51, 2774-2783.

36 A. Ghosh, O. F. Mohammed and O. M. Bakr, Acc. Chem. Res., 2018, 51, 3094-3103.

37 J. Yan, B. K. Teo and N. Zheng, Acc. Chem. Res., 2018, 51, 3084-3093.

38 S. Lee, M. S. Bootharaju, G. Deng, S. Malola, W. Baek, H. Häkkinen, N. Zheng and T. Hyeon, J. Am. Chem. Soc., 2020, 142, 13974-13981.

39 H. Kawamata, Y. Negishi, R. Kishi, S. Iwata, A. Nakajima and K. Kaya, J. Chem. Phys., 1996, 105, 5369-5376.

40 Y. Negishi, H. Kawamata, F. Hayakawa, A. Nakajima and K. Kaya, Chem. Phys. Lett., 1998, 294, 370-376.

41 Y. Negishi, T. Yasuike, F. Hayakawa, M. Kizawa, S. Yabushita, A. Nakajima and K. Kaya, J. Chem. Phys., 2000, 113, 1725-1731.

42 Y. Negishi and T. Tsukuda, J. Am. Chem. Soc., 2003, 125, 4046-4047.

43 Y. Shichibu, Y. Negishi, T. Tsukuda and T. Teranishi, J. Am. Chem. Soc., 2005, 127, 13464-13465.

44 Y. Negishi, H. Tsunoyama, Y. Yanagimoto and T. Tsukuda, Chem. Lett., 2005, 34, 1638-1639.

45 Y. Negishi, H. Tsunoyama, M. Suzuki, N. Kawamura, M. M. Matsushita, K. Maruyama, T. Sugawara, T. Yokoyama and T. Tsukuda, J. Am. Chem. Soc., 2006, 128, 12034-12035.

46 Y. Negishi, N. K. Chaki, Y. Shichibu, R. L. Whetten and T. Tsukuda, J. Am. Chem. Soc., 2007, 129, 11322-11323.

47 N. K. Chaki, Y. Negishi, H. Tsunoyama, Y. Shichibu and T. Tsukuda, J. Am. Chem. Soc., 2008, 130, 8608-8610.

48 T. Kawawaki, A. Ebina, Y. Hosokawa, S. Ozaki, D. Suzuki, S. Hossain and Y. Negishi, Small, 2021, 17, 2005328.

49 Y. Negishi, W. Kurashige, Y. Niihori and K. Nobusada, Phys. Chem. Chem. Phys., 2013, 15, 18736-18751.

50 Y. Negishi, Bull. Chem. Soc. Jpn., 2014, 87, 375-389.

51 W. Kurashige, Y. Niihori, S. Sharma and Y. Negishi, Coord. Chem. Rev., 2016, 320-321, 238-250.
52 Y. Niihori, S. Hossain, S. Sharma, B. Kumar, W. Kurashige and Y. Negishi, Chem. Rec., 2017, 17, 473-484.

53 Y. Niihori, C. Uchida, W. Kurashige and Y. Negishi, Phys. Chem. Chem. Phys., 2016, 18, 4251-4265.

54 S. Hossain, Y. Niihori, L. V. Nair, B. Kumar, W. Kurashige and Y. Negishi, Acc. Chem. Res., 2018, 51, 3114-3124.

55 Y. Niihori, K. Yoshida, S. Hossain, W. Kurashige and Y. Negishi, Bull. Chem. Soc. Jpn., 2019, 92, 664-695.

56 T. Kawawaki, Y. Kataoka, S. Ozaki, M. Kawachi, M. Hirata and Y. Negishi, Chem. Commun., 2021, 57, 417-440.

57 T. Kawawaki, N. Shimizu, Y. Mitomi, D. Yazaki, S. Hossain and Y. Negishi, Bull. Chem. Soc. Jpn., 2021, 94, 2853-2870.

58 W. Kurashige, Y. Niihori, S. Sharma and Y. Negishi, J. Phys. Chem. Lett., 2014, 5, 4134-4142.

59 Y. Niihori, S. Hossain, B. Kumar, L. V. Nair, W. Kurashige and Y. Negishi, APL Mater., 2017, 5, 053201.

60 T. Kawawaki, Y. Negishi and H. Kawasaki, Nanoscale Adv., 2020, 2, 17-36.

61 Y. Negishi, S. Hashimoto, A. Ebina, K. Hamada, S. Hossain and T. Kawawaki, Nanoscale, 2020, 12, 8017-8039.

62 A. Ebina, S. Hossain, H. Horihata, S. Ozaki, S. Kato, T. Kawawaki and Y. Negishi, Nanomaterials, 2020, 10, 1105.

63 T. Kawawaki and Y. Negishi, Nanomaterials, 2020, 10, 238.

64 T. Kawawaki, Y. Mori, K. Wakamatsu, S. Ozaki, M. Kawachi, S. Hossain and Y. Negishi, J. Mater. Chem. A, 2020, 8, 16081-16113.

65 T. Kawawaki, Y. Imai, D. Suzuki, S. Kato, I. Kobayashi, T. Suzuki, R. Kaneko, S. Hossain and Y. Negishi, Chem. Eur. J., 2020, 26, 16150-16193.

66 T. Kawawaki, Y. Kataoka, M. Hirata, Y. Iwamatsu, S. Hossain and Y. Negishi, Nanoscale Horiz., 2021, 6, 409-448.

67 M. Akutsu, K. Koyasu, J. Atobe, N. Hosoya, K. Miyajima, M. Mitsui and A. Nakajima, J. Phys. Chem. A, 2006, 110, 12073-12076.

68 A. Sanchez, S. Abbet, U. Heiz, W.-D. Schneider, H. Häkkinen, R. N. Barnett and U. Landman, J. Phys. Chem. A, 1999, 103, 9573-9578.

69 S. Nagaoka, T. Matsumoto, K. Ikemoto, M. Mitsui and A. Nakajima, J. Am. Chem. Soc., 2007, 129, 1528-1529.

70 F. S. Roberts, M. D. Kane, E. T. Baxter and S. L. Anderson, Phys. Chem. Chem. Phys., 2014, 16, 26443-26457.

71 J. Li, X. Li, H.-J. Zhai and L.-S. Wang, Science, 2003, 299, 864-867.

72 Y. Watanabe, X. Wu, H. Hirata and N. Isomura, Catal. Sci. Technol., 2011, 1, 1490-1495.

73 A. Bettac, L. Köller, V. Rank and K. H. Meiwes-Broer, Surf. Sci., 1998, 402-404, 475-479.

74 T. P. Martin, T. Bergmann, H. Göhlich and T. Lange, J. Phys. Chem., 1991, 95, 6421-6429.

75 S. C. Richtsmeier, E. K. Parks, K. Liu, L. G. Pobo and S. J. Riley, J. Chem. Phys., 1985, 82, 3659-3665.

76 P. Fayet, F. Granzer, G. Hegenbart, E. Moisar, B. Pischel and L. Wöste, Z. Phys. D: At., Mol. Clusters, 1986, 3, 299-302.

77 K. Tono, A. Terasaki, T. Ohta and T. Kondow, Chem. Phys. Lett., 2007, 449, 276-281. 
78 K. Sattler, J. Mühlbach and E. Recknagel, Phys. Rev. Lett., 1980, 45, 821-824.

79 S. Gilb, K. Jacobsen, D. Schooss, F. Furche, R. Ahlrichs and M. M. Kappes, J. Chem. Phys., 2004, 121, 4619-4627.

80 W. E. Kaden, T. Wu, W. A. Kunkel and S. L. Anderson, Science, 2009, 326, 826-829.

81 P. Kruit and F. H. Read, J. Phys. E: Sci. Instrum., 1983, 16, 313-324.

82 Y. Negishi, H. Kawamata, T. Hayase, M. Gomei, R. Kishi, F. Hayakawa, A. Nakajima and K. Kaya, Chem. Phys. Lett., 1997, 269, 199-207.

83 Y. Negishi, H. Kawamata, A. Nakajima and K. Kaya, J. Electron Spectrosc. Relat. Phenom., 2000, 106, 117-125.

84 Y. Negishi, Y. Nakamura, A. Nakajima and K. Kaya, J. Chem. Phys., 2001, 115, 3657-3663.

85 Y. Negishi, S. Nagao, Y. Nakamura, A. Nakajima, S. Kamei and K. Kaya, J. Appl. Phys., 2000, 88, 6037-6043.

86 T. Tsukuda, N. Kimura, T. Sasaki and T. Nagata, Trans. MRS-J., 2000, 25, 929-932.

87 Y. Negishi, H. Murayama and T. Tsukuda, Chem. Phys. Lett., 2002, 366, 561-566.

88 Y. Negishi and T. Tsukuda, Chem. Phys. Lett., 2004, 383, 161-165.

89 R. G. Nuzzo and D. L. Allara, J. Am. Chem. Soc., 1983, 105, 4481-4483.

90 C. A. Widrig, C. A. Alves and M. D. Porter, J. Am. Chem. Soc., 1991, 113, 2805-2810.

91 L. Strong and G. M. Whitesides, Langmuir, 1988, 4, 546-558.

92 R. D. Piner, J. Zhu, F. Xu, S. Hong and C. A. Mirkin, Science, 1999, 283, 661-663.

93 D. S. Ginger, H. Zhang and C. A. Mirkin, Angew. Chem., Int. Ed., 2004, 43, 30-45.

94 A. Kumar and G. M. Whitesides, Appl. Phys. Lett., 1993, 63, 2002-2004.

95 M. Brust, M. Walker, D. Bethell, D. J. Schiffrin and R. Whyman, J. Chem. Soc., Chem. Commun., 1994, 801-802.

96 E. G. Mednikov, N. K. Eremenko, Y. L. Slovokhotov and Y. T. Struchkov, J. Organomet. Chem., 1986, 301, C35-C37.

97 T. G. Schaaff, M. N. Shafigullin, J. T. Khoury, I. Vezmar, R. L. Whetten, W. G. Cullen, P. N. First, C. Gutiérrez-Wing, J. Ascensio and M. J. Jose-Yacamán, J. Phys. Chem. B, 1997, 101, 7885-7891.

98 V. L. Jimenez, D. G. Georganopoulou, R. J. White, A. S. Harper, A. J. Mills, D. Lee and R. W. Murray, Langmuir, 2004, 20, 6864-6870.

99 T. G. Schaaff, G. Knight, M. N. Shafigullin, R. F. Borkman and R. L. Whetten, J. Phys. Chem. B, 1998, 102, 10643-10646.

100 T. G. Schaaff and R. L. Whetten, J. Phys. Chem. B, 2000, 104, 2630-2641.

101 B. Palpant, Y. Negishi, M. Sanekata, K. Miyajima, S. Nagao, K. Judai, D. M. Rayner, B. Simard, P. A. Hackett, A. Nakajima and K. Kaya, J. Chem. Phys., 2001, 114, 8459-8466.

102 Y. Negishi, K. Nobusada and T. Tsukuda, J. Am. Chem. Soc., 2005, 127, 5261-5270.
103 Y. Negishi, Y. Takasugi, S. Sato, H. Yao, K. Kimura and T. Tsukuda, J. Am. Chem. Soc., 2004, 126, 6518-6519.

104 Y. Negishi, Y. Takasugi, S. Sato, H. Yao, K. Kimura and T. Tsukuda, J. Phys. Chem. B, 2006, 110, 12218-12221.

105 Y. Shichibu, Y. Negishi, H. Tsunoyama, M. Kanehara, T. Teranishi and T. Tsukuda, Small, 2007, 3, 835-839.

106 K. Ikeda, Y. Kobayashi, Y. Negishi, M. Seto, T. Iwasa, K. Nobusada, T. Tsukuda and N. Kojima, J. Am. Chem. Soc., 2007, 129, 7230-7231.

107 B. K. Teo and H. Zhang, Coord. Chem. Rev., 1995, 143, 611-636.

108 Y. Negishi, C. Sakamoto, T. Ohyama and T. Tsukuda, J. Phys. Chem. Lett., 2012, 3, 1624-1628.

109 Y. Negishi, T. Nakazaki, S. Malola, S. Takano, Y. Niihori, W. Kurashige, S. Yamazoe, T. Tsukuda and H. Häkkinen, J. Am. Chem. Soc., 2015, 137, 1206-1212.

110 Y. Negishi, W. Kurashige, Y. Niihori, T. Iwasa and K. Nobusada, Phys. Chem. Chem. Phys., 2010, 12, 6219-6225.

111 Y. Negishi, T. Iwai and M. Ide, Chem. Commun., 2010, 46, 4713-4715.

112 Y. Negishi, K. Munakata, W. Ohgake and K. Nobusada, J. Phys. Chem. Lett., 2012, 3, 2209-2214.

113 W. Kurashige and Y. Negishi, J. Cluster Sci., 2012, 23, 365-374.

114 Y. Negishi, K. Igarashi, K. Munakata, W. Ohgake and K. Nobusada, Chem. Commun., 2012, 48, 660-662.

115 S. Sharma, W. Kurashige, K. Nobusada and Y. Negishi, Nanoscale, 2015, 7, 10606-10612.

116 S. Sharma, S. Yamazoe, T. Ono, W. Kurashige, Y. Niihori, K. Nobusada, T. Tsukuda and Y. Negishi, Dalton Trans., 2016, 45, 18064-18068.

117 S. Hossain, T. Ono, M. Yoshioka, G. Hu, M. Hosoi, Z. Chen, L. V. Nair, Y. Niihori, W. Kurashige, D.-e. Jiang and Y. Negishi, J. Phys. Chem. Lett., 2018, 9, 2590-2594.

118 Y. Negishi, R. Arai, Y. Niihori and T. Tsukuda, Chem. Commun., 2011, 47, 5693-5695.

119 I. Chakraborty, W. Kurashige, K. Kanehira, L. Gell, H. Häkkinen, Y. Negishi and T. Pradeep, J. Phys. Chem. Lett., 2013, 4, 3351-3355.

120 L. V. Nair, S. Hossain, S. Wakayama, S. Takagi, M. Yoshioka, J. Maekawa, A. Harasawa, B. Kumar, Y. Niihori, W. Kurashige and Y. Negishi, J. Phys. Chem. C, 2017, 121, 11002-11009.

121 T. Kawawaki, N. Shimizu, K. Funai, Y. Mitomi, S. Hossain, S. Kikkawa, D. J. Osborn, S. Yamazoe, G. F. Metha and Y. Negishi, Nanoscale, 2021, 13, 14679-14687.

122 Y. Negishi, U. Kamimura, M. Ide and M. Hirayama, Nanoscale, 2012, 4, 4263-4268.

123 Y. Negishi, W. Kurashige and U. Kamimura, Langmuir, 2011, 27, 12289-12292.

124 W. Kurashige, M. Yamaguchi, K. Nobusada and Y. Negishi, J. Phys. Chem. Lett., 2012, 3, 2649-2652.

125 W. Kurashige, K. Munakata, K. Nobusada and Y. Negishi, Chem. Commun., 2013, 49, 5447-5449.

126 W. Kurashige, S. Yamazoe, K. Kanehira, T. Tsukuda and Y. Negishi, J. Phys. Chem. Lett., 2013, 4, 3181-3185. 
127 W. Kurashige, S. Yamazoe, M. Yamaguchi, K. Nishido, K. Nobusada, T. Tsukuda and Y. Negishi, J. Phys. Chem. Lett., 2014, 5, 2072-2076.

128 S. Hossain, W. Kurashige, S. Wakayama, B. Kumar, L. V. Nair, Y. Niihori and Y. Negishi, J. Phys. Chem. C, 2016, 120, 25861-25869.

129 L. V. Nair, S. Hossain, S. Takagi, Y. Imai, G. Hu, S. Wakayama, B. Kumar, W. Kurashige, D.-E. Jiang and Y. Negishi, Nanoscale, 2018, 10, 18969-18979.

130 S. Hossain, Y. Imai, Y. Motohashi, Z. Chen, D. Suzuki, T. Suzuki, Y. Kataoka, M. Hirata, T. Ono, W. Kurashige, T. Kawawaki, T. Yamamoto and Y. Negishi, Mater. Horiz., 2020, 7, 796-803.

131 S. Hossain, S. Miyajima, T. Iwasa, R. Kaneko, T. Sekine, A. Ikeda, T. Kawawaki, T. Taketsugu and Y. Negishi, J. Chem. Phys., 2021, 155, 024302.

132 Y. Niihori, Y. Koyama, S. Watanabe, S. Hashimoto, S. Hossain, L. V. Nair, B. Kumar, W. Kurashige and Y. Negishi, J. Phys. Chem. Lett., 2018, 9, 4930-4934.

133 Y. Niihori, M. Matsuzaki, C. Uchida and Y. Negishi, Nanoscale, 2014, 6, 7889-7896.

134 Y. Niihori, M. Matsuzaki, T. Pradeep and Y. Negishi, J. Am. Chem. Soc., 2013, 135, 4946-4949.

135 Y. Niihori, Y. Kikuchi, D. Shima, C. Uchida, S. Sharma, S. Hossain, W. Kurashige and Y. Negishi, Ind. Eng. Chem. Res., 2017, 56, 1029-1035.

136 Y. Niihori, D. Shima, K. Yoshida, K. Hamada, L. V. Nair, S. Hossain, W. Kurashige and Y. Negishi, Nanoscale, 2018, 10, 1641-1649.

137 Y. Niihori, Y. Kikuchi, A. Kato, M. Matsuzaki and Y. Negishi, ACS Nano, 2015, 9, 9347-9356.

138 Y. Niihori, S. Hashimoto, Y. Koyama, S. Hossain, W. Kurashige and Y. Negishi, J. Phys. Chem. C, 2019, 123, 13324-13329.

139 N. A. Sakthivel, S. Theivendran, V. Ganeshraj, A. G. Oliver and A. Dass, J. Am. Chem. Soc., 2017, 139, 15450-15459.

140 C. Zeng, Y. Chen, K. Kirschbaum, K. J. Lambright and R. Jin, Science, 2016, 354, 1580-1584.

141 C. A. Fields-Zinna, R. Sardar, C. A. Beasley and R. W. Murray, J. Am. Chem. Soc., 2009, 131, 16266-16271.

142 H. Qian and R. Jin, Nano Lett., 2009, 9, 4083-4087.

143 K. Kimura, N. Sugimoto, S. Sato, H. Yao, Y. Negishi and T. Tsukuda, J. Phys. Chem. C, 2009, 113, 14076-14082.

144 R. L. Wolfe and R. W. Murray, Anal. Chem., 2006, 78, 1167-1173.

145 C. Kumara and A. Dass, Anal. Chem., 2014, 86, 4227-4232.

146 H. Qian, Y. Zhu and R. Jin, Proc. Natl. Acad. Sci. U. S. A., 2012, 109, 696-700.

147 C. Kumara, X. Zuo, J. Ilavsky, K. W. Chapman, D. A. Cullen and A. Dass, J. Am. Chem. Soc., 2014, 136, 7410-7417.

148 C. Kumara, X. Zuo, D. A. Cullen and A. Dass, ACS Nano, 2014, 8, 6431-6439.

149 S. Malola, L. Lehtovaara, J. Enkovaara and H. Häkkinen, ACS Nano, 2013, 7, 10263-10270.

150 M. Zhou, C. Zeng, Y. Song, J. W. Padelford, G. Wang, M. Y. Sfeir, T. Higaki and R. Jin, Angew. Chem., Int. Ed., 2017, 56, 16257-16261.
151 T. Higaki, M. Zhou, K. J. Lambright, K. Kirschbaum, M. Y. Sfeir and R. Jin, J. Am. Chem. Soc., 2018, 140, 5691-5695.

152 N. A. Sakthivel, M. Stener, L. Sementa, A. Fortunelli, G. Ramakrishna and A. Dass, J. Phys. Chem. Lett., 2018, 9, 1295-1300.

153 M. W. Heaven, A. Dass, P. S. White, K. M. Holt and R. W. Murray, J. Am. Chem. Soc., 2008, 130, 3754-3755.

154 M. Zhu, C. M. Aikens, F. J. Hollander, G. C. Schatz and R. Jin, J. Am. Chem. Soc., 2008, 130, 5883-5885.

155 J. Akola, M. Walter, R. L. Whetten, H. Häkkinen and H. Grönbeck, J. Am. Chem. Soc., 2008, 130, 3756-3757.

156 H. Qian, W. T. Eckenhoff, Y. Zhu, T. Pintauer and R. Jin, J. Am. Chem. Soc., 2010, 132, 8280-8281.

157 O. Lopez-Acevedo, H. Tsunoyama, T. Tsukuda, H. Häkkinen and C. M. Aikens, J. Am. Chem. Soc., 2010, 132, 8210-8218.

158 S. Yamazoe, W. Kurashige, K. Nobusada, Y. Negishi and T. Tsukuda, J. Phys. Chem. C, 2014, 118, 25284-25290.

159 Y. Niihori, W. Kurashige, M. Matsuzaki and Y. Negishi, Nanoscale, 2013, 5, 508-512.

160 Y. Niihori, M. Eguro, A. Kato, S. Sharma, B. Kumar, W. Kurashige, K. Nobusada and Y. Negishi, J. Phys. Chem. C, 2016, 120, 14301-14309.

161 S. Hossain, Y. Imai, D. Suzuki, W. Choi, Z. Chen, T. Suzuki, M. Yoshioka, T. Kawawaki, D. Lee and Y. Negishi, Nanoscale, 2019, 11, 22089-22098.

162 S. Hossain, D. Suzuki, T. Iwasa, R. Kaneko, T. Suzuki, S. Miyajima, Y. Iwamatsu, S. Pollitt, T. Kawawaki, N. Barrabés, G. Rupprechter and Y. Negishi, J. Phys. Chem. C, 2020, 124, 22304-22313.

163 Z. Wu, E. Lanni, W. Chen, M. E. Bier, D. Ly and R. Jin, J. Am. Chem. Soc., 2009, 131, 16672-16674.

164 T. U. B. Rao, B. Nataraju and T. Pradeep, J. Am. Chem. Soc., 2010, 132, 16304-16307.

165 M. R. Branham, A. D. Douglas, A. J. Mills, J. B. Tracy, P. S. White and R. W. Murray, Langmuir, 2006, 22, 11376-11383.

166 H. Qian, Y. Zhu and R. Jin, ACS Nano, 2009, 3, 3795-3803.

167 Z. Han, X.-Y. Dong, P. Luo, S. Li, Z.-Y. Wang, S.-Q. Zang and T. C. W. Mak, Sci. Adv., 2020, 6, eaay0107.

168 M. Yamamoto, T. Yoshida, N. Yamamoto, T. Nomoto, Y. Yamamoto, S. Yagi and H. Yoshida, J. Mater. Chem. A, 2015, 3, 16810-16816.

169 H. Yang, Y. Wang, H. Huang, L. Gell, L. Lehtovaara, S. Malola, H. Häkkinen and N. Zheng, Nat. Commun., 2013, 4, 2422.

170 A. Desireddy, B. E. Conn, J. Guo, B. Yoon, R. N. Barnett, B. M. Monahan, K. Kirschbaum, W. P. Griffith, R. L. Whetten, U. Landman and T. P. Bigioni, Nature, 2013, 501, 399-402.

171 X.-Y. Li, Z. Wang, H.-F. Su, S. Feng, M. Kurmoo, C.H. Tung, D. Sun and L.-S. Zheng, Nanoscale, 2017, 9, 3601-3608.

172 N. de Silva and L. F. Dahl, Inorg. Chem., 2005, 44, 9604-9606.

173 I. Ciabatti, C. Femoni, M. C. Iapalucci, G. Longoni, T. Lovato and S. Zacchini, Inorg. Chem., 2013, 52, 4384-4395. 
174 P. D. Jadzinsky, G. Calero, C. J. Ackerson, D. A. Bushnell and R. D. Kornberg, Science, 2007, 318, 430-433.

175 H. Dong, Y.-C. Chen and C. Feldmann, Green Chem., 2015, 17, 4107-4132.

176 C. Bock, C. Paquet, M. Couillard, G. A. Botton and B. R. MacDougall, J. Am. Chem. Soc., 2004, 126, 8028-8037.

177 Y. Wang, J. Ren, K. Deng, L. Gui and Y. Tang, Chem. Mater., 2000, 12, 1622-1627.

178 B.-J. Hwang, L. S. Sarma, C.-H. Chen, C. Bock, F.-J. Lai, S.-H. Chang, S.-C. Yen, D.-G. Liu, H.-S. Sheu and J.-F. Lee, J. Phys. Chem. C, 2008, 112, 19922-19929.

179 I. Schrader, J. Warneke, S. Neumann, S. Grotheer, A. A. Swane, J. J. K. Kirkensgaard, M. Arenz and S. Kunz, J. Phys. Chem. C, 2015, 119, 17655-17661.

180 R. Jin, H. Qian, Z. Wu, Y. Zhu, M. Zhu, A. Mohanty and N. Garg, J. Phys. Chem. Lett., 2010, 1, 2903-2910.

181 D. Lee, R. L. Donkers, G. Wang, A. S. Harper and R. W. Murray, J. Am. Chem. Soc., 2004, 126, 6193-6199.

182 R. Guo and R. W. Murray, J. Am. Chem. Soc., 2005, 127, 12140-12143.

183 A. H. Holm, M. Ceccato, R. L. Donkers, L. Fabris, G. Pace and F. Maran, Langmuir, 2006, 22, 10584-10589.

184 M. S. Devadas, K. Kwak, J.-W. Park, J.-H. Choi, C.-H. Jun, E. Sinn, G. Ramakrishna and D. Lee, J. Phys. Chem. Lett., 2010, 1, 1497-1503.

$185 \mathrm{Z} . \mathrm{Wu}$ and R. Jin, Nano Lett., 2010, 10, 2568-2573.

186 S. Kumar and R. Jin, Nanoscale, 2012, 4, 4222-4227.

187 M. Irie, Chem. Rev., 2000, 100, 1683-1684.

188 N. Tamai and H. Miyasaka, Chem. Rev., 2000, 100, 1875-1890.

189 M. Suda, N. Kameyama, M. Suzuki, N. Kawamura and Y. Einaga, Angew. Chem., Int. Ed., 2008, 47, 160-163.

190 M. Suda, N. Kameyama, A. Ikegami and Y. Einaga, J. Am. Chem. Soc., 2009, 131, 865-870.

191 Y. Chen, C. Liu, Q. Tang, C. Zeng, T. Higaki, A. Das, D.-E. Jiang, N. L. Rosi and R. Jin, J. Am. Chem. Soc., 2016, 138, 1482-1485.

192 T. Kawai and M. Hashizume, Stimuli-Responsive Interfaces Fabrication and Application, Springer, Singapore, 2017.

193 C. K. Yee, A. Ulman, J. D. Ruiz, A. Parikh, H. White and M. Rafailovich, Langmuir, 2003, 19, 9450-9458.

194 L. V. Romashov and V. P. Ananikov, Chem. - Eur. J., 2013, 19, 17640-17660.

195 S. Kano, Y. Azuma, M. Kanehara, T. Teranishi and Y. Majima, Appl. Phys. Express, 2010, 3, 105003.

196 J.-i. Nishigaki, K. Koyasu and T. Tsukuda, Chem. Rec., 2014, 14, 897-909.

197 B. K. Teo and H. Zhang, Inorg. Chem., 1991, 30, 3115-3116.

198 B. K. Teo, H. Zhang and X. Shi, J. Am. Chem. Soc., 1990, 112, 8552-8562.

199 Y. Shichibu, Y. Negishi, T. Watanabe, N. K. Chaki, H. Kawaguchi and T. Tsukuda, J. Phys. Chem. C, 2007, 111, 7845-7847.

200 R. Jin, C. Liu, S. Zhao, A. Das, H. Xing, C. Gayathri, Y. Xing, N. L. Rosi, R. R. Gil and R. Jin, ACS Nano, 2015, 9, 8530-8536.
201 Y. Song, F. Fu, J. Zhang, J. Chai, X. Kang, P. Li, S. Li, H. Zhou and M. Zhu, Angew. Chem., Int. Ed., 2015, 54, 8430-8434.

202 M. S. Bootharaju, S. M. Kozlov, Z. Cao, M. Harb, N. Maity, A. Shkurenko, M. R. Parida, M. N. Hedhili, M. Eddaoudi, O. F. Mohammed, O. M. Bakr, L. Cavallo and J.-M. Basset, J. Am. Chem. Soc., 2017, 139, 1053-1056.

203 S. Yang, J. Chai, Y. Lv, T. Chen, S. Wang, H. Yu and M. Zhu, Chem. Commun., 2018, 54, 12077-12080.

204 M. De Nardi, S. Antonello, D.-E. Jiang, F. Pan, K. Rissanen, M. Ruzzi, A. Venzo, A. Zoleo and F. Maran, ACS Nano, 2014, 8, 8505-8512.

205 S. Antonello, T. Dainese, F. Pan, K. Rissanen and F. Maran, J. Am. Chem. Soc., 2017, 139, 4168-4174.

206 W. Fei, S. Antonello, T. Dainese, A. Dolmella, M. Lahtinen, K. Rissanen, A. Venzo and F. Maran, J. Am. Chem. Soc., 2019, 141, 16033-16045.

207 J. Chen, L. Liu, X. Liu, L. Liao, S. Zhuang, S. Zhou, J. Yang and Z. Wu, Chem. - Eur. J., 2017, 23, 18187-18192.

208 R.-W. Huang, Y.-S. Wei, X.-Y. Dong, X.-H. Wu, C.-X. Du, S.-Q. Zang and T. C. W. Mak, Nat. Chem., 2017, 9, 689-697.

209 M. J. Alhilaly, R.-W. Huang, R. Naphade, B. Alamer, M. N. Hedhili, A.-H. Emwas, P. Maity, J. Yin, A. Shkurenko, O. F. Mohammed, M. Eddaoudi and O. M. Bakr, J. Am. Chem. Soc., 2019, 141, 9585-9592.

210 S.-H. Lu, Y. Li, S.-X. Yang, R.-D. Zhao, Z.-X. Lu, X.-L. Liu, Y. Qin, L.-Y. Zheng and Q.-E. Cao, Inorg. Chem., 2019, 58, 11793-11800.

211 Z.-K. Wang, M.-M. Sheng, S.-S. Qin, H.-T. Shi, M. Strømme, Q.-F. Zhang and C. Xu, Inorg. Chem., 2020, 59, 2121-2126.

212 X.-H. Wu, P. Luo, Z. Wei, Y.-Y. Li, R.-W. Huang, X.-Y. Dong, K. Li, S.-Q. Zang and B. Z. Tang, Adv. Sci., 2019, 6, 1801304.

213 Z. Lei, X.-L. Pei, Z.-G. Jiang and Q.-M. Wang, Angew. Chem., Int. Ed., 2014, 53, 12771-12775.

214 Y. Song, M. LAV Heien, V. Jimenez, R. M. Wightman and R. W. Murray, Anal. Chem., 2004, 76, 4911-4919.

215 Y. Song, V. Jimenez, C. McKinney, R. Donkers and R. W. Murray, Anal. Chem., 2003, 75, 5088-5096.

216 D. R. Stoll and P. W. Carr, J. Am. Chem. Soc., 2005, 127, 5034-5035.

217 I. Dolamic, S. Knoppe, A. Dass and T. Bürgi, Nat. Commun., 2012, 3, 798.

218 S. Takano, S. Ito and T. Tsukuda, J. Am. Chem. Soc., 2019, 141, 15994-16002.

219 A. Fujishima and K. Honda, Nature, 1972, 238, 37-38.

220 K. Kwak, W. Choi, Q. Tang, M. Kim, Y. Lee, D.-E. Jiang and D. Lee, Nat. Commun., 2017, 8, 14723.

221 S. Zhao, R. Jin, Y. Song, H. Zhang, S. D. House, J. C. Yang and R. Jin, Small, 2017, 13, 1701519.

222 W. Choi, G. Hu, K. Kwak, M. Kim, D.-E. Jiang, J.-P. Choi and D. Lee, ACS Appl. Mater. Interfaces, 2018, 10, 44645-44653.

223 D. Eguchi, M. Sakamoto and T. Teranishi, Chem. Sci., 2018, 9, 261-265.

224 B. Kumar, T. Kawawaki, N. Shimizu, Y. Imai, D. Suzuki, S. Hossain, L. V. Nair and Y. Negishi, Nanoscale, 2020, 12, 9969-9979. 
225 K. Kwak, W. Choi, Q. Tang, D.-E. Jiang and D. Lee, J. Mater. Chem. A, 2018, 6, 19495-19501.

226 E. J. Popczun, J. R. McKone, C. G. Read, A. J. Biacchi, A. M. Wiltrout, N. S. Lewis and R. E. Schaak, J. Am. Chem. Soc., 2013, 135, 9267-9270.

227 J. Xie, J. Zhang, S. Li, F. Grote, X. Zhang, H. Zhang, R. Wang, Y. Lei, B. Pan and Y. Xie, J. Am. Chem. Soc., 2013, 135, 17881-17888.

228 P. Xiao, M. A. Sk, L. Thia, X. Ge, R. J. Lim, J.-Y. Wang, K. H. Lim and X. Wang, Energy Environ. Sci., 2014, 7, 2624-2629.

229 H. Jin, J. Wang, D. Su, Z. Wei, Z. Pang and Y. Wang, J. Am. Chem. Soc., 2015, 137, 2688-2694.

230 Y. Du, J. Xiang, K. Ni, Y. Yun, G. Sun, X. Yuan, H. Sheng, Y. Zhu and M. Zhu, Inorg. Chem. Front., 2018, 5, 2948-2954.

231 C. Jiang, S. J. A. Moniz, A. Wang, T. Zhang and J. Tang, Chem. Soc. Rev., 2017, 46, 4645-4660.

232 M. G. Walter, E. L. Warren, J. R. McKone, S. W. Boettcher, Q. Mi, E. A. Santori and N. S. Lewis, Chem. Rev., 2010, 110, 6446-6473.

233 W. Chen and S. Chen, Angew. Chem., Int. Ed., 2009, 48, 4386-4389.

234 Y. Lu, Y. Jiang, X. Gao and W. Chen, Chem. Commun., 2014, 50, 8464-8467.

235 L. Wang, Z. Tang, W. Yan, H. Yang, Q. Wang and S. Chen, ACS Appl. Mater. Interfaces, 2016, 8, 20635-20641.

236 L. Sumner, N. A. Sakthivel, H. Schrock, K. Artyushkova, A. Dass and S. Chakraborty, J. Phys. Chem. C, 2018, 122, 24809-24817.

237 T. C. Jones, L. Sumner, G. Ramakrishna, M. B. Hatshan, A. Abuhagr, S. Chakraborty and A. Dass, J. Phys. Chem. C, 2018, 122, 17726-17737.

238 M. Liu, Z. Zhao, X. Duan and Y. Huang, Adv. Mater., 2019, 31, 1802234.

239 R. M. Heck, R. J. Farrauto and S. T. Gulati, Catalytic Air Pollution Control: Commercial Technology: Third edition, Wiley-VCH, Weinheim, 2009.

240 K. Domen, S. Naito, M. Soma, T. Onishi and K. Tamaru, J. Chem. Soc., Chem. Commun., 1980, 543-544.

241 B. Kraeutler and A. J. Bard, J. Am. Chem. Soc., 1978, 100, 4317-4318.

242 Y. Liu, H. Tsunoyama, T. Akita, S. Xie and T. Tsukuda, ACS Catal., 2011, 1, 2-6.

243 S. Xie, H. Tsunoyama, W. Kurashige, Y. Negishi and T. Tsukuda, ACS Catal., 2012, 2, 1519-1523.

244 N. Sakamoto, H. Ohtsuka, T. Ikeda, K. Maeda, D. Lu, M. Kanehara, K. Teramura, T. Teranishi and K. Domen, Nanoscale, 2009, 1, 106-109.

245 D. Bahnemann, A. Henglein, J. Lilie and L. Spanhel, J. Phys. Chem., 1984, 88, 709-711.

246 H. N. Ghosh, J. B. Asbury and T. Lian, J. Phys. Chem. B, 1998, 102, 6482-6486.

247 B. Ohtani, R. M. Bowman, D. P. Colombo Jr., H. Kominami, H. Noguchi and K. Uosaki, Chem. Lett., 1998, 579-580.

248 A. Yamakata, T.-a. Ishibashi and H. Onishi, Chem. Phys. Lett., 2001, 333, 271-277.
249 T. Yoshihara, R. Katoh, A. Furube, Y. Tamaki, M. Murai, K. Hara, S. Murata, H. Arakawa and M. Tachiya, J. Phys. Chem. B, 2004, 108, 3817-3823.

250 J. Lee, H. S. Shim, M. Lee, J. K. Song and D. Lee, J. Phys. Chem. Lett., 2011, 2, 2840-2845.

251 X.-Q. Gong, A. Selloni, O. Dulub, P. Jacobson and U. Diebold, J. Am. Chem. Soc., 2008, 130, 370-381.

252 M. R. Nellist, F. A. L. Laskowski, J. Qiu, H. Hajibabaei, K. Sivula, T. W. Hamann and S. W. Boettcher, Nat. Energy, 2018, 3, 46-52.

253 M. R. Nellist, J. Qiu, F. A. L. Laskowski, F. M. Toma and S. W. Boettcher, ACS Energy Lett., 2018, 3, 2286-2291.

254 G. N. Vayssilov, Y. Lykhach, A. Migani, T. Staudt, G. P. Petrova, N. Tsud, T. Skála, A. Bruix, F. Illas, K. C. Prince, V. V. Matolin, K. M. Neyman and J. Libuda, Nat. Mater., 2011, 10, 310-315.

255 K. He, J. Xie, Z.-Q. Liu, N. Li, X. Chen, J. Hu and X. Li, J. Mater. Chem. A, 2018, 6, 13110-13122.

256 A. Kudo and Y. Miseki, Chem. Soc. Rev., 2009, 38, 253-278.

257 K. Maeda, ACS Catal., 2013, 3, 1486-1503.

258 J. Yang, D. Wang, H. Han and C. Li, Acc. Chem. Res., 2013, 46, 1900-1909.

259 Q. Wang and K. Domen, Chem. Rev., 2020, 120, 919-985.

260 Y. Wang, H. Suzuki, J. Xie, O. Tomita, D. J. Martin, M. Higashi, D. Kong, R. Abe and J. Tang, Chem. Rev., 2018, 118, 5201-5241.

261 G. Zhang, Z.-A. Lan, L. Lin, S. Lin and X. Wang, Chem. Sci., 2016, 7, 3062-3066.

262 X. Li, J. Yu, J. Low, Y. Fang, J. Xiao and X. Chen, J. Mater. Chem. A, 2015, 3, 2485-2534.

263 T. Hisatomi, J. Kubota and K. Domen, Chem. Soc. Rev., 2014, 43, 7520-7535.

264 Z. Wang, C. Li and K. Domen, Chem. Soc. Rev., 2019, 48, 2109-2125.

265 X. Chen, S. Shen, L. Guo and S. S. Mao, Chem. Rev., 2010, 110, 6503-6570.

266 S. Sato and J. M. White, Chem. Phys. Lett., 1980, 72, 83-86.

267 T. Takata, J. Jiang, Y. Sakata, M. Nakabayashi, N. Shibata, V. Nandal, K. Seki, T. Hisatomi and K. Domen, Nature, 2020, 581, 411-414.

268 Q. Wang, T. Hisatomi, Q. Jia, H. Tokudome, M. Zhong, C. Wang, Z. Pan, T. Takata, M. Nakabayashi, N. Shibata, Y. Li, I. D. Sharp, A. Kudo, T. Yamada and K. Domen, Nat. Mater., 2016, 15, 611-615.

269 Z. W. Seh, J. Kibsgaard, C. F. Dickens, I. Chorkendorff, J. K. Nørskov and T. F. Jaramillo, Science, 2017, 355, eaad4998.

270 Y. Miseki, H. Kato and A. Kudo, Energy Environ. Sci., 2009, 2, 306-314.

271 Y. Negishi, M. Mizuno, M. Hirayama, M. Omatoi, T. Takayama, A. Iwase and A. Kudo, Nanoscale, 2013, 5, 7188-7192.

272 Y. Negishi, Y. Matsuura, R. Tomizawa, W. Kurashige, Y. Niihori, T. Takayama, A. Iwase and A. Kudo, J. Phys. Chem. C, 2015, 119, 11224-11232.

273 W. Kurashige, R. Kumazawa, D. Ishii, R. Hayashi, Y. Niihori, S. Hossain, L. V. Nair, T. Takayama, A. Iwase, 
S. Yamazoe, T. Tsukuda, A. Kudo and Y. Negishi, J. Phys. Chem. C, 2018, 122, 13669-13681.

274 T. Ikeda, A. Xiong, T. Yoshinaga, K. Maeda, K. Domen and T. Teranishi, J. Phys. Chem. C, 2013, 117, 2467-2473.

275 K. Maeda, A. Xiong, T. Yoshinaga, T. Ikeda, N. Sakamoto, T. Hisatomi, M. Takashima, D. Lu, M. Kanehara, T. Setoyama, T. Teranishi and K. Domen, Angew. Chem., Int. Ed., 2010, 49, 4096-4099.

276 A. Xiong, T. Yoshinaga, T. Ikeda, M. Takashima, T. Hisatomi, K. Maeda, T. Setoyama, T. Teranishi and K. Domen, Eur. J. Inorg. Chem., 2014, 767-772.

277 K. Maeda and K. Domen, J. Phys. Chem. C, 2007, 111, 7851-7861.

278 K. Maeda, J. Photochem. Photobiol., C, 2011, 12, 237-268.

279 K. Maeda, D. Lu and K. Domen, Chem. - Eur. J., 2013, 19, 4986-4991.

280 K. Maeda, K. Teramura, D. Lu, N. Saito, Y. Inoue and K. Domen, Angew. Chem., Int. Ed., 2006, 45, 7806-7809.

281 M. Yoshida, K. Takanabe, K. Maeda, A. Ishikawa, J. Kubota, Y. Sakata, Y. Ikezawa and K. Domen, J. Phys. Chem. C, 2009, 113, 10151-10157.

282 K. Maeda, K. Teramura, D. Lu, N. Saito, Y. Inoue and K. Domen, J. Phys. Chem. C, 2007, 111, 7554-7560.

283 K. Maeda and K. Domen, J. Phys. Chem. Lett., 2010, 1, 2655-2661.

284 W. Kurashige, R. Hayashi, K. Wakamatsu, Y. Kataoka, S. Hossain, A. Iwase, A. Kudo, S. Yamazoe and Y. Negishi, ACS Appl. Energy Mater., 2019, 2, 4175-4187.

285 S. Trasatti, J. Electroanal. Chem. Interfacial Electrochem., 1972, 39, 163-184.

286 T. Hisatomi, K. Maeda, K. Takanabe, J. Kubota and K. Domen, J. Phys. Chem. C, 2009, 113, 21458-21466.

287 K. Maeda, K. Teramura, H. Masuda, T. Takata, N. Saito, Y. Inoue and K. Domen, J. Phys. Chem. B, 2006, 110, 13107-13112.

288 T. Ohno, L. Bai, T. Hisatomi, K. Maeda and K. Domen, J. Am. Chem. Soc., 2012, 134, 8254-8259.

289 K. Maeda, D. Lu, K. Teramura and K. Domen, Energy Environ. Sci., 2010, 3, 471-478.

290 W. Kurashige, Y. Mori, S. Ozaki, M. Kawachi, S. Hossain, T. Kawawaki, C. J. Shearer, A. Iwase, G. F. Metha, S. Yamazoe, A. Kudo and Y. Negishi, Angew. Chem., Int. Ed., 2020, 59, 7076-7082.

291 Y. Sakata, T. Hayashi, R. Yasunaga, N. Yanaga and H. Imamura, Chem. Commun., 2015, 51, 12935-12938.

292 T. H. Chiang, H. Lyu, T. Hisatomi, Y. Goto, T. Takata, M. Katayama, T. Minegishi and K. Domen, ACS Catal., 2018, 8, 2782-2788.

293 T. Imaoka, H. Kitazawa, W.-J. Chun, S. Omura, K. Albrecht and K. Yamamoto, J. Am. Chem. Soc., 2013, 135, 13089-13095.

294 T. Imaoka, H. Kitazawa, W.-J. Chun and K. Yamamoto, Angew. Chem., Int. Ed., 2015, 54, 9810-9815.

295 H. Tsunoyama, A. Ohnuma, K. Takahashi, A. Velloth, M. Ehara, N. Ichikuni, M. Tabuchi and A. Nakajima, Chem. Commun., 2019, 55, 12603-12606.
296 B. Garlyyev, K. Kratzl, M. Rück, J. Michalička, J. Fichtner, J. M. Macak, T. Kratky, S. Günther, M. Cokoja, A. S. Bandarenka, A. Gagliardi and R. A. Fischer, Angew. Chem., Int. Ed., 2019, 58, 9596-9600.

297 F. Calle-Vallejo, J. Tymoczko, V. Colic, Q. H. Vu, M. D. Pohl, K. Morgenstern, D. Loffreda, P. Sautet, W. Schuhmann and A. S. Bandarenka, Science, 2015, 350, 185-189.

298 B. Garlyyev, J. Fichtner, O. Piqué, O. Schneider, A. S. Bandarenka and F. Calle-Vallejo, Chem. Sci., 2019, 10, 8060-8075.

299 Y. Negishi, N. Shimizu, K. Funai, R. Kaneko, K. Wakamatsu, A. Harasawa, S. Hossain, M. E. Schuster, D. Ozkaya, W. Kurashige, T. Kawawaki, S. Yamazoe and S. Nagaoka, Nanoscale Adv., 2020, 2, 669-678.

300 J. H. Kwak, J. Hu, D. Mei, C.-W. Yi, D. H. Kim, C. H. F. Peden, L. F. Allard and J. Szanyi, Science, 2009, 325, 1670-1673.

301 C. Yin, F. R. Negreiros, G. Barcaro, A. Beniya, L. Sementa, E. C. Tyo, S. Bartling, K.-H. Meiwes-Broer, S. Seifert, H. Hirata, N. Isomura, S. Nigam, C. Majumder, Y. Watanabe, A. Fortunelli and S. Vajda, J. Mater. Chem. A, 2017, 5, 4923-4931.

302 U. Heiz, A. Sanchez, S. Abbet and W.-D. Schneider, J. Am. Chem. Soc., 1999, 121, 3214-3217.

303 V. Matsouka, M. Konsolakis, R. M. Lambert and I. V. Yentekakis, Appl. Catal., B, 2008, 84, 715-722.

304 J. Březina, P. Boutikos, A. B. Arvajová, R. Pečinka and P. Kočí, Top. Catal., 2019, 62, 252-258.

305 S. B. Kang, C. Kalamaras, V. Balakotaiah and W. Epling, Ind. Eng. Chem. Res., 2017, 56, 13628-13633.

306 D. R. Kauffman, D. R. Alfonso, D. N. Tafen, C. Wang, Y. Zhou, Y. Yu, J. W. Lekse, X. Deng, V. Espinoza, J. Trindell, O. K. Ranasingha, A. Roy, J.-S. Lee and H. L. Xin, J. Phys. Chem. C, 2018, 122, 27991-28000.

307 N. Austin, S. Zhao, J. R. McKone, R. Jin and G. Mpourmpakis, Catal. Sci. Technol., 2018, 8, 3795-3805.

308 T. Kawawaki, Y. Kataoka, M. Hirata, Y. Akinaga, R. Takahata, K. Wakamatsu, Y. Fujiki, M. Kataoka, S. Kikkawa, A. S. Alotabi, S. Hossain, D. J. Osborn, T. Teranishi, G. G. Andersson, G. F. Metha, S. Yamazoe and Y. Negishi, Angew. Chem., Int. Ed., 2021, 60, 21340-21350.

309 B. Zhang, S. Kaziz, H. Li, M. G. Hevia, D. Wodka, C. Mazet, T. Bürgi and N. Barrabés, J. Phys. Chem. C, 2015, 119, 11193-11199.

310 J. Liu, K. S. Krishna, Y. B. Losovyj, S. Chattopadhyay, N. Lozova, J. T. Miller, J. J. Spivey and C. S. S. R. Kumar, Chem. - Eur. J., 2013, 19, 10201-10208.

311 C. García, S. Pollitt, M. van der Linden, V. Truttmann, C. Rameshan, R. Rameshan, E. Pittenauer, G. Allmaier, P. Kregsamer, M. Stöger-Pollach, N. Barrabés and G. Rupprechter, Catal. Today, 2019, 336, 174-185.

312 B. Zhang, A. Sels, G. Salassa, S. Pollitt, V. Truttmann, C. Rameshan, J. Llorca, W. Olszewski, G. Rupprechter, T. Bürgi and N. Barrabés, ChemCatChem, 2018, 10, 5372-5376. 
313 Z. Wu, G. Hu, D.-E. Jiang, D. R. Mullins, Q.-F. Zhang, L. F. Allard, Jr., L.-S. Wang and S. H. Overbury, Nano Lett., 2016, 16, 6560-6567.

314 H. A. Almukhlifi and R. C. Burns, Appl. Catal., A, 2015, 502, 174-187.

315 L. M. Rossi, J. L. Fiorio, M. A. S. Garcia and C. P. Ferraz, Dalton Trans., 2018, 47, 5889-5915.

316 H. Yano, M. Kataoka, H. Yamashita, H. Uchida and M. Watanabe, Langmuir, 2007, 23, 6438-6445.

317 H. Asakura, S. Hosokawa, T. Ina, K. Kato, K. Nitta, K. Uera, T. Uruga, H. Miura, T. Shishido, J. Ohyama, A. Satsuma, K. Sato, A. Yamamoto, S. Hinokuma, H. Yoshida, M. Machida, S. Yamazoe, T. Tsukuda, K. Teramura and T. Tanaka, J. Am. Chem. Soc., 2018, 140, 176-184.

318 Z. Luo, V. Nachammai, B. Zhang, N. Yan, D. T. Leong, D.-E. Jiang and J. Xie, J. Am. Chem. Soc., 2014, 136, 10577-10580.

319 T. Chen, V. Fung, Q. Yao, Z. Luo, D.-E. Jiang and J. Xie, J. Am. Chem. Soc., 2018, 140, 11370-11377.

320 K. R. Krishnadas, A. Baksi, A. Ghosh, G. Natarajan and T. Pradeep, Nat. Commun., 2016, 7, 13447.

321 K. R. Krishnadas, A. Baksi, A. Ghosh, G. Natarajan, A. Som and T. Pradeep, Acc. Chem. Res., 2017, 50, 1988-1996.
322 A. Baksi, E. K. Schneider, P. Weis, K. R. Krishnadas, D. Ghosh, H. Hahn, T. Pradeep and M. M. Kappes, J. Phys. Chem. C, 2019, 123, 28477-28485.

323 B. Zhang, G. Salassa and T. Bürgi, Chem. Commun., 2016, 52, 9205-9207.

324 B. Huang and Y. Pei, J. Mater. Chem. A, 2020, 8, 10242-10251.

325 X. Kang and M. Zhu, Chem. Mater., 2019, 31, 9939-9969.

326 J. E. McMurry, Organic Chemistry 9th Edition, Cengage Learning, Boston, 2015.

327 J. R. Gispert, Coordination Chemistry, Wiley-VCH, Weinheim, 2008.

328 S. Takano and T. Tsukuda, J. Am. Chem. Soc., 2021, 143, 1683-1698.

329 D. E. Bergeron, P. J. Roach, A. W. Castleman, Jr., N. O. Jones and S. N. Khanna, Science, 2005, 307, 231-235.

330 T. Omoda, S. Takano and T. Tsukuda, Small, 2021, 17, 2001439.

331 K. Yamamoto, T. Imaoka, M. Tanabe and T. Kambe, Chem. Rev., 2020, 120, 1397-1437.

332 T. Kawawaki, M. Kawachi, D. Yazaki, Y. Akinaga, D. Hirayama and Y. Negishi, Nanomaterials, 2022, 12, 344. 